\title{
Socio-political Violence in Cambodia Between 1990 and 2008: An Explanatory Mixed Methods Study of Social Coherence
}

\author{
Lee C. Fergusson ${ }^{1, *} \&$ Kenneth L. Cavanaugh ${ }^{2}$ \\ ${ }^{1}$ Education and the Environment, Maharishi Vedic Research Institute, Australia \\ ${ }^{2}$ Maharishi Vedic Research Institute, Australia, and Institute of Science, Technology, and Public Policy, Maharishi \\ University of Management, USA \\ *Correspondence: Maharishi Vedic Research Institute, Australia. E-mail: lee@maharishivedicresearch.org
}

Received: February 11, 2019 Accepted: March 19, $2019 \quad$ Online Published: April 19, 2019

doi:10.5430/sass.v6n2p1 URL: https://doi.org/10.5430/sass.v6n2p1

\begin{abstract}
The relationship between individual and group practice of the Transcendental Meditation and TM-Sidhi program and reductions in social stress, tension, and violence has been the topic of systematic exploration since the 1970s in Canada, India, Israel, Lebanon, New Zealand, Norway, the Philippines, Puerto Rico, United Kingdom, and United States. Findings from these quantitative studies have been published in leading international conflict resolution and peace studies journals. However, research in Cambodia has to date only been of a descriptive and qualitative nature with a focus on economic and social variables not violence or crime.

The purpose of the present study is therefore to examine socio-political violence in Cambodia between January 1990 and December 1992 (the baseline period) and the possible influence of group practice of the Transcendental Meditation and TM-Sidhi program at Maharishi Vedic University (MVU) by 550 undergraduate students beginning in January 1993 through December 2008 (the impact-assessment period). This study uses an explanatory mixed methods design to examine socio-political violence using time series analysis of machine-coded news reports (quantitative data) and document analysis of national and international media reports, personal statements, and public documents (qualitative data).

Results indicate that beginning in January 1993, when meditating students at MVU began their group practice, a marked downward shift occurred in the trends of socio-political violence and other forms of violent crime in Cambodia, contrary to predicted baseline trends and contrary to widespread community and media expectations. Such a conclusion can be drawn from both the quantitative and qualitative evidence when comparing baseline and impact-assessment periods, suggesting that the observed decline in socio-political violence during this time was associated with an increase in peace, order, and harmony-that is, a rise of social coherence-in the collective consciousness of Cambodia generated by the group of meditating students at MVU.
\end{abstract}

Keywords: Cambodia, Maharishi Vedic University, coherence, socio-political violence, mixed methods, Transcendental Meditation, Transcendental Meditation-Sidhi program

\section{Introduction}

Since the mid-1950s, Maharishi Mahesh Yogi made a series of testable predictions related to the individual and group practice of his Transcendental Meditation and TM-Sidhi program on the one hand and coherence in collective consciousness of society on the other. At its most fundamental, Maharishi suggested that because the individual is the unit of society, any change in orderliness of the brain physiology of individuals will spontaneously affect the quality of collective behaviour of society as measured by decreases in crime, violence, terrorism, and other variables of social turbulence.

Maharishi's prediction is based on the twofold notion that his program, when practiced individually or in a group, generates orderliness in the brain physiology of participants, as recorded in the electroencephalographic (EEG) signature, and that this acute brainwave orderliness simultaneously creates orderliness in society. Orderliness in human 
brain physiology has been referred to by Maharishi and others as brainwave coherence (Maharishi, 1976a) and electroencephalic ordering (Maharishi, 1976b).

Specifically, this phenomenon in individual brain physiology is said by Maharishi to spontaneously generate an influence of peace, order, and harmony in the so-called 'collective consciousness' of society (e.g., Maharishi Vedic University, 1995), in what he had earlier called the "collective intellect of the nation" (Maharishi, 1960, p. 4) and in what social scientists refer to as the social field (Levitt \& Schiller, 2004; Schiller, 2017). The social field is described as the 'collective whole' which is created when many individuals and groups come together to form a society, and the "unbounded terrain of multiple interlocking egocentric networks" (Schiller, 2017, p. 50). According to Maharishi, such an influence of peacefulness, orderliness, and harmony in society can be caused by the generation of greater coherence in the consciousness of individuals within a community created by a small subset of representatives of that group who are experiencing increased brainwave coherence as well as by a concurrent reduction in the social stress and tension of its collective members.

Consider the following statements by Maharishi. In 1960, he said that his Transcendental Meditation technique is a means of accessing "a great storehouse of peace and happiness, creativity and wisdom" that exists within every individual, and that the "brain of man is equipped with the ability to experience Absolute Bliss, Absolute Happiness, Absolute Peace, Absolute Creativity, Absolute Wisdom" (Maharishi, 1960, p. 5). This "Absolute Field of Life can be fathomed and experienced and lived constantly by man" (Maharishi, 1960, p. 5). Elsewhere, Maharishi referred to this 'great storehouse of peace and happiness' as a state of pure consciousness (Maharishi, 1977), the least excited state of consciousness (Maharishi International University, 1977), and the "field of infinite correlation" (Maharishi, 1978, p. 423). It is of interest in the context of the present study that as early as 1960, Maharishi had already identified the "brain of man' as being important in the creation of a more peaceful and less violent world, a topic to which he repeatedly returned in the context of brainwave coherence (e.g., Maharishi, 1978; Maharishi European Research University, 1977a; Maharishi International University, 1974).

Maharishi (1986) went on in 1962 to point out that a solution to social stress and violence cannot realistically be sought in the work of governments but only in changes to the lives of individuals when he said

the sum, the mass of these infinitely small conflicts [in the world], which, put together, help to make a total atmosphere of tension and hostility. It is useless and infinitely dangerous to look to governments, politicians, and conferences for help in this predicament. This is simply a rejection of responsibility and a declaration of helplessness on the part of the individual. It is precisely what we have been doing for the whole of the world's history, and yet war is still with us. The only change has been in scale, so that now our fear is a thousand-fold more powerful than it has ever been before. If this state of affairs is to be changed, individuals must change. There is no other way. (pp. 448-449; author's emphasis)

In 1964, Maharishi went further and linked the collective practice of Transcendental Meditation with harmony in society when, at the end of May of that year, he directed all the meditators of India to conduct a week of meditation to neutralise "atmospheric tensions and hostile feelings, and promote an influence of peace and harmony in the world" (Maharishi, 1986, p. 55). At the time, Maharishi (1966, p. 244) declared "the problem of world peace can be solved only by solving the problem of the individual's peace, and the problem of the individual's peace can only be solved by creating in him a state of happiness". For this reason, he maintained (Maharishi, 1960) that

world war originates in the tensions of the individual man. The cause of all world wars has been the tensions of individual life. The presidents or the leaders of two countries seem to be fighting, but the intellect of the leader of a nation is canalized by the collective intellect of the nation, and to this each individual adds his part. Tensions in the atmosphere in a country are the product of the tension of the individuals in that country. Each individual has his own share to offer. (p. 4; author's emphasis)

Maharishi (1966, p. 79) went on to point out that "when a man does not live a normal life, or a life using his full potential, he feels miserable and tense and suffers in many ways". In order to reduce 'tensions of the individual man' in any given country and to live a 'normal life', Maharishi recommended not only an improvement in the general good health of individuals by considering all aspects of "absolute and relative" life-consciousness, mind, body, surroundings, and the coordination between these different spheres of life (Maharishi, 1966, p. 188) - but most fundamentally an increase in the orderliness of brain functioning by enlivening through the Transcendental Meditation technique "the state of least excitation of consciousness...the source of all the excitations of thoughts experienced by the mind" (Maharishi, 1978, p. 399). 


\subsection{Transcendental Meditation Technique}

According to Maharishi (1978), during the Transcendental Meditation technique,

the entire physiology gains a very deep state of rest. Oxygen consumption, breath rate, and heart rate decrease markedly, but all in a natural manner without any manipulation, resulting in a level of rest deeper than that gained during sleep. Simultaneously, skin resistance measurements indicate a stable and profound level of relaxation. However, this state is one of high alertness, and electro-encephalographic recordings of the electrical activity in the brain show unique patterns of extremely high coherence, or orderliness, reflecting the inner experience of unbounded wakefulness and integration. The orderly patterns of brain wave activity indicate perfect transfer of information from one part of the brain to another, and account for the greatly enhanced orderliness of thinking and integration of the personality following the practice. (pp. 403-404)

The relationship between deep physiological rest and reduced mental excitation and the spontaneous ordering of brain functioning has been likened to that of a physical system undergoing a transition from disorder to order due to the Third Law of Thermodynamics (World Government of the Age of Enlightenment, 1978a, p. 9). Moreover, the 'orderly patterns of brainwave activity' and 'enhanced orderliness of thinking and integration of the personality' (such as more orderly behaviour and more harmonious relations with others, including reduced hostility) that Maharishi speaks of in relation to the practice of the Transcendental Meditation technique, have been documented in a variety of experiments conducted on several continents since the 1970s (e.g., Arenander \& Travis, 2004; Banquet, 1973; Banquet \& Lesèvre, 1980; McEvoy, Frumkin, \& Harkins, 1980; Travis, 2004; Travis \& Arenander, 2009; Travis, Haaga, Hagelin, Tanner, Arenander, \& Nidich, 2009). Some of these early experiments reported coherence in brainwave activity using a Coherence Spectral Array (COSPAR).

The relationship of the Transcendental Meditation technique to brainwave coherence and stress reactivity (Travis, Haaga, Hagelin, Tanner, Nidich, \& Gaylord-King, 2009) and attention deficit hyperactivity disorder (Travis, Sarina, \& Stixrud, 2011) has also been the subject of research, with later studies moving from COSPARs to neuroimaging, such as functional magnetic resonance imaging (e.g., Orme-Johnson, Schneider, Son, Nidich, \& Cho, 2006). The association of pure consciousness and heightened alpha brainwave coherence with the Transcendental Meditation technique has been the subject of more recent research by Travis (2014).

For the purposes of this paper, we define coherence as a high degree of synchrony in both brainwave power (i.e., amplitude) and brainwave frequency. The degree of synchrony required to reach the 'coherence threshold' may vary according to researcher priority, but typically power and frequency of two brainwaves must be matched to $>75 \%$ within a millisecond. Bennet and Bennet (2008, p. 278) thus define brainwave coherence as "the orderly and harmonious connectedness between the two hemispheres of the brain... [that is] when the two hemispheres of the brain are synchronized....Borrowing from physics, when the brain is in a coherent state, systems are performing optimally and virtually no energy is wasted". However, coherent brainwave activity can also occur intra-hemispherically (i.e., homolaterally) as well as inter-hemispherically (i.e., bilaterally), and thus coherence occurs when "synchronization [is observed at a given threshold] between the neurons in different brain areas" (Bischoff, 2008, p. 442).

According to recent advances in neuroscience, which draw on theories and research associated with integrative cortical structures, coordination (or integration) of various parts of the organism, pattern-forming and oscillating chemical reactions (in so-called 'dissipative structures') that exhibit cooperative behaviour, and cognitive binding, coherence may represent "an important organizing principle in the organism, providing optimal functioning and coordination of body systems" (Bischoff, 2008, p. 440). It is this organizing principle of optimal functioning that underpins the predictive power of brainwave coherence in social change theory.

Consider the results of this type of orderly brainwave activity in Figure 1 as reported in the early experiments of Levine, Hebert, Haynes, and Strobel (1977), which show left (C3/F3) and right (C4/F4) homolateral and left central (C3/C4) and frontal (F3/F4) bilateral COSPARs for a representative four-year practitioner of the Transcendental Meditation technique. In this experiment, brainwave coherence registered only when synchrony between two electrodes was $>95 \%$. In each COSPAR, a 45 -minute time period is shown from bottom to top, with frequency bands from left to right.

Figure 1 indicates that in the initial five-minute eyes-open, pre-meditation period and early ten-minute eyes closed (EC) stage of the practice, there was little or no coherence in the brain, but as time progressed, significant levels of brainwave coherence can be seen emerging in mostly alpha $(8-12 \mathrm{~Hz})$ frequencies (with minimal evidence of theta [4-7 $\mathrm{Hz}]$ and beta $[16-31 \mathrm{~Hz}]$ coherence), indicated by rising white waves in the COSPAR, in all homolateral and bilateral regions of the brain during the 20-30 minute Transcendental Meditation period. In most cases, brainwave coherence 
continued after the meditation period ended, indicative of a sustained beneficial ordering effect. The functional presence of alpha brainwaves, particularly in the frontal cortex, has been associated with creativity and happiness (Lustenberger, Boyle, Foulser, Mellin, \& Fröhlich, 2015), and Tomljenović, Begić, and Maštrović (2016) have examined the practice of Transcendental Meditation in relation to alpha coherence and state and trait anxiety.

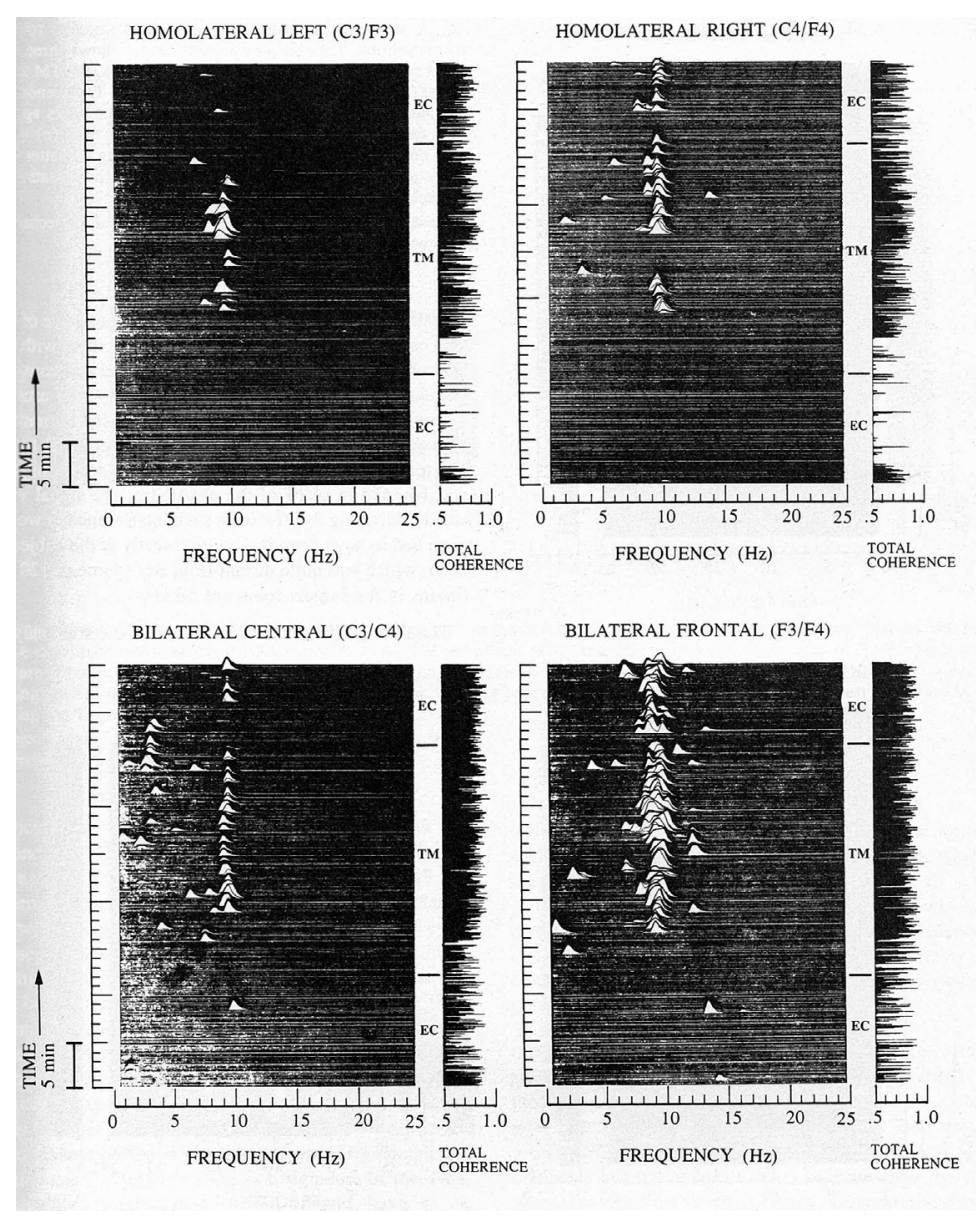

Figure 1. Homolateral and Bilateral COSPARs for a Medium-Term Practitioner During the Transcendental Meditation Technique (Source: Levine, Hebert, Haynes, \& Strobel, 1977)

Figure 2 shows the same homolateral and bilateral results, but in this case the subject is an advanced practitioner, and levels of coherence during the practice are more acute, indicative of sustained brainwave development across all frequencies of the brain, but with a pronounced alpha effect (Orme-Johnson, Clements, Haynes, \& Badaoui, 1977). Such comprehensive coherence across all frequencies has more recently been identified with what are called "unified cognitive operations" (Palva \& Palva, 2007, p. 150).

Levine, Hebert, Haynes, and Strobel (1977), state that sleep studies show "drowsiness and loss of consciousness are accompanied by decreases in coherence. Thus, the present findings indicate that the neurological state reached during the Transcendental Meditation technique differs from drowsiness, sleep onset, and simple eyes-closed relaxation" (p. 187). Correlates of brainwave coherence include increased galvanic skin resistance (GSR, a measure of stress and tension), improved information processing, increased creativity, and faster Hoffman-reflex recovery, a measure of reduced stimulation in the brain (Maharishi European Research University, 1977a, pp. 4-5).

In the same way that 'extremely high coherence' encourages 'the perfect transfer of orderliness in one part of the brain to another' through the practice of the Transcendental Meditation technique, so too does it generate an influence of orderliness and harmony in the surroundings, a phenomenon described in more detail at the individual, family, and community levels in relation to the social field (World Government of the Age of Enlightenment, 1979, pp. 28-29). For example, as a result of these changes to individual brain physiology, early research indicated that "wherever the 
Transcendental Meditation technique has been used in a classroom setting, very great improvements have been seen in the synergy, harmony, and performance of the group" (Maharishi, 1978, p. 405). Indeed, as indicated above, Maharishi predicted that a small percentage of any given population practicing the Transcendental Meditation technique would create an influence of harmony, order, and coherence throughout a group or even an entire society. Examples of an individual's EEG affecting another unrelated individual's EGG, even when pairs are spatially and sensorially separated, have recently been observed in a setting unrelated to practice of the Transcendental Meditation technique (Giroldini, Pederzoli, Bilucaglia, Caini, Ferrini, Melloni, Prati, \& Tressoldi, 2016) and Bischoff (2008, pp. 443-444) presents several compelling examples of what he calls "interactional synchrony" of brainwaves between unrelated pairs of individuals, finding "a transfer of evoked potentials [i.e., stimulated brainwave coherence] at a distance between the two individuals, in spite of electromagnetic shielding by Faraday cages".
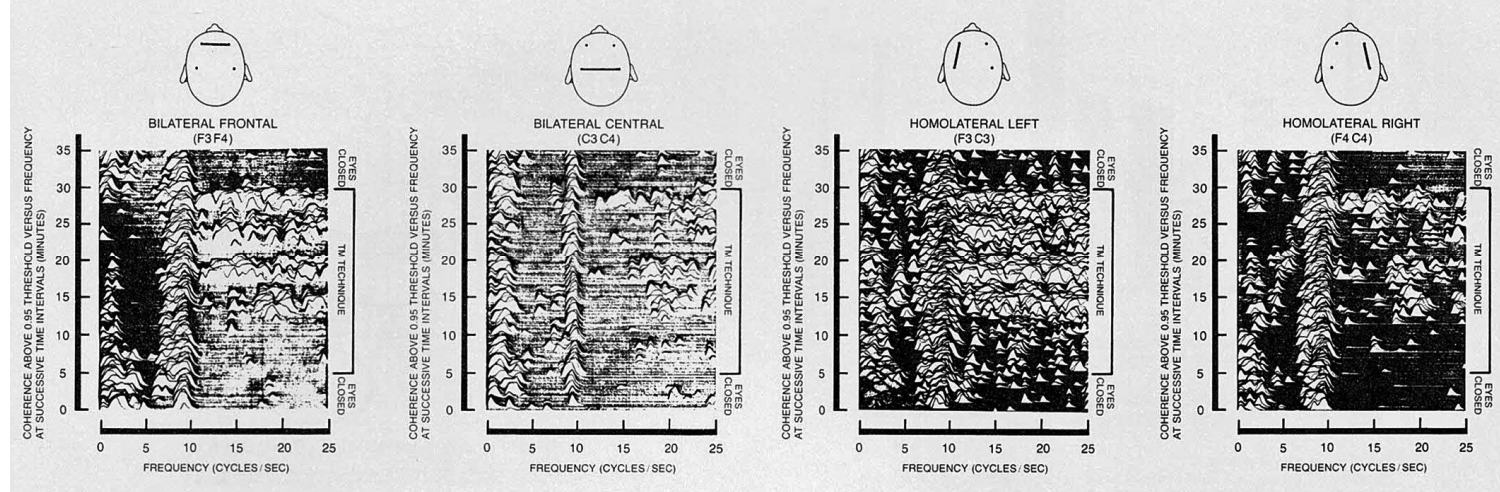

Figure 2. Homolateral and Bilateral COSPARs for an Advanced Practitioner during the Transcendental Meditation Technique (Source: Orme-Johnson et al., 1977)

Furthermore, biochemists have found that practice of the Transcendental Meditation technique significantly reduces biochemical markers of stress, such as the 'stress hormone' glucocorticoid cortisol, and increases secretion of 5-hydroxyindoleacetic acid (5-HIAA), a metabolite of serotonin (Bujatti \& Riederer, 1976; MacLean, Walton, Wenneberg, Levitsky, Mandarino, Waziri,...Schneider, 1997; Walton, Pugh, Gelderloos, \& Macrae, 1995). The observed increases in 5-HIAA were also found to be correlated with reductions in anger, anxiety, aggression, and other negative emotions.

As a consequence, "individuals become incapable of thinking wrong things. Their thinking changes in favour of society. Crime rate falls, sickness becomes less, and all other negative aspects of life diminish" (Maharishi, 1978, p. 163). Maharishi (1978, p. 163) has therefore also stated "whenever one percent of the people in any community practise Transcendental Meditation, balance in nature increases, accidents become less, and all the collective values, which we call social values of society, become more positive". As early as 1962, Maharishi had predicted that as few as $1 \%$ of the population practicing the Transcendental Meditation technique could affect the many (e.g., Katz, 2011, p. 60 ), and later research explored this prediction based on the principle of coherence in physical systems in which the coherent elements of a system are more powerful than incoherent elements (e.g., Borland \& Landrith, 1977; Hagelin, 1987, 1989; Orme-Johnson, Gelderloos, \& Dillbeck, 1988).

This phenomenon was first observed at the city level when in 1974 researcher Garland Landrith tested Maharishi's prediction on crime rate in four midwestern cities in the U.S. where $1 \%$ of the population had learned the Transcendental Meditation technique (Borland \& Landrith, 1977). Landrith initially reported that 1973 crime rates decreased significantly the year after each city achieved the $1 \%$ threshold when compared with other cities of a similar size and geographic location. Using publicly available data from the Federal Bureau of Investigation's Uniform Crime Reports, Borland and Landrith (1977) then expanded the first exploratory study to include 11 cities with a population over 25,000 which had 1\% of their population practicing the Transcendental Meditation technique and showed that when the threshold was reached, crime in the city decreased by an average of approximately $16 \%$ relative to control cities ( $p<.002$ for two-tailed paired $t$-tests).

At the time it was hypothesised that this effect, subsequently named the Maharishi Effect because of his prediction of 
the phenomenon, might even be created by $0.34 \%$ of the population practicing the Transcendental Meditation technique for larger populations, such as an entire nation, or by as few as $0.1 \%$ for the world (Maharishi, 1978, p. 422). Maharishi also recognised and encouraged the group practice of the Transcendental Meditation technique throughout the 1960s and indeed in a number of cases during that period called together groups of meditators to avert social calamity, including during the Cuban Missile Crisis (e.g., Maharishi, 1986, p. 450). Sociologists at Maharishi European Research University likened this social phenomenon to those observed in physical systems. For example, the introduction of a catalyst into a chemical system can cause the disorderly behaviour of elements to change to order throughout the entire system (World Government of the Age of Enlightenment, 1979, p. 31). Moreover, the action-at-a-distance principle apparently harnessed by the Maharishi Effect appears to utilise something akin to the Josephson Effect of quantum tunneling, in which an electrical current mediated by a quantum field passes through an insulating barrier between superconductors, because, as Maharishi (1978) explains:

Individuals practicing the Transcendental Meditation technique produce coherence in their individual consciousness and are found to generate orderliness and coherence in the collective consciousness of those around them by enlivening the field of infinite correlation on the level of pure consciousness. This is the basis of the Maharishi Effect-the increase of positivity as a whole when one per cent or more practice Transcendental Meditation. (p. 423)

This so-called "field dimension of synchrony and coherence" (Bischoff, 2008, p. 444), in which a field of consciousness mediates biological organisms (including neurological processes, as shown in the research of Nobel Laureate Ilya Prigiogine who worked closely with Maharishi during the 1970s) and social phenomena, has been explored by others (e.g., Bischoff, 2008). Such a phenomenon has been referred to as "quantum neurodynamics" (e.g., Bernroider, 2007; Bischoff, 2008, p. 444; Pibram, 2014).

To summarise the argument, Figure 3 shows the relationship of individual practice of the Transcendental Meditation technique - either by single individuals (top row), by individuals dispersed throughout society but at the critical $1 \%$ threshold (middle row), or by individuals practicing the technique in a group (bottom row) - to personal and collective outcomes.

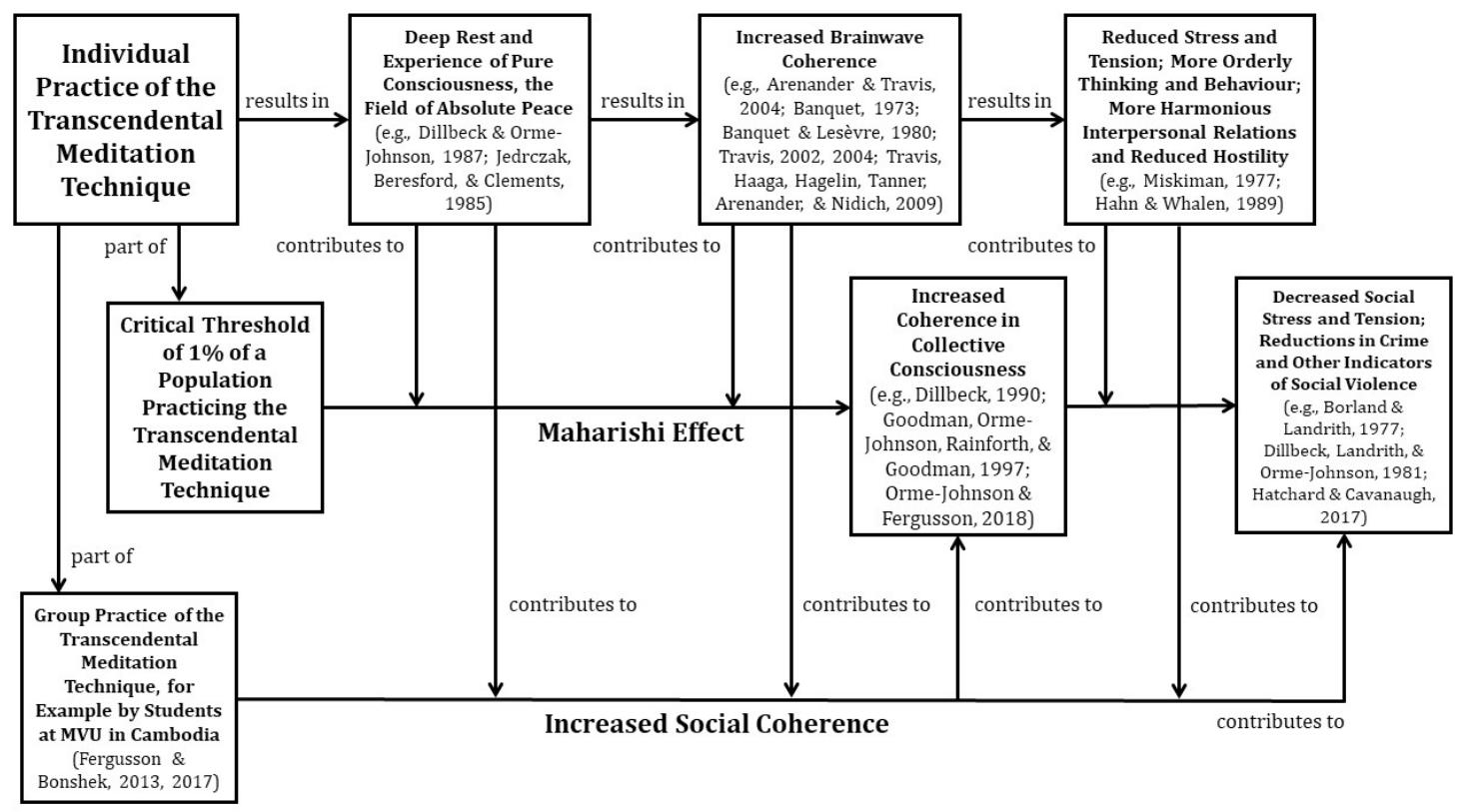

Figure 3. Conceptual Model of Individual and Group Practice of the Transcendental Meditation Technique and Their Relation to Changes in the Social Field

The top row of Figure 3, with supporting references to sample research findings, shows how the practice produces deep mental and physical rest as a result of experiencing pure consciousness, the field of absolute peace from Maharishi's 
perspective. This, in turn, produces an increase of homolateral and bilateral brainwave coherence (which is correlated with a variety of psychophysiological changes), leading to reduced stress and tension, more orderly thinking and behaviour, and more harmonious interpersonal relations and reduced hostility in the individual. These benefits are similarly produced in the social field when $1 \%$ of the population (i.e., create the Maharishi Effect, middle row) or individuals practice the Transcendental Meditation technique in a group (bottom row), which result in an increase of coherence in collective consciousness, as measured by decreases in social stress and tension, and in crime and other indicators of social violence. As discussed below, it is this third type of coherent effect on the social field that the group of students at Maharishi Vedic University may have generated in the collective consciousness of Cambodia, which is the phenomenon being explored for the first time in this study.

\subsection{The Transcendental Meditation-Sidhi Program}

To supplement and enhance the social phenomenon of individual and group practice of the Transcendental Meditation technique, in the 1970s Maharishi introduced his Transcendental Meditation-Sidhi program, including Yogic Flying (Maharishi European Research University, 1977b; Maharishi Vedic University, 2008). Derived from Maharishi's reinterpretation of the Yoga Sütras of Maharishi Patanjali (Maharishi, 1978, p. 406; Gelderloos \& Van den Berg, 1989, p. 376), this program enhances the effect of coherence in the brain physiology of its practitioners, and thereby is said to create an even greater influence of coherence in society via the same mechanism. Such a phenomenon occurs because the Transcendental Meditation-Sidhi program "develops increasingly optimal states of functioning in all areas of intellect, emotions, thinking, perception, and behavior" as a result of bringing the mind "in attunement with the cosmic psyche - the state of pure subjectivity and the full potential of natural law" (Gelderloos \& Van den Berg, 1989, p. 377). These terms - cosmic psyche, pure subjectivity, and full potential of natural law —all relate to what Maharishi calls the state of pure consciousness, the state of absolute peace within each individual, as introduced earlier in this paper.

Consider the results of this type of orderly brainwave activity in Figure 4 as reported by Beresford and Clements (1989). Figure 4 shows left (F3/C3, top left) and right (F4/C4, top right) homolateral and frontal (F3/F4, lower left) and central (C3/C4, lower right) bilateral COSPARS for a representative early-stage practitioner. In this experiment, brainwave coherence registered only when synchrony between two electrodes was $>75 \%$. Each COSPAR represents five minutes sitting with eyes open, 15 minutes practicing the Transcendental Meditation technique, five minutes practicing the Transcendental Meditation-Sidhi program, and a five-minute post-control period sitting with eyes closed; the total 30-minute experimental period is shown from bottom to top, with frequency bands from left to right. Figure 4 indicates that in the initial five-minute eyes-open period there was some degree of coherence in the brain, mostly in the alpha frequency, but as time progressed through both the Transcendental Meditation and TM-Sidhi periods, significantly higher levels of brainwave coherence can be seen in both theta and alpha frequencies in all homolateral and bilateral regions of the brain, spreading to beta frequency in the homolateral regions of the brain (i.e., between the frontal and central regions).

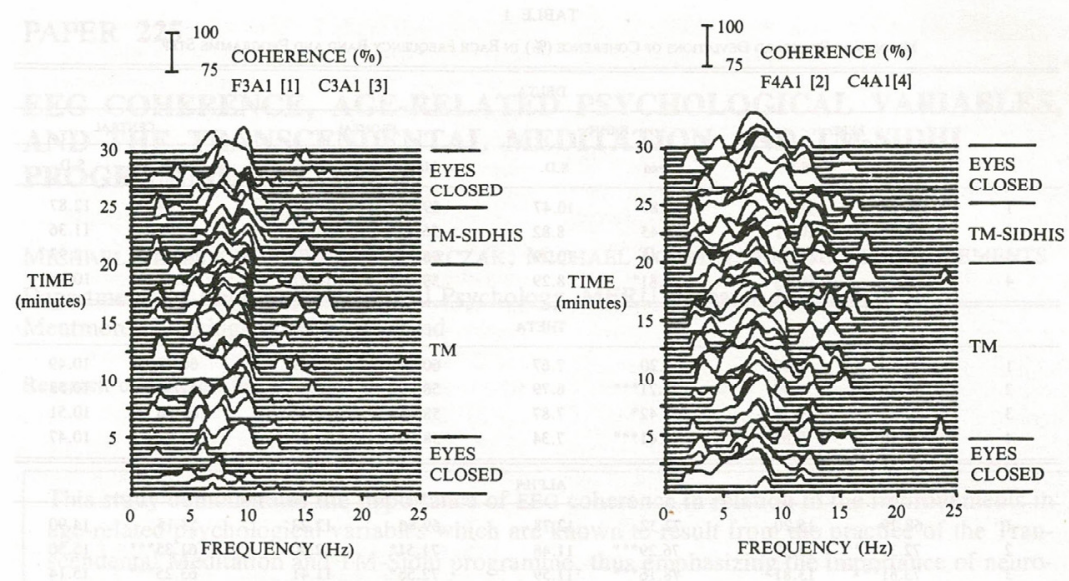

Figure 4. Homolateral and Bilateral COSPARs for a Practitioner of the Transcendental Meditation and Transcendental Meditation-Sidhi Program (Source: Beresford \& Clements, 1989) 
Observed differences between eyes open and the experimental periods were generally significant in the order of $p<$ 0.01 for two-tailed paired $t$-tests. In each case, brainwave coherence continued, albeit at a lower level, after the Transcendental Meditation and TM-Sidhi periods ended, indicative of a sustained beneficial effect. In particular, the COSPARs of homolateral left and right regions of the brain indicate an improvement in "the functional organization of the brain" (Beresford \& Clements, 1989, p. 1740), and EEG coherence in both theta and alpha frequencies increased in experimental subjects over a two-month period on learning the Transcendental Meditation-Sidhi program (Orme-Johnson, 1989).

Neurophysiological correlates of the Transcendental Meditation-Sidhi program, for which there is evidence of EEG coherence indicative of a state of maximum (i.e., 100\%) integration of brain functioning (Orme-Johnson et al., 1977) as shown in Figure 5, include the following: higher levels of creativity and intelligence; more efficient processing of information; enhanced concept learning; improved Hoffman-reflex recovery; reductions in elevated levels of serum dehydroepiandrosterone (DHEA) sulfate and other endocrinologic changes; and experiences of pure consciousness (Chalmers, Clements, Schenkluhn, \& Weinless, 1989; Glaser, Brind, Vogelman, Eisner, Dillbeck, \& Wallace, 1992; Jedrczak, Beresford, \& Clements, 1985; Werner, Wallace, Charles, Janssen, Stryker, \& Chalmers, 1986). Nidich, Ryncarz, Abrams, Orme-Johnson, and Wallace (1983) even found practice of the Transcendental Meditation and TM-Sidhi program increased moral reasoning and judgement in participants.

To isolate the impact of the Transcendental Meditation-Sidhi program on brainwave coherence, Orme-Johnson, Clements, Haynes, and Badaoui (1977) measured brainwave coherence for a 55-minute period on the first day of instruction of the program and eight days later, as shown in Figure 5. The COSPAR presents the start of the program at the bottom with a five-minute eyes closed period, proceeding through a ten-minute period of Transcendental Meditation, and then 40 minutes of the Transcendental Meditation-Sidhi program, then five minutes of Transcendental Meditation, and finally a five-minute eyes closed period.

The results show coherence spreading across all frequencies in the homolateral right (F4/C4) regions of the brain (Orme-Johnson, Clements, Haynes, \& Badaoui, 1977), a phenomenon also observed by Travis and Orme-Johnson (1990). However, the later study also found coherence in the frontal, central, and parietal regions. In Orme-Johnson et al.'s (1977) experiment, brainwave coherence registered only when synchrony between two electrodes was $>95 \%$. This optimal level of brain functioning is the basis of what was subsequently called the Extended Maharishi Effect, an effect which has the same or expanded social outcomes of the Maharishi Effect but with a significantly smaller number of participants needed to generate the ordering effect on society due to the higher levels of brainwave coherence and more optimal brain functioning shown in Figures 4 and 5.

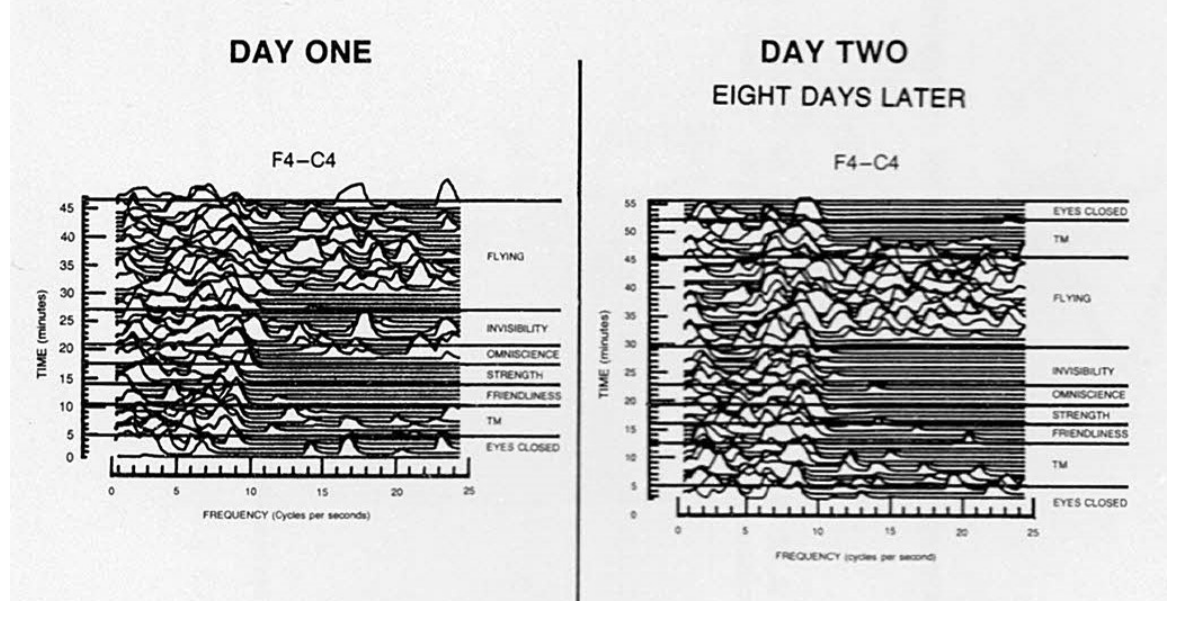

Figure 5. COSPARs Showing Homolateral Coherence on Learning the Transcendental Meditation-Sidhi Program (Source: Orme-Johnson et al., 1977)

Research supports the principle of a small, but highly coherent, subset of a system affecting the order and harmony of the total system, even when the subset of participants (or elements in a physical system) is located at a distance from the main group. For example, Orme-Johnson, Dillbeck, Wallace, and Landrith (1982) showed EEG coherence of practitioners of the Transcendental Meditation technique increased when a large group of 2,500 individuals more than 
a one thousand miles away practiced the Transcendental Meditation-Sidhi program. Travis and Orme-Johnson (1989) showed a similar effect on a non-meditating control group performing a computer task when EEG coherence in a group practicing the Transcendental Meditation and TM-Sidhi program temporally led coherence in the blind control, as documented in subjective reports, coherence patterns, and strength of impact effects. Research has also shown that an increase in the number of group participants practicing the Transcendental Meditation and TM-Sidhi program together is a predictor of increases in both the secretion rate of 5-HIAA $(p=.03)$ and the ratio of excretion rates of 5-HIAA to cortisol $(p<.0001)$ in non-meditators outside the group, thereby providing further evidence of how a small subset of a population can affect the stress levels of a larger population via the mediating effect of the social field (Walton, Cavanaugh, \& Pugh, 2005).

Figure 6 conceptually shows the relationship of practice of the Transcendental Meditation and TM-Sidhi program - either by single individuals (top row) or by individuals practicing in a group at a critical threshold (bottom row) - to personal and collective outcomes.

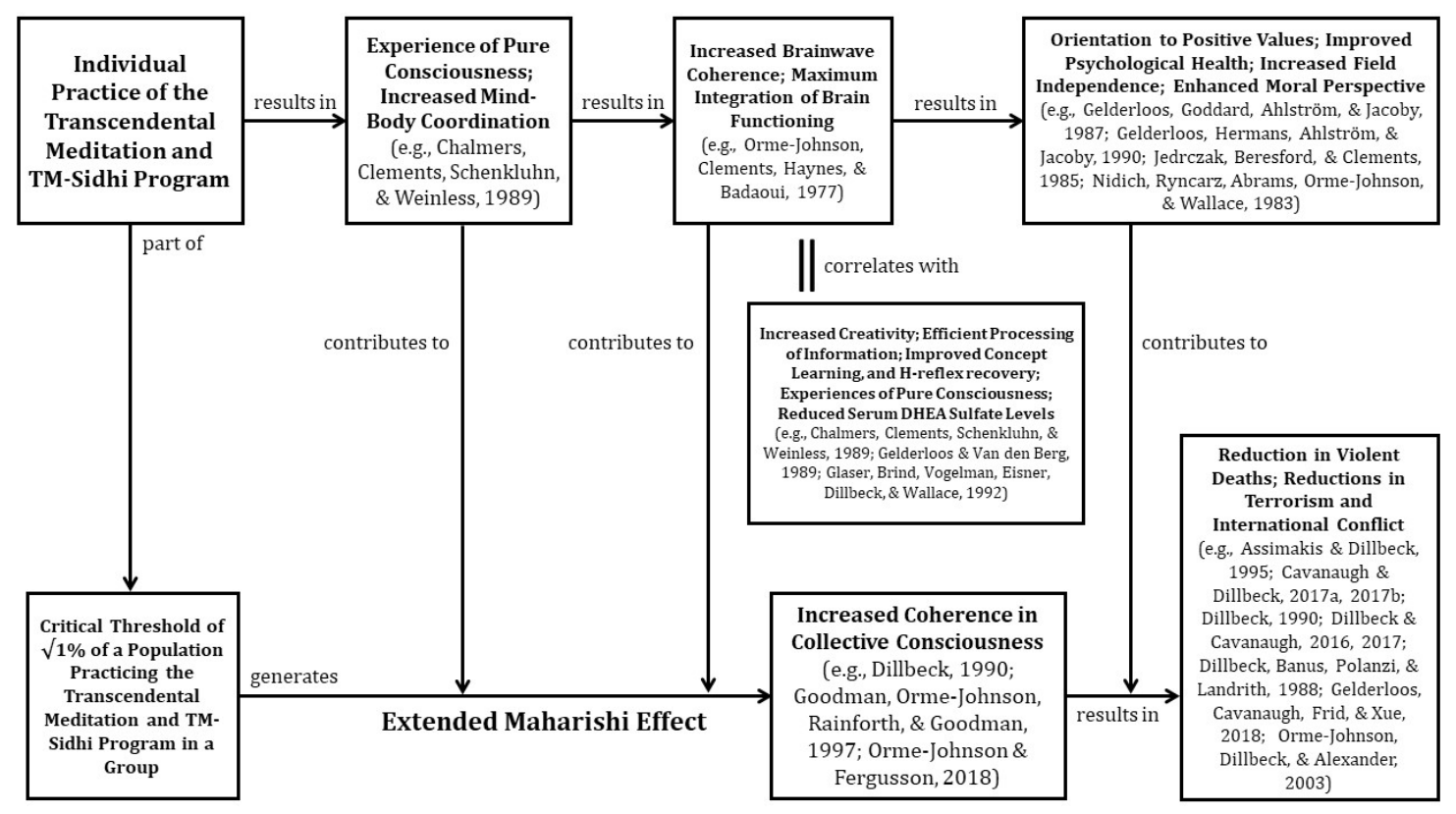

Figure 6. Conceptual Model of Individual and Group Practice of the Transcendental Meditation and TM-Sidhi Program and Their Relation to Changes in the Social Field

The top row of Figure 6 shows how, in addition to those features identified in Figure 3, the practice produces experiences of pure consciousness and increases mind-body coordination. The latter can be measured as maximum integration of brain functioning (which is correlated with an expanded set of psychophysiological changes), leading to greater orientation toward positive values, improved mental health, increased field independence, and an enhanced moral perspective.

When the square root of $1 \%$ of a population practices the Transcendental Meditation and TM-Sidhi program in a group (bottom row), the same societal benefits are produced as those when $1 \%$ of the population practice the Transcendental Meditation technique (see Figure 3). In both cases, the predicted result is an increase of coherence in collective consciousness as measured by decreases in violent deaths, terrorism, and international conflict. These research outcomes are described in more detail in the following section.

\section{Research on Reductions in Violence and Conflict}

Since the early 1970s, social scientists have sought to test Maharishi's proposition about creating social harmony through the individual and/or group practice of his Transcendental Meditation and TM-Sidhi program. As of this writing, 25 research articles have been published in independent peer-reviewed journals or proceedings of scholarly conferences that report empirical, quantitative research on the macro-social impacts of the program. In total more than 
56 such articles have been published, including those appearing in research anthologies, book chapters, and doctoral dissertations. Reviews of this research program have been provided by Cavanaugh and Dillbeck (2017a), Cavanaugh, Gelderloos, and Dillbeck (2018), Orme-Johnson and Dillbeck (1987), and Orme-Johnson and Fergusson (2018), and the following is a summary of these reviews.

Previous studies have examined the impact of Maharishi's coherence-creating program on social indicators that reflect a reduction in social stress and tension on the city, provincial, intra-national, and international levels. Measures of such reductions include decreased terrorism, war deaths and injuries, war intensity, and international conflict, increased international cooperation, reductions in rates of homicide and violent crime, and decreases in a composite index of violent death. Other research has examined improved trends in a variety of individual social indicators as well as aggregated indexes measuring societal wellbeing and quality of life. External validity of these studies has been enhanced by the research employing different outcome measures in countries located in diverse geographical regions, different cultures, different time periods, and various levels of economic development, for example in countries such as Canada, India, Israel, Lebanon, New Zealand, Norway, the Philippines, Puerto Rico, the United Kingdom, and the United States. Studies relevant to the present research on reductions in violence at the national level include the following.

\subsection{Studies on Reduced Fatalities and Injuries Due to War and Terrorism}

A prospective, quasi-experimental project in Israel in August and September of 1983 (Orme-Johnson, Alexander, Davies, Chandler, \& Larimore, 1988) assessed the impact of a temporary group of participants in the Transcendental Meditation and TM-Sidhi program on military conflict in neighbouring Lebanon, which involved Israeli troops. This study of the Extended Maharishi Effect also examined measures of quality of life in Israel.

Based on the findings of earlier studies, research hypotheses and predictions of improvement in the specific outcomes examined in this study were lodged in advance with an independent review board of Israeli and U.S. scientists. Daily data on the Lebanese conflict obtained by means of content-analysed news reports was examined using Box-Tiao interrupted time series (ITS) analysis or impact analysis (Box \& Tiao, 1975). Statistically significant reductions of $45 \%$ in war intensity as well as a $76 \%$ decline in war deaths were found during periods when the group size was above the third quartile relative to the smallest quartile. Quartiles were used in the analysis to model hypothesised nonlinear relationships between the group size and the outcome measures. Similar results were reported for both measures using Box-Jenkins transfer function (TF) analysis (Box \& Jenkins, 1976). Significant improvements were also reported for daily composite indices of Israel's quality of life at city and national levels, respectively. Consistent with the hypothesised causal influence, TF analysis and cross-correlations indicated that changes in the number of participants consistently led future changes in the outcome measures, rather than the reverse. Responding to critiques of their study (Schrodt, 1990; Fales \& Markovsky, 1997), the authors published follow-up research supporting their original findings (Orme-Johnson, Alexander, \& Davies, 1990; Orme-Johnson \& Oates, 2009).

One of these follow-up studies evaluated the impact of seven temporary assemblies of Transcendental Meditation-Sidhi participants, each of which was large enough to have the theoretically predicted effect on the Lebanon conflict according to the $\sqrt{ } 1 \%$ principle (Davies \& Alexander, 2005). The assemblies were held at various times during a 27-month period between June 1983 and August 1985 either in Lebanon, Israel, Yugoslavia, the U.S. (three large assemblies), or the Netherlands. Daily events data from international news sources were coded by an experienced Lebanese coder who was blind to the research hypotheses and unaware of the assemblies or peace-creating technology employed. Box-Tiao ITS analysis indicated that compared to the 728 baseline control days, during the 93 days when the assemblies were large enough for the predicted impact on the Lebanese conflict there were highly statistically significant mean reductions in war fatalities (71\%), war injuries (68\%), level of conflict (48\%), and a $66 \%$ average increase in cooperation among the warring parties, as well as a highly significant improvement in a composite Peace/War index. The analysis controlled for the possible influence of temperature, weekends, religious holidays, trends, drifts, and seasonal patterns. The ITS research design with multiple replications employed in this and other related studies is considered a powerful quasi-experimental design for causal inference (Cook \& Campbell, 1979, p. 222).

Similarly, Orme-Johnson, Dillbeck, and Alexander (2003) examined the impact of three large assemblies of participants in the Transcendental Meditation and TM-Sidhi program on fatalities and injuries due to international terrorism as well as on content-analysed news reports of international conflict. Each of the three assemblies, ranging from 8-11 days held during 1983-1985, approached or exceeded the $\sqrt{ } 1 \%$ of the world's population, a level sufficient to generate the predicted global effect of reduced violence and conflict. For this study of the Global Maharishi Effect (i.e., the Extended Maharishi Effect at a global scale), daily terrorism counts from the RAND corporation database were 
aggregated into five-day periods to form a single time series (TS). A similar daily TS of international conflict data was obtained from date-blind coding of events reported in The New York Times and The Times. Analysis of both TS using Box-Tiao ITS modeling found a significant $72 \%$ drop in fatalities and injuries due to international terrorism and a $32 \%$ decline in international conflict during the assemblies. These results could not be explained by seasonal effects of pre-existing trends, drifts, or correlation patterns in both data series.

\subsection{Research on Improved International Relations}

Two ITS studies using Box-Tiao methods reported that the quality of relations between the U.S. and Soviet Union, as reflected in public statements about the U.S.S.R. made by the then President of the United States, improved significantly, as predicted, during and/or shortly following weeks when the size of the Iowa group was larger (Gelderloos, Cavanaugh, Frid, \& Xue, 2019; Gelderloos, Frid, Goddard, Xue, \& Löliger, 1988). On four occasions when the number of participants in the group practice at temporary assemblies (in Amherst, MA; twice in Washington, D.C.; and in The Hague, the Netherlands) was greater than the size of the group in Iowa, the attendance figures for the assemblies were included in the calculation of monthly average group size. Extending these findings, Gelderloos, Cavanaugh, and Davies $(1990,2011)$ examined the impact of the group practice on U.S.-Soviet interactions 1979 to 1986 using simultaneous TF analysis (Liu, 2009) of monthly, content-analyzed events. Binary impact-assessment variables representing quartiles of the group size were included in each TF equation to estimate possibly nonlinear impacts of the group.

The ITS analysis found a significant improvement in U.S. actions toward the Soviet Union, during or shortly following months in which the average group size was in the range 1,500-1,700, thus exceeding the predicted $\sqrt{1} \%$ critical Extended Maharishi Effect coherence threshold for the U.S. of approximately 1,500. Groups greater than 1,700 (third quartile) were associated with even greater improvements in U.S. behaviour toward the Soviet Union. Likewise, a sizeable and significant improvement in Soviet actions toward the U.S., controlling for U.S. actions toward the U.S.S.R., was found during and after months in which the average daily number of participants was approximately 1,700 or more. These months in which group participation exceeded 1,700 included four large assemblies held during 1983-1986 in which the number of participants approached or exceeded the $\sqrt{ } 1 \%$ of the world's population, the group size required to produce the predicted Global Maharishi Effect.

Subsequent follow-up research (Cavanaugh \& Gelderloos, 2011; Cavanaugh, Gelderloos, \& Dillbeck, 2018) extended the analysis of Gelderloos, Cavanaugh, and Davies $(1990,2011)$ by examining the effect on Soviet behaviour toward the U.S. during the four large 1983-1986 global assemblies when the group size was sufficient to produce a predicted global effect. The Assemblies were held 27 December 1983 to 6 January 1984 (8,000 participants in Fairfield, Iowa); 1-13 July 1984 (5,100 participants in Fairfield, Iowa); 28 December 1984 to 6 January 1985 (6,100 participants in The Hague, Holland); and 8-17 July 1985 (5,500 participants in Washington, D.C.). These Assemblies may be viewed as a prospective quasi-experiment (Cook \& Campbell, 1979) in international conflict resolution because their publicly announced purpose was to reduce global stress and tension in order to generate greater harmony and peace in international relations, especially in superpower relations.

Analysis of data was based on a TF model that included a binary impact-assessment variable to measure the effect of the assemblies on Soviet behaviour toward the U.S. controlling for U.S. actions toward the U.S.S.R. A highly significant improvement in Soviet behaviour toward the U.S., on average, was found during and shortly following the assemblies. The estimated total impact of the global assemblies was larger than that reported by Gelderloos, Cavanaugh, and Davies $(1990,2011)$ for groups over 1,700 in size, and the findings were both practically and statistically significant. Sensitivity analysis and diagnostic tests indicated that the impact of the assemblies could not be explained by seasonal or other cycles in Soviet behaviour, U.S. actions toward the Soviet Union, pre-existing trends, the impact of Mikhail Gorbachev's presidency, or spurious regression.

\subsection{Other Research on Social Violence}

A large, stable group of participants in the Transcendental Meditation and TM-Sidhi program was established during 1979 in the U.S. at Maharishi University of Management (MUM) in Fairfield, Iowa. Dillbeck (1990) examined the impact of this group during 1982-1985 on a violence index composed of weekly fatality totals due to homicide, suicide, and motor-vehicle accidents. When the group was sufficiently large to have a predicted effect on the entire U.S. as well as on both the U.S. and Canada (i.e., the Extended Maharishi Effect), respectively, statistically significant reductions in violence were found in each country using Box-Tiao ITS and TF analysis. TF analysis indicated a significant leading impact of the group on reductions in the violence index in the case of both the U.S. and Canada, with no significant evidence of a leading influence of the index on group participation. 
Two subsequent, prospective quasi-experimental studies of the Extended Maharishi Effect examined the impact of the MUM group during 2007-2010 on monthly rates of U.S. homicide, as well as rates of murder and violent crime in 206 large urban areas for which monthly FBI data were available (Cavanaugh \& Dillbeck, 2017a; Dillbeck \& Cavanaugh, 2016). During the four-year experimental period, the number of participants in the group consistently exceeded or approached the $\sqrt{ } 1 \%$ of the U.S. population at that time (approximately 1,725 participants). The ITS analysis employed a segmented-trend TS regression model and found a highly significant reduction in trend for all three violence rates beginning in January 2007, the month when the group size first exceeded the $\sqrt{ } 1 \%$ threshold. The decline in linear trend in each case resulted in a reduction of $21.2 \%$ in the national homicide rate, a $28.4 \%$ decline in the urban murder rate, and an $18.5 \%$ drop in the urban violent crime rate relative to the baseline mean for each series. An estimated 8,157 U.S. homicides and 186,774 urban violent crimes were prevented by these reductions in trend.

The observed declines in rates of violence could not be plausibly attributed to changes in economic conditions, incarceration rates, demographic factors, temperature, policing strategies, surveillance technology, seasonal effects, pre-existing trends, or 'spurious regression' effects due to nonstationarity. Additional studies of monthly data for the same time period employing the same ITS design found significant reductions in trend for fatality rates due to motor-vehicle accidents, other accidents, infant mortality, and drug-related deaths (Cavanaugh \& Dillbeck, 2017b; Dillbeck \& Cavanaugh, 2017).

Other ITS studies have reported significant positive impacts of temporary groups of participants on violent and other crime rates and other indicators of social quality of life in the Union Territory of Delhi in India, Metro Manila in the Philippines, Puerto Rico, Washington, D.C., and the state of Rhode Island in the U.S. (Dillbeck, Cavanaugh, Glenn, Orme-Johnson, \& Mittlefehldt, 1987; Hagelin, Rainforth, Orme-Johnson, Cavanaugh, Alexander, Shatkin,...Ross, 1999). Orme-Johnson and Fergusson (2018) and Dillbeck and Cavanaugh (2016) discuss these studies; they also discuss other earlier landmark research on the Maharishi Effect that found significant reductions in crime rates at the city level in samples of U.S. cities when at least $1 \%$ of the city population learned the Transcendental Meditation technique. However, to date, no empirical mixed methods research has been conducted on the possible impact a group of meditators might have on socio-political violence. It is to this phenomenon the present study is now directed.

\section{Maharishi Vedic University in Cambodia}

In 1991, Maharishi said to a group of Australian educators and experts in the Transcendental Meditation and TM-Sidhi program that "it is very necessary for all of us who know how to create the field effect [of coherence in collective consciousness] from the most basic level of life to cater for the world requirement [of non-violence]...As a national group of enlightened people in your country, [you should] take it upon yourselves to create a permanent centre for happiness and world peace [in Cambodia]" (Fergusson \& Bonshek, 2017, p. 185). "Our thinking", Maharishi (1991), said, "is that the existing political uncertainties in any country will not be taken to be barriers....We are heading towards the day when Cambodia will be known as Heaven on Earth, and with this example all the developing countries and all the developed countries will begin to follow the example of Cambodia" (p. 95).

As a consequence, in conjunction with the Ministry of Education, Youth, and Sport (MoEYS) of the Royal Government of Cambodia and Maharishi European Research University (MERU) in the Netherlands, a non-governmental organisation named the Australian Aid for Cambodia Fund (AACF) established Maharishi Vedic University (MVU). Against a backdrop of adverse and under-developed educational circumstances (Fergusson, Le Masson, \& Bonshek, 1996), MVU began operations in Kamcheymear district, Prey Veng province, on 1 January 1993 (Fergusson \& Bonshek, 2013, 2017) with financial and administrative support from AACF and the people of Australia. In subsequent years, branch campuses of MVU opened in Kampong Cham city and Prey Veng city.

Among the features of importance for MVU identified by MoEYS and articulated by His Excellency Dr Ung Huot, former Minister of Education of the Royal Government of Cambodia and First Prime Minister of Cambodia, were: a) degree programs which developed technical skills and contemporary understanding in business and management (including leadership, strategic planning, and public administration), Vedic agriculture (specializing in self-sustainable, ecologically-sensitive farming and management practices), and preventive medicine (with a focus on Maharishi Ayur-Ved, a traditional, cost-effective, prevention-oriented therapeutic approach with roots in Cambodian culture); b) placement of high school graduates in rural higher education; c) development of cultural and international understanding through a variety of courses in Khmer culture which explore links to ancient Vedic culture (for example, the history of Khmer civilization and its relation to Sanskrit); d) incorporation of health-related training strategies, such as the Transcendental Meditation and TM-Sidhi program, into the curriculum in order to 
promote the psychophysiological health of students and to reduce stress; e) decentralisation of higher education, thereby making it more widely available to students from provinces other than Phnom Penh; and f) research into these new strategies and programs (Fergusson \& Bonshek, 2013, pp. v-vi).

With enrolments at any one time of 550-700 undergraduate students on MVU's main Kamcheymear campus between 1993 and 2008, beginning in January 1993 more than 550 students practiced the Transcendental Meditation technique together twice a day in a group. Moreover, beginning in June 1994, between 100 and 200 undergraduate students practiced the Transcendental Meditation-Sidhi program together twice a day in a group (excluding vacations) as part of their curriculum. In addition, up to 1,250 other students practiced the Transcendental Meditation technique together in sub-groups during these years across all three campuses. These groups, combined with an additional cumulative 4,500+ practitioners of the Transcendental Meditation technique both at MVU and elsewhere in Cambodia at various times during this period, approached the theoretical proportion of the population needed to create social coherence in Cambodia between 1993 and 2008.

\subsection{Research on Student Wellbeing}

Research conducted during 1993 suggested the curriculum at MVU had a salutary effect on student intelligence, general health, anxiety, and other characteristics of post-traumatic stress disorder, such as depression. For example, Fergusson, Bonshek, and Le Masson (1996) found the curriculum contributed to an increase in non-verbal intelligence of MVU students when compared to other Cambodian university students, and Fergusson, Bonshek, and Boudigues (1995) reported declines in anxiety and depression, improvements in mental and physical health, and increases in sociability of MVU students compared to students at two other universities in Phnom Penh.

When approximately $40 \%$ of all MVU students in 1993 were asked to self-report their experiences, published research showed $97 \%$ of them found the practice of Transcendental Meditation was easy, $96 \%$ reported it helped them retain knowledge, $88 \%$ reported it improved their memory, 93\% reported it increased self-confidence, $89 \%$ reported it improved their comprehension of difficult subject matter, and $76 \%$ reported that Transcendental Meditation decreased their levels of worry about the future (Fergusson, Bonshek, \& Boudigues, 1994). No brainwave coherence research was conducted at MVU during these start-up years due to a lack of requisite technology, but research elsewhere had earlier confirmed its development in university students (e.g., Travis, 1979).

\subsection{Research on Social Impacts}

Social Impact Assessment (SIA) research, in which lifecycle and comparison data (in this case, comparison data with Thailand, Vietnam, and Lao PDR) and baseline data for preceding and subsequent periods were used as controlling variables, was carried out in a study of Cambodian economic and social wellbeing. The SIA study was conducted across data from 1980-2015, with MVU student meditating years of 1993-2008 serving as the impact-assessment period (Fergusson, 2016a, 2016b).

Cambodia was the poorest country of the 42 poorest countries in the world based on income levels in 1990 (Maharishi Vedic University, 1991, pp. 98-101) and the poorest of all 152 countries in the early 1990s. However, after implementation of the Transcendental Meditation and TM-Sidhi program, Cambodia's gross domestic product (GDP) growth rates averaged $8.9 \%$ until 2008, and the World Bank reported that Cambodia's industrial sector GDP growth rates equaled as much as 30\% per year after the late 1990s. As shown in Figure 7 (left-hand chart), annual per capita GDP growth rates also ranged between $6 \%$ and $7 \%$ per year during this period for an overall increase of $179 \%$ between 1996 and 2008 (World Bank, 2015). During this period, the percentage of undernourished people in Cambodia fell from $30 \%$ of the population in 1993 when MVU was established to $18 \%$ by 2008 , a $40 \%$ reduction in undernourishment.

The percentage of the population living in poverty also fell from $45 \%$ to $21 \%$ during the same period, and other measures indicated a decrease in poverty of 63\% between 1994 and 2008, resulting in Cambodia by 2010 being ranked $63^{\text {rd }}$ out of 152 on the international scale of poverty, a jump of 89 places in under one generation. Moreover, of the 47 poorest countries in the world in 2002, Cambodia was one of only 17 countries to achieve $90 \%$ or more of its target for reducing the percentage of its population who were undernourished, one of 16 to achieve target rates for enrolments in primary education, one of 21 to achieve target infant mortality rates, one of 13 to achieve maternal mortality rate objectives, and one of 20 to achieve improvements in access to clean drinking water.

As shown in Figure 7 (right-hand chart), Cambodia also experienced a reduction of inflation from an average 114\% per annum for the years 1988-1992 before the meditating group was formed at MVU to around $0-10 \%$ per annum thereafter (International Monetary Fund, 2105, p. 179). Similarly, Figure 8 (left-hand chart) shows total apparel export revenue to the U.S. grew from zero in 1993 to $\$ 2.5$ billion per year by 2008 , and rice production increased from 
Cambodia (formerly the 'rice basket' of Asia) being a net importer of 100,000 tonnes of rice per year when MVU began to a production of 7.0 million tonnes in 2008. By 2010, Cambodia had a rice surplus of 51,000 tonnes, most of it exported to Thailand, Vietnam, China, Russia, and the European Union. During this period, Cambodia's total exports also grew from $2.5 \%$ of all Asian exports to $12 \%$, leading The World Bank (2014) to ask: "Where have all the poor gone?"
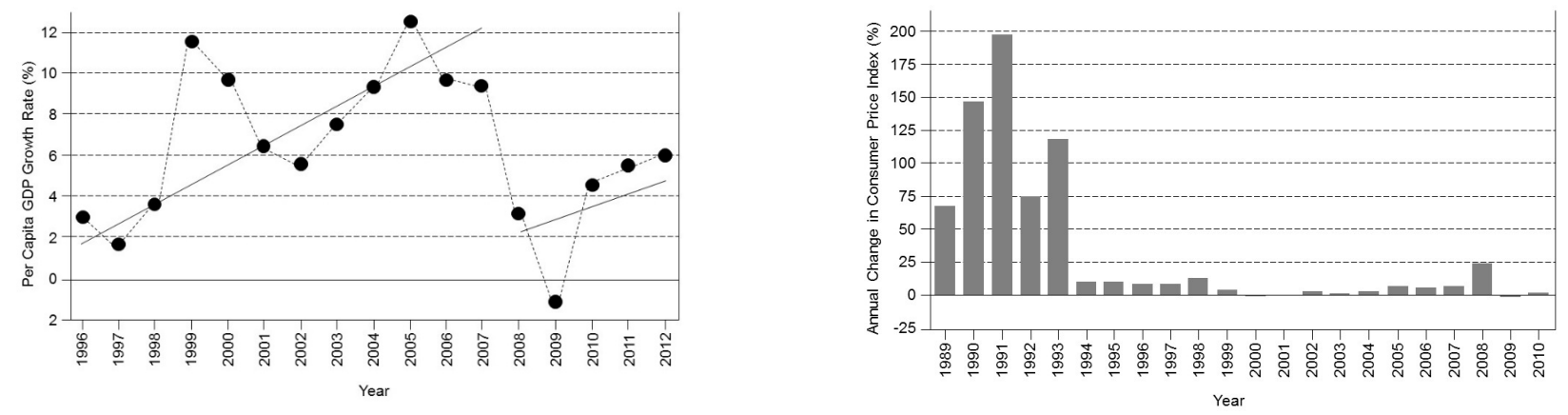

Figure 7. Cambodia's Annual Per Capita GDP Growth Rate Between 1996 and 2012, with Trend Lines Between 1996 and 2007 and between 2008 and 2012, Left (Source: World Bank, 2015); Cambodia Annual Percent Change in Consumer Price Index Between 1989 and 2010, Right (Source: International Monetary Fund, 2015)
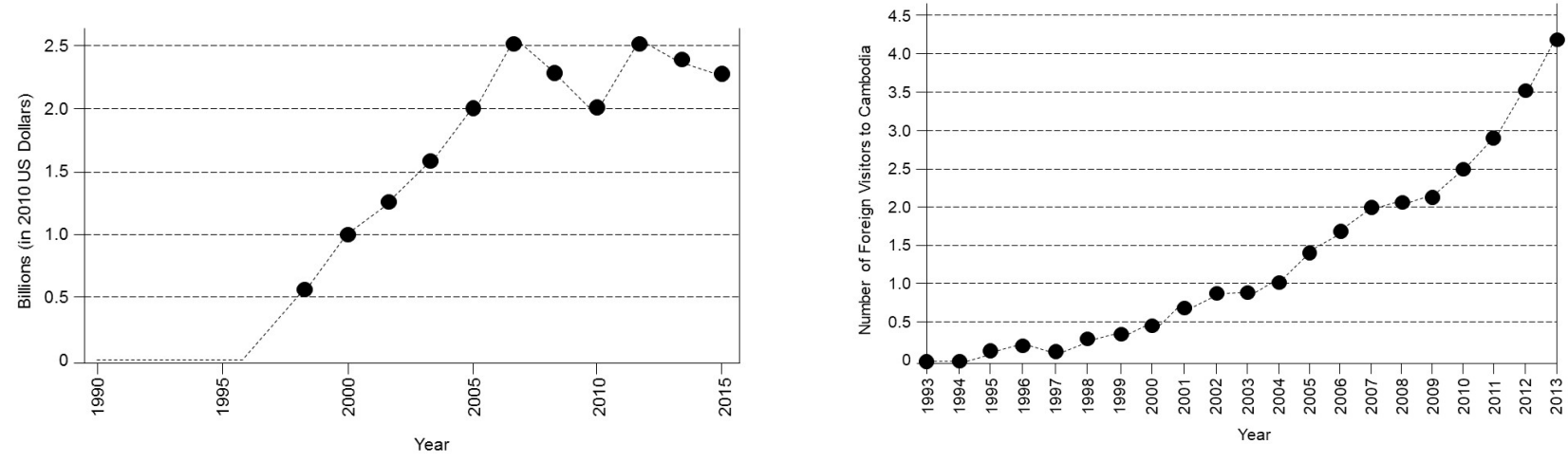

Figure 8. Cambodia's Annual Apparel Manufacturing Revenue in Billions of Dollars from Exports to the U.S. between 1990 and 2015, Left (Source: World Bank Group, 2015, p. 18); Number of foreign visitors in millions to Cambodia between 1995 and 2013, right (Source: Ministry of Tourism, 2008, p. 2; World Bank, 2015)

Health and education data bear out these general trends. During the period 1993-2008 there was a 51\% decrease in infant mortality (the practical significance of which meant averting 308,000 infant deaths), a 58\% decrease in young child mortality, and a $47 \%$ decline in maternal mortality (the practical significance of which meant averting 70,000 maternal deaths). Primary school enrolments increased from 1.3 million students before MVU to 2.65 million students by 2006 , a $105 \%$ increase when compared to Lao PDR, whose primary school enrolments barely changed over the same period. This growth in primary education in Cambodia is "significant", according to UNESCO (2011, p. 33). Similarly, secondary school enrolments increased from 300,000 children in 1990 to 800,000 children in 2006, a $160 \%$ increase over 16 years. Moreover, the Royal Government of Cambodia spent 10.9\% of its total budget on education in 1994 growing to $20.8 \%$ by 2010 . This compares favourably to Vietnam, which spent $5.7 \%$ of its budget on education in 2008 .

UNESCO (2011, p. 103) maintained the Cambodian government's annual education budget grew by $17 \%$ between 1999 and 2008, whereas the growth in the education budget of Thailand was 7\% during the same period. Even after the Global Financial Crisis of 2008-2009, the Cambodian government increased education spending. UNESCO (2011, p. 227) specifically highlighted the fact that entry into the last grade of primary school in Cambodia increased from $41 \%$ in 1999 to $79 \%$ in 2008 due to the decline in civil unrest. As shown in Figure 8 (right-hand chart), as a result of the greater harmony, order, and coherence, and reduced violence in Cambodia during the MVU years, the number of 
foreign visitors increased from 100,000 per year in 1993 to 2.0 million per year in 2008, an increase of 900\% (World Bank, 2015). Research also showed that after the introduction of the Transcendental Meditation and TM-Sidhi program at MVU, war deaths declined from 268 per year in 1993 to 14 in 2011.

A number of alternative hypotheses have been advanced to explain these data (Fergusson, 2016b). However, most of these relate to events which occurred after implementation of the group at MVU. Thus, each of the alternative explanations in the earlier study tend to support an explanation that changes in the number of participants at MVU led future changes in increased social coherence rather than the reverse. Moreover, from 1990-1998 a total of 70 nations sought to change their system of government to a multi-party democracy. Of these, 33 nations did not experience war either before or after their transition to democracy, nine had civil war both before and after elections, and 26 nations had no war prior to democratic elections but bloody civil conflict soon thereafter. Only three nations out of 70 during this period had war before, but peace after, democratic elections - Cambodia after 1993, Mozambique, and Namibia (Hatchard \& Cavanaugh, 2009). Uniquely among nations that changed to democracy, each of these three nations benefited directly from the influence of widespread practice of Transcendental Meditation or groups practicing the Transcendental Meditation and TM-Sidhi program. An overview of this phenomenon for Mozambique and the promotion of individual and group practice of the Transcendental Meditation and TM-Sidhi program has been provided by representatives of that country's government (Maharishi Vedic University, 1994, pp. 6-8).

\subsection{Research Questions}

As there have been no investigations of socio-political violence in Cambodia relative to the establishment of MVU, the present study asks two research questions: RQ1) To what degree and in what direction did baseline trend data for socio-political violence in Cambodia change beginning in January 1993; and RQ2) If the observed change in trend is downward, a finding which would be consistent with both the theory and previously measured changes in violence and crime when the Transcendental Meditation and TM-Sidhi program is practiced in a group, did the change in social coherence generated by the group practice of the Transcendental Meditation and TM-Sidhi program at MVU between 1993 and 2008 significantly contribute to the declining trend in socio-political violence during the same period?

\section{Method}

In order to the answer these two research questions, this empirical investigation of social coherence and its relation to socio-political violence in Cambodia used a two-stage, explanatory mixed methods design (notated as QUAN $>$ qual by Teddlie and Tashakkori, 2009, p. 162). The study seeks to explore to what extent the qualitative (qual) findings enhance and explain the primary quantitative (QUAN) findings. Such a design is said to be particularly useful in assessing trends in quantitative data as well as explaining "mechanisms or reasons behind the resultant trends" as well as outlier results (Creswell \& Plano Clark, 2011, p. 83). This design also meets acceptable standards of reliability and validity for QUAN methods and dependability and trustworthiness for qual methods.

Moreover, an explanatory mixed methods design is suitable when a postpositivist orientation to the quantitative (QUAN) stage needs support from multiple perspectives and when in-depth descriptions of the phenomenon under investigation, in this case social coherence and its relation to socio-political violence, are required as explananda by the qualitative (qual) stage.

Thus, the two-stage design allows for a combined postpositivist and constructivist lens through which to view the phenomenon. As such, the explanatory design "appeals to quantitative researchers, because it often begins with a strong quantitative orientation" (Creswell \& Plano Clark, 2011, p. 84) but supplements that viewpoint with the multiple qualitative views provided by first- and second-hand accounts of participants 'on-the-ground' at the time of the phenomenon. Such is the case with the present design.

\subsection{Quantitative Method}

\subsubsection{Dependent Variable}

The dependent variable analyzed in this study is the comprehensive monthly measure of socio-political violence in Cambodia between 1990-2008 based on automated content analysis of events data obtained from news leads in Reuters and Agence France-Presse (AFP). The coded QUAN data were obtained from Virtual Research Associates (VRA), a leading provider of automated content-analyzed international events data and related research services for government agencies, international organizations, NGOs, businesses, and academia.

Specifically, this study focuses on the VRA variable defined as 'all violent actions', a time series of monthly counts of violent actions by government and non-government actors as defined in VRA's Integrated Events Data for Events 
Analysis (IDEA) framework for categorizing international and intra-national events data (Bond, Bond, Oh, Jenkins, \& Taylor, 2003; King \& Lowe, 2003). The intra-national events in this category encompass violent actions and threats of violent actions regardless of source or target sector. Examples include reported acts of physical assault, beatings, riots, armed attacks, armed battles, assassinations, coups, bombings, violent crowd control, and other events involving the use or threat of force by any actor.

VRA's computerised, automated coding of events data using the IDEA framework allows generation of content-analyzed data with coding reliability that is comparable to that obtained using trained human coders, but at far less cost and vastly greater speed (Bond et al., 2003; King \& Lowe, 2003). In their independent empirical evaluation of VRA's automated coding performance, King and Lowe (2003) noted that automated coding may prove to be far more reliable than human coding in the long run due to fatigue and boredom experienced by human coders as well as the difficulty of retaining experienced coders for such tedious tasks. Similarly, a reliability test of another widely-used automated coding system likewise found that due to fatigue, misapplication of coding rules, and misunderstanding of grammar, contextually knowledgeable human coders missed more events than machine coding (Schrodt \& Gerner, 2001).

\subsubsection{Plot of All Violent Actions}

Figure 9 shows a time series (TS) plot of the monthly counts of violent events in Cambodia for the years 1990 through 2008, where the counts have been transformed using the square root transformation, which is commonly used to make count variables suitable for analysis by ordinary least squares (OLS) TS regression methods (Cameron \& Trivedi, 2013). The usual OLS $t$ statistics for the estimated regression coefficients then can be used for statistical inference. We denote the monthly event counts as all violent actions or ' $A V A$ '. As explained below (see Regression Results for $A V A$ ), Figure 9 also displays superimposed linear trend segments for the 1990-1992 baseline period and the 1993-2008 impact-assessment period, respectively, as well as a temporary downward shift in the level of the trend in late 1999 to early 2000 .

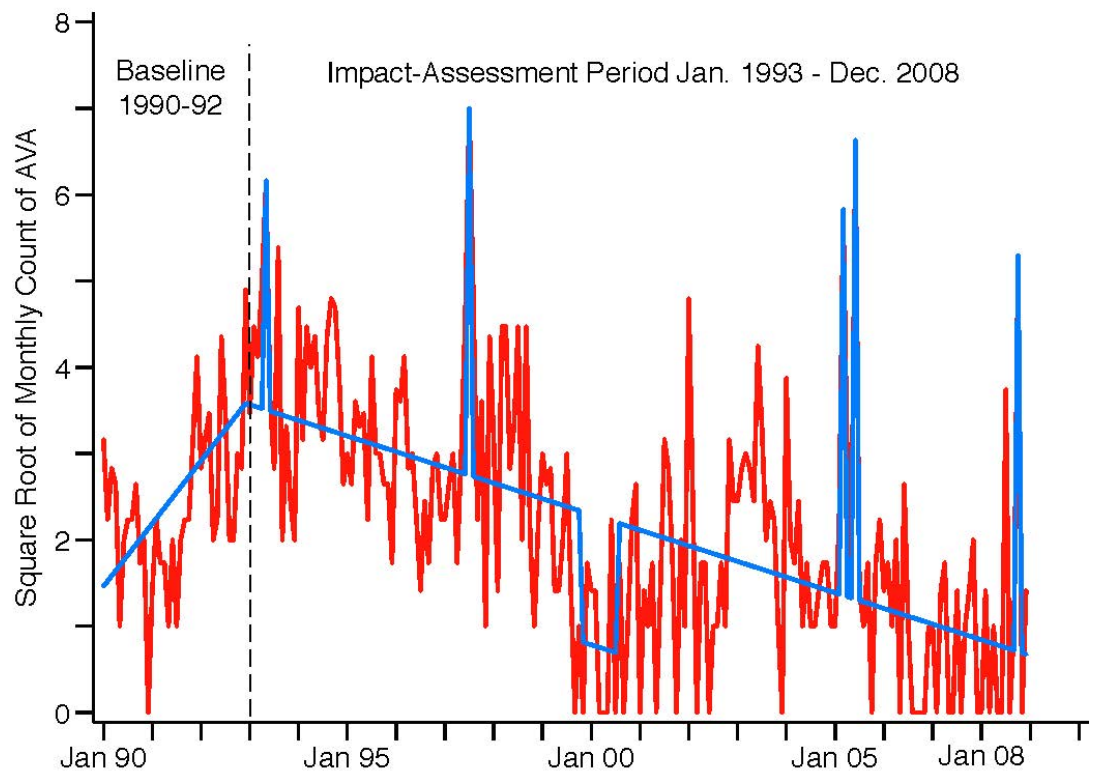

Figure 9. Time Series Plot of Monthly Counts of Violent Events in Cambodia for the Baseline Period of January 1990 to December 1992 and Impact-Assessment Period of January 1993 to December 2008

In Figure 9, AVA displays a rising linear trend during the three-year baseline period 1990-1992, followed by a shift beginning in 1993 to a gradual declining trend that continues through 2008. Considerable irregular variation around both trend segments is also apparent in the plot. During the temporary downward level shift (November 1999 through July 2000), the monthly average size of the meditating group at MVU was at its maximum recorded level of 1,194 participants, reaching 1,250 in November 1999. The five blue 'spikes' in the plot indicate extreme outliers identified by an automated procedure in the modeling process (Doornik \& Hendry, 2013a). 


\subsubsection{Quantitative Research Design}

The $A V A$ data are used to evaluate the impact of a prospective, quasi-experiment using an interrupted time series (ITS) research design (Campbell \& Stanley, 1966; Cook \& Campbell, 1979; Glass, 1997; Glass, Willson, \& Gottman, 1975; Shadish, Cook, \& Campbell, 2002). When randomised, controlled experiments are not feasible, ITS quasi-experimental designs are appropriate designs for the analysis of the longitudinal impact (or 'treatment effect') of new programs, laws, or policy changes, or other specific events in social (or other) systems. ITS research designs can be used for evaluating the impact of a program on a single unit of observation such as a country, province, city, organization, or individual, with or without a comparison group. ITS analysis is also sometimes termed 'impact analysis' or 'intervention analysis'.

ITS designs are characterised by potentially high internal validity for causal inferences in quasi-experiments (Campbell \& Stanley, 1966; Shadish et al., 2002; Glass et al., 1975). Such designs require that an adequate number of equally spaced TS observations on the outcome (dependent) variable of interest are available prior to and during the program or policy to be evaluated, and are called ITS designs because it is anticipated that the implemented program can 'interrupt', or alter, the trend and/or level of the TS outcome variable following introduction of the program. Even in the absence of a comparison group, ITS designs have strong internal validity due to their control over 'regression to the mean' (Linden, 2017) and because the TS behaviour of the outcome during the baseline period prior to introduction of the program provides an empirically based 'counterfactual' that can be used for calculating treatment effects (Linden, 2017; Wagner, Soumerai, Zhang, \& Ross-Degnan, 2002; Zhang, Wagner, Soumerai, \& Ross-Degnan, 2009).

In addition to the application of ITS analysis to studies of societal impacts of the Maharishi Effect (see Introduction), ITS designs have been used in diverse areas of research in the social and other sciences, including, among others, political science, criminology, health sciences, psychology, sociology, economics, business, education, transportation safety research, and ecology. Applications of ITS designs to research on the impacts of violence and the evaluation of approaches to reducing international and intra-national violence and conflict include, among others, the analysis of terrorism impacts and anti-terrorism measures (Enders \& Sandler, 2005, 2012), international relations (Box-Steffensmeier, Freeman, Hitt, \& Pevehouse, 2014, pp. 64-65; Smoker, 1969), domestic impacts of war, revolution, and major politico-economic shifts (Lewis-Beck, 1979; Pridemore, Chamlin, \& Cochran, 2007; Rasler, 1986), and programs to reduce criminal violence (Cochran, Chamlin, \& Seth, 1994; Dugan, 2010; Pridemore, Chamlin, \& Trahan, 2008; Simpson, Bouffard, Garner, \& Hickman, 2006).

\subsubsection{Statistical Analysis of Interrupted Time Series Analysis}

Two approaches to TS regression analysis are commonly used in the statistical evaluation of data from ITS quasi-experimental designs: (1) Box-Tiao autoregressive integrated moving average (ARIMA) methods of time series analysis of ITS models (also see McCleary, McDowall, \& Bartos, 2017), and (2) ordinary least squares (OLS) regression with correction for serial correlation of regression errors (Lewis-Beck, 1986; Linden, 2015, 2017; Wagner et al., 2002; Zhang et al., 2008).

In the current study, we use the OLS-based approach because of the availability of robust standard errors (SEs) to correct for serial correlation and/or nonstable error variance (heteroskedasticity) (Newey \& West, 1987), more extensive available diagnostic tests for assessing fitting models, and its greater simplicity. Additionally, OLS-based modeling allows intuitive graphical presentation of results and data (Zhang et al., 2009).

\subsection{Qualitative Method}

The qualitative approach used in this study draws from a combination of descriptive and archived document analyses, many accessed through Wayback Machine and Dow Jones Factiva. The various data sources were searched for the four key words 'violence', 'political violence', 'peace', and 'Cambodia', specifically with reference to the baseline period of 1990-1992, prior to the predicted phenomenon, and 1993 or later, during the impact-assessment period; data associated with adverse and advantageous outliers in the TS data have also been identified using this method.

These archived data have been obtained from public-domain sources, including edited national newspapers such as The Phnom Penh Post (published since July 1992) and The Cambodia Daily (published from August 1993 to 2017), both prominent and respected news sources in Cambodia, and international newspapers and news outlets, such as The New York Times, The Times, Far Eastern Economic Review, Reuters, Agence France-Presse, and The Associated Press, as well as The Asia Foundation and other reputable published sources.

The use of independent news sources to monitor and assess change in collective consciousness as a result of increasing coherence is a technique used in the past by Maharishi (e.g., World Government of the Age of Enlightenment, 1978a, p. $12 ; 1978$ b, p. 12; 1979, pp. 8-11), particularly when these sources quote world leaders or heads of state. For example, 
when Maharishi assembled large groups of practitioners of the Transcendental Meditation and TM-Sidhi program along the Thai border in late October 1978 to generate coherence in collective consciousness of the region, world press reports related to changes in Cambodia in November 1978, during the last days of KR rule, were cited in the following ways (World Government of the Age of Enlightenment, 1979, pp. 8-11):

Newsweek, 6 November [1978]. "Last week Ieng Sary, [KR] Foreign Minister of Cambodia, re-established ties with two non-Communist Southeast Asian nations [Philippines and Indonesia] that had previously balked at any dealings with Cambodia....He invited U.N. Secretary-General Kurt Waldheim to 'come and see with his own eyes' the situation in Cambodia, and promised to admit Western journalists later in the year";

International Herald Tribune, 14 November [1978]. "Thai foreign ministry sources said that an invitation to...discuss the opening of Angkor [in Cambodia] was the first indication that the present [KR] government would admit tourists to Cambodia"; and

International Herald Tribune, 11 December [1978]. "Cambodia has allowed a group of U.S. journalists into the country for the first time since the Communist victory of 1975".

For neighbouring Thailand during the same period, the Far Eastern Economic Review, 10 November [1978], said "Prime Minister Kriangsak Chamanand of Thailand has declared Thailand's intention to be on good terms 'with all counties regardless of ideology'... [He also said] I will continue to try [all] ways and means to keep peace in this part of the world...Any action that does not support the principle of peace, I do not like".

Other researchers have similarly used newspaper sources in social science research on 'collective action' (e.g., Earl, Martin, McCarthy, \& Soule, 2004).

No audio- or visual-based sources were used in this study but, where available, primary sources, including historically contemporary and first-hand accounts, rather than secondary, spatially distant and second-hand ones have been accessed. Where possible, accounts of events have been cross-checked across sources (e.g., national to international or vice versa) to avoid bias or misrepresentation, and care has been taken to not quote sources out-of-context nor to cherry-pick results. This approach allows for repeated viewings of the archive and is unobtrusive.

However, due to a relative paucity of reliable research data in Cambodia (as discussed by Fergusson \& Le Masson, 1997), the availability of data from these sources may suffer from selectivity bias, and most reported elements of socio-political violence in Cambodia remain embedded in the popular press rather than in verifiable academic sources. Thus, unidentifiable bias of source authors may occur in some documents. Elsewhere, the matter of reporting bias and reliability of research data in Cambodia have been explained (e.g., Broadhurst, 2002; Fergusson \& Le Masson, 1997).

\section{Results}

\subsection{Quantitative Results}

\subsubsection{Regression Model}

To test an observable decrease in trend for AVA during the period 1993-2008 using ITS analysis, we estimate the following segmented-trend, TS regression model via OLS:

$$
A V A_{t}=\beta_{0}+\beta_{1} T_{1 t}+\beta_{2} I_{t}+\left(\beta_{3}-\beta_{1}\right) T_{2 t}+\beta_{4} L S_{t}+\Sigma_{j} S_{j t}\left[D_{j}-(1 / k)\right]+\varepsilon_{t}
$$

In equation $1, A V A_{t}$ is the square root of the monthly count of all violent actions, $T_{l t}$ is the linear time trend for the baseline period 1990-1992 $\left(T_{l t}=1,2,3, \ldots, N\right)$, and $I_{t}$ is a binary indicator (or dummy) variable equal to 1 during the 1993-2008 impact-assessment period and zero during the baseline period. The linear trend during the experimental period is given by $T_{2 t}=\left(T_{1 t}-T_{B}\right)$, where $T_{B}$ is the time of the hypothesised break in the trend function (December 1992). Thus, starting in January $1993 T_{2 t}$ takes the value $1,2,3, \ldots,\left(T_{l t}-T_{B}\right)$, and is zero otherwise.

The binary indicator variable $L S_{t}$ models the temporary downward shift in the level of the trend discussed above (see Plot of All Violent Actions). $L S_{t}$ equals 1 during the months November 1999 through July 2000 and is otherwise equal to zero. The regression error term $\varepsilon_{t}$ in equation 1 is an independent and identically distributed, serially uncorrelated normal error with mean zero and variance $\sigma^{2}$. The regression coefficient $\beta_{0}$ is the intercept, or starting level, of the outcome variable $A V A_{t} . \quad \beta_{1}$ is the slope of the time trend $T_{l t}$ which gives the monthly rate of change for $A V A_{t}$ during the baseline period 1990-1992. $\beta_{2}$ represents the change in the level of $A V A_{t}$ that occurs starting in the first month of the experimental period 1993-2008, as compared to its baseline level. The regression coefficient $\left(\beta_{3}-\beta_{1}\right)$ for $T_{2 t}$ gives the change in slope of the $A V A_{t}$ trend from its baseline value $\left(\beta_{1}\right)$ to its value during 1993-2008 $\left(\beta_{3}\right)$. Thus $\beta_{3}$, the slope of the $T_{2 t}$ trend segment, is calculated by addition of the estimated coefficients: $\left(\beta_{3}-\beta_{1}\right)+\beta_{1}$. The term involving a summation 
operator in equation 1 is a centered seasonal component to control for potential monthly seasonal variation in $A V A_{t}$. This deterministic seasonal component includes eleven binary (0-1) seasonal indicator (or dummy) variables $D_{j}$ with monthly index $j=1,2, \ldots, 11$, where January is denoted by $j=1$ (Ghysels \& Osborn, 2001, p. 20). In order that the seasonal effects for each year sum to zero (centering), $1 / k$ is subtracted from each indicator, where $k=12$ is the number of seasonal periods per year (Doornik \& Hendry, 2013b, p. 19). The indicator for December is omitted from equation 1 to avoid exact linear dependence among the seasonal indicators. The estimated seasonal effect is given by the regression coefficient $S_{j t}$.

After estimation of equation 1 by OLS, standard statistical testing of the estimated regression coefficients requires that the regression error $\varepsilon_{t}$ in equation 1 be a serially uncorrelated 'white noise' process with stable variance. If the estimated regression errors display significant autocorrelation and/or nonstable variance, SES that are robust to autocorrelation (Baum, 2006, p. 199) or both autocorrelation and heteroskedascity of the regression errors (HAC SES) (Newey \& West, 1987) can be used for significance testing of regression coefficients.

\subsubsection{Working Hypothesis}

The proposition, or working hypothesis $(\mathrm{H})$, motivating this study is that an influence of coherence in the collective consciousness of Cambodia generated by the student group practicing the Transcendental Meditation program initially beginning in January 1993 and then later the Transcendental Meditation-Sidhi program at MVU contributed to the observed reduction in the trend of socio-political violence in Cambodia during the impact-assessment period. Specifically, this proposition suggests a reversal of the rising baseline trend of violence observed between January 1990 and December 1992 as indicated by a negative sign for the estimated value of the trend-shift coefficient $\left(\beta_{3}-\beta_{1}\right)$ in equation 1.

Therefore, we test the null hypothesis of no trend shift $\left(\beta_{3}-\beta_{1}\right)=0$ versus the alternative hypothesis $\left(\beta_{3}-\beta_{1}\right)<0$. Although our working hypothesis is one-sided, to be conservative, two-tailed statistical tests are used to evaluate the null hypothesis. In addition to the standard $p$-value, or null-hypothesis-testing (NHT) procedure, we also implemented an assessment of the statistical results reported in Table 1 using a model-comparison approach based on an objective criterion of model adequacy, the Akaike Information Criterion (AIC) (Akaike, 1973).

Unlike the standard NHT approach, this information-theoretic approach allows direct comparison of the relative strength of empirical evidence supporting alternative possible fitted models for the data, including using it to compare two alternative models based on NHT null and alternative hypotheses (Anderson, 2008; Burnham \& Anderson, 2002).

\subsubsection{Regression Results for All Violent Actions}

The OLS regression results for the final fitted model for $A V A$, as well as diagnostic tests for model adequacy, are summarised in Table 1. As discussed below (see Model Comparisons Using the $A I C c$ ), decisions about which variables to include or exclude from the final fitted model were based on the objective criterion of minimising the AICc, a version of the $A I C$ that is recommended for both small and large sample sizes (Anderson, 2008; Brockwell \& Davis, 2016; Burnham \& Anderson, 2002). The AICc criterion provides a theoretically based criterion for optimally balancing the trade-off between improved model fit and model complexity (parsimony).

Because the $A I C c$ is not a statistical test (Anderson, 2008, p. 64), this approach to model selection avoids the issue of repeated testing in interpreting the reported regression coefficients. The regression results were calculated using Stata 15 statistical software (StataCorp, 2017), with the exception of the reported stationarity tests for regression residuals, which were calculated using TSM 4.49 time series analysis software (Davidson, 2016). Because the test for serial correlation of residuals at lags 1-12 indicates the presence of modest autocorrelation of residuals (significant at the $10 \%$ but not $5 \%$ level), robust $t$ ratios and SEs for the regression coefficients are reported in Table 1 that remain valid (consistent) in the case of autocorrelated regression errors (Baum, 2006, p. 199).

As discussed below in Regression Diagnostics for Analysis of $A V A$, all of the other diagnostic tests in Table 1 are satisfactory, indicating that the statistical assumptions of the OLS analysis are satisfied and supporting statistical conclusion validity for the analysis. As explained below (see Model Comparisons Using the $A I C c$ ), the $A I C c$ criterion supported dropping the seasonal dummy variables and the change in intercept $\beta_{2}$ from the estimated regression equation, which resulted in a substantial decrease in the $A I C c$ (see Table 2). Thus, these components were dropped from the final fitted model reported in Table 1. 
Table 1. OLS Regression Results for $A V A$ with Adjustment for Serially Correlated Errors

\begin{tabular}{lcrr}
\hline \multicolumn{1}{c}{ Coefficient } & Estimate & $\boldsymbol{S}$ & $\boldsymbol{t}$ ratio \\
\hline Intercept $\left(\beta_{0}\right)$ & 1.402 & 0.371 & $3.78^{* * *}$ \\
Baseline trend $\left(\beta_{1}\right)$ & 0.0606 & 0.0122 & $5.80^{* * *}$ \\
Change in trend $\left(\beta_{3}-\beta_{1}\right)$ & -0.0757 & 0.0130 & $-7.01^{* * *}$ \\
Level shift $\left(\beta_{4}\right)$ & -1.510 & 0.404 & $-3.73^{* * *}$ \\
Outlier May 1993 & 2.658 & 0.997 & $2.67^{* *}$ \\
Outlier July 1997 & 4.250 & 0.995 & $4.27^{* * *}$ \\
Outlier March 2005 & 4.473 & 0.996 & $4.49^{* * *}$ \\
Outlier June 2005 & 5.321 & 0.996 & $5.34^{* * *}$ \\
Outlier October 2008 & 4.584 & 1.000 & $4.59^{* * *}$ \\
\hline
\end{tabular}

$F$ statistic: $F(8,219)=23.31^{* * *}$

$S E$ of regression: 0.9939

Sum of squared residuals: 225.226

$R^{2}=0.524 ;$ Adjusted $R^{2}=0.507$
Mean of $A V A=2.219$

$S E$ of $A V A=1.444$

Log-likelihood $=-322.122$

$\operatorname{AIC}(\mathrm{H} 0)=709.241, \operatorname{AICC}(\mathrm{H} 1)=665.259$

\section{Diagnostics:}

Serial correlation tests:

Lags $1-6: \chi^{2}(6)=8.873(p=0.181)$

Lags 1-12: $\chi^{2}(12)=18.637(p=0.098)$

Normality test: $\chi^{2}(2)=2.215(p=0.330)$

HML test for stationarity:

$$
Z=-0.518(p=0.698)
$$

$\mathrm{V} / \mathrm{S}$ test for stationarity:

$$
M_{n}=0.0837(p=0.381)
$$

Note: Sample is January 1990 to December 2008, $N=228$; OLS $=$ ordinary least squares; $A I C c(\mathrm{H} 0)=\mathrm{Akaike}$ Information Criterion $(A I C c)$ under the null hypothesis of no trend shift $\left(\beta_{3}-\beta_{1}\right)=0 ; A I C c(\mathrm{H} 1)=A I C c$ under the alternative hypothesis $\left(\beta_{3}-\beta_{1}\right)<0 ; \mathrm{ARCH}=$ autoregressive conditional heteroskedasticity; ${ }^{1} d f=219$; All $t$ ratios and SEs adjusted for autocorrelation of residuals using Stata 15 add-in module ivreg210 with bandwith 7 lags selected automatically via Newey-West plug-in (Baum, 2006, p. 199; Newey \& West, 1994); All $p$ values are two-sided; ${ }^{*} p<$ $0.05^{* *} p<0.01^{* * *} p<0.001$.

The estimated baseline trend for $A V A$ is positive and highly statistically significant. Beginning January 1993, the slope of the linear trend function then, as predicted, displays a highly significant negative $\operatorname{shift}\left(t(219)=-5.80, p<1 \times 10^{-7}\right)$ with $95 \%$ confidence interval $[-0.1013,-0.0501]$. Thus, the null hypothesis of no reduction in trend slope for $A V A$ during the 1993-2008 impact-assessment period can be rejected, offering empirical support for RQ 1. The effect size $(E S)$ for the change in trend is $f=-0.392$, a medium effect (Cohen, 1988).

The $E S$ measure $f$ is the square root of Cohen's $f^{2}$ for a regression variable (or set of variables) with $0.59,0.39$, and 0.14 considered large, medium, and small effects, respectively (Cohen, 1988). The effect size $f$ is given by the $t$ ratio (or square root of the $F$ statistic) for a variable's regression coefficient divided by the square root of the effective sample size (residual degrees of freedom). Darlington and Hayes (2017) show that the unsquared ES metric better indicates the relative magnitude of effects across variables. The guidelines for large, medium, and small values of $f$ mentioned above are the square root of those given by Cohen (1988) for $f^{2}(0.35,0.15$, and 0.02 , respectively).

As noted above, Figure 9 shows the TS plot of $A V A$ with superimposed trends for both the 1990-1992 baseline and 1993-2008 impact-assessment periods. The plot also shows the temporary downward level shift in the trend (November 1999 to July 2000) as well as five outliers, or atypical extreme observations, which were included in the model to reduce possible bias in the remaining model coefficients and improve model diagnostics. Figure 10 compares 
the magnitude of the AVA trends for both the 1990-1992 baseline and 1993-2008 impact-assessment periods. The estimated trend slope $\beta_{3}$ for 1993-2008 is given by the sum of the coefficient estimates for $\beta_{1}$ and the 1993 change in slope $\left(\beta_{3}-\beta_{1}\right): \beta_{3}=-.0151\left(t(219)=-9.85, p<1 \times 10^{-18}\right)$ with $95 \%$ confidence interval $[-.0181,-.0121]$. The estimated regression coefficient $\beta_{4}$ for the level shift variable in equation 1 is negative and statistically significant $\left(t(219)=-3.73, p=2.4 \times 10^{-4}\right)$ with $95 \%$ confidence interval $[-2.303,-0.718]$. The effect size for the level shift is $f=$ -0.252 , a small to medium effect.

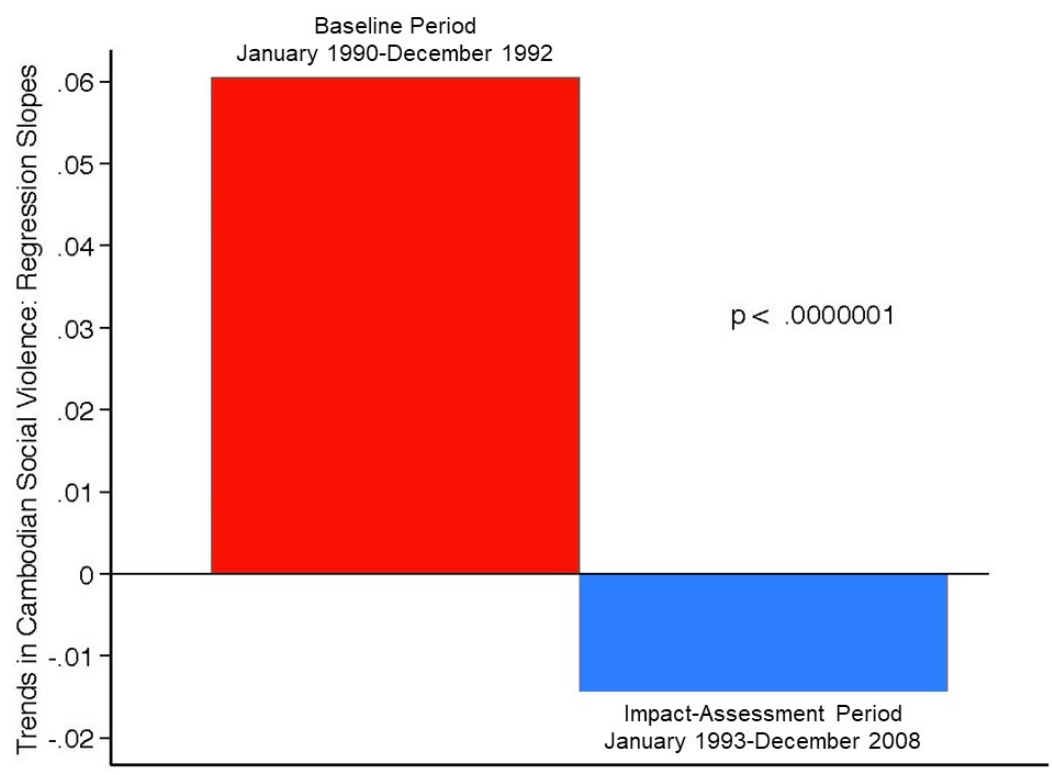

Figure 10. Magnitude of AVA Trends for 1990-1992 Baseline and 1993-2008 Impact-Assessment Periods

Table 1 reports the estimated regression coefficients for the five outliers that were identified by the automatic outlier-identification module of PcGive 14 statistical software (Doornik \& Hendry, 2013a). As shown below in Table 2, inclusion of these outliers in the fitted regression model is strongly supported by the $A I C c$ criterion. The reported coefficient for each outlier in Table 1 is that for a binary (0-1) indicator variable that takes the value 1.0 for the specific month of the outlier and is otherwise equal to zero. The five extreme observations are modeled as additive outliers, defined as temporary, one-time deviations of $A V A$ from the estimated trend (predicted value) of $A V A$. It is standard practice in TS analysis to adjust for such outliers because they can seriously bias the regression coefficient estimates as well as bias tests of significance for coefficients due to inflation of the variance of residuals (Liu, 2009, pp. 7.12-7.13; Liu \& Chen, 1991).

The positive-signed May 1993 outlier reflects an upsurge in violence associated with Cambodia's first-ever national elections. The 1997 outlier with positive sign is associated with armed battles on 5-6 July between military forces loyal to the first and second Prime Ministers of the coalition government in the lead-up to the second national election (Brinkley, 2011; Kamm, 1998; Widyono, 2008) during a student vacation period when group numbers at MVU were between 20-60 participants. The two positive-signed outliers in 2005 are likely associated with ongoing unrest in the garment industry (The Associated Press, 2005) and an upsurge in reporting of incidents of domestic violence (Brickell \& Springer, 2016), although no obvious association with MVU students is apparent. The positive outlier of October 2008 reflects an increase in violence associated with the lead-up to the July 2008 elections and to the government's intimidation of opposition parties, ban on controversial publications, and shutdown of independent radio stations (Human Rights Watch, 2009) following the disbanding of the MVU meditation group in June 2008.

The temporary downward shift in the level of $A V A$ during November 1999 through July 2000 appears correlated with an increase in meditating students at MVU (i.e., approximately 900 per month), but it does not correlate with a similar increase in the size of group practice of the Transcendental Meditation-Sidhi program. Correspondingly, media reports indicate that a number of social advancements were made during this time, including the consecration of a commemorative stupa to the lives lost during the turmoil associated with July 1997 (Post Staff, 2007) cited above. Also, 
a statement made by a representative of United Nations High Commission on Refugees (UNHCR) about the possible 'genetic disposition' of Cambodians to commit violence was decried at the time as unscientific and ignorant by many prominent Cambodians (Post Staff, 2000), but little other evidence can explain the temporary reduction in the level of $A V A$ in early 2000 that is observed in Figure 9.

The trend shift remains highly significant and the estimated coefficient for the change in slope is essentially unchanged $(-0.0723)$ if the temporary level shift and five additive outliers are omitted from the regression: $t(225)=-4.30, p<1 \mathrm{x}$ $10^{-4}$, based on robust (HAC) $S E$ s that remain valid (consistent) in the presence of possible autocorrelation and non-stable variance (heteroskedasticity) of the regression errors (Newey \& West, 1987; Verbeek, 2012). Standard errors (SEs) for latter test were calculated using Stata 15 module ivreg210 with a Bartlett window and bandwidth of 10 autocorrelation lags selected automatically by the Newey-West plug-in (Baum, 2006, p. 199; Newey \& West, 1994). While the omission of these six variables from the fitted regression in Table 1 is useful for sensitivity analysis, it is not supported by the $A I C c$ criterion which strongly supports their inclusion in the model (see Table 2).

\subsubsection{Practical Significance}

Following standard practice in ITS studies (e.g., Linden, 2015, 2017) we use the fitted (or predicted values) of $A V A$ from the regression in Table 1 to estimate the impact of the reduced trend in $A V A$ over 1993-2008. For this calculation we reverse the square root transformation of the original count data by squaring the fitted values of $A V A$ to obtain the estimated count of violent actions in the original units.

To calculate the total program impact or 'treatment effect' associated with the reduction in $A V A$ trend over the period January 2003 through December 2008, the 'counterfactual' behaviour of $A V A$ that is projected to occur in the absence of the MVU group must be defined. Typically, the counterfactual is based on a statistical projection of the baseline trend prior to program implementation (Linden, 2015, 2017). Rather than projecting that the level of violence would continue its rising 1990-1992 baseline trend during 2003-2008, we conservatively assume that $A V A$ would fluctuate around a flat trend at the level of $A V A$ 's fitted value for December 1992, the month prior to the establishment of MVU. The treatment effect is 11.519 for the reduction in the monthly average count of violent actions in the original data units, as given by subtracting the squared $A V A$ predicted value for December 2008 (.4584) from that for December 1992 (11.977). Alternatively stated, the predicted value for the count of violent actions was estimated to be 26.13 times higher (11.977/.4584) in the last month of the baseline period, December 2002, than in the final month of the impact-assessment period, December 2008. The significantly reduced trend slope for $A V A$ reported in Table 1 yields a total predicted reduction of $96.17 \%$ (6.01\% per year) in the (untransformed) count of violent actions over 16 years (December 1992 to December 2008) relative to the December 1992 regression fitted value. The large estimated total treatment effect indicates that the reduction in $A V A$ trend reported in Table 1 is highly significant practically as well as statistically.

\subsubsection{Regression Diagnostics for Analysis of AVA}

Table 1 reports diagnostic tests to assess whether the key assumptions of the statistical analysis are satisfied. A key OLS assumption is no significant autocorrelation, or serial correlation, of the regression errors in equation 1. Serial correlation means that the regression error, or residual, for any given month is correlated with errors for one or more previous months. Significant positive serial correlation of the regression residuals downwardly biases the standard errors (SEs) of regression coefficients and inflates their $t$ ratios (Enders, 2015; Verbeek, 2012).

The Lagrange Multiplier (LM) test for serial correlation of residuals (Godfrey, 1978) fails to reject the null hypothesis of serially uncorrelated, or 'white noise', residuals at the 5\% level for time lags 1-6 and 1-12 months. But the test for lags 1-12 is barely significant at the $10 \%$ level, so to be conservative, Table 1 reports $t$ ratios and $S E$ s for the regression coefficients that remain valid (consistent) in the presence of autocorrelated regression errors. The robust $S E$ s and $t$ ratios were calculated using Stata 15 module ivreg210 with a Bartlett window and bandwidth of seven autocorrelation lags selected automatically using the Newey-West plug-in (Baum, 2006, p. 199; Newey \& West, 1994).

The modest serial correlation of the regression residuals for the estimated model in Table 1 suggests that residuals are likely stationary. Stationarity of the regression residuals is required for valid statistical inferences regarding the estimated coefficients in the regression model (Banerjee, Dolado, Galbraith, \& Hendry, 1993; Enders, 2015; Pickup, 2015). A TS is defined to be weakly stationary (or covariance stationary) if its mean, variance, and autocorrelations are invariant with respect to time origin (Enders, 2015). A weakly stationary series is said to be integrated of order zero, or $\mathrm{I}(d)$ with differencing parameter $d=0$, where $d$ is the number of times the series must be differenced to induce stationarity. For example, a nonstationary I(1) monthly TS that contains a random walk (or unit root) component can often be transformed to an $\mathrm{I}(0)$ series by calculating first-differences, or month-to-month changes, in the series. The 
assumption of weak stationarity required for valid statistical inference in TS regression needs to hold only after statistically controlling for the explanatory variables (or 'regressors') in the model-including trends, trend breaks, outliers, and any other explanatory variables (Pickup, 2015, p. 29). Thus, stationarity conditional on the regressors is the relevant condition - that is, stationarity of the regression errors, not stationarity of the dependent variable itself (Pickup, 2015, p. 24).

Two formal tests that are appropriate for testing the null hypothesis of $\mathrm{I}(0)$ regression residuals are reported in Table 1 (Davidson, 2016, pp. 55-56). The Harris-McCabe-Leybourne (HML) test (Choi, 2015, p. 126; Harris, McCabe, \& Leybourne, 2008) fails to reject the null hypothesis of I $(0)$ residuals $(p=0.698)$. The HML tests were calculated using TSM 4.49 time series analysis software (Davidson, 2016) with the default settings $(\mathrm{c}=1.0, \mathrm{~L}=0.66)$ and bandwidth six lags. The HML test thus supports the conclusion that $A V A$ is 'segmented-trend stationary', exhibiting weakly stationary fluctuations around a segmented trend. Under the null hypothesis, the distribution of the test statistic is asymptotically standard Normal $\mathrm{N}(0,1)$.

The alternate hypothesis for the HML test is $d>0$, including the unit root case $d=1$ as well as possible stationary or nonstationary fractional values of the differencing parameter $d$ ('fractional integration') (Patterson, 2012, pp. 77-142). Stationarity of the residuals is further supported by the V/S test, or rescaled variance test (Giraitis, Kokoszka, Leipus, \& Teyssiere, 2003). The V/S test is a modified form of the KPSS test for I(0) (Kwiatkowski, Phillips, Schmidt, \& Shin, 1992) that has been shown to have higher power than the KPSS test (Giraitis et al., 2003). The V/S test was calculated using TSM 4.49 software (Davidson, 2016) using a bandwith of zero lags selected via Newey-West plug-in.

The finding that the AVA regression errors appear to be modestly correlated but stationary indicates that, after adjustment for the observed serial correlation of residuals, the robust $t$ ratios and other statistics in Table 1 are valid (consistent) and have standard statistical distributions, thus supporting conventional statistical testing. Nonstationary regression residuals invalidate standard statistical test procedures, leading to spurious conclusions regarding relationships between variables (Banerjee et al., 1993; Granger \& Newbold, 1986). Spurious regressions can arise, for example, when time trends are fitted to nonstationary variables that contain a random walk component (i.e., a 'stochastic trend'). A key signature of such spurious regressions is highly autocorrelated, nonstationary regression residuals, which violate the distributional assumptions underlying statistical inference for TS regression. Thus, stationarity of the regression residuals for the analysis reported in Table 1 indicates that the observed significant change in $A V A$ trend cannot be attributed to the well-known 'spurious regression' phenomenon. Although not required to establish stationarity of the regression errors, a supplemental formal test for nonstationarity of the $A V A$ series itself was performed. The augmented Dickey-Fuller (ADF) test (Said \& Dickey, 1984) rejects the null hypothesis of nonstationarity in favour of the alternative of weakly stationary fluctuations around a linear trend $(t-\mathrm{ADF}=-4.793, p<$ 0.01). The auxiliary regression for the ADF test includes trend and intercept. Using the minimum $A I C$ criterion, three lags of first-differenced $A V A$ were selected for inclusion in the regression. The conclusion of trend stationarity for $A V A$ is not sensitive to the number of lags in the regression.

The results of all other diagnostic tests for model adequacy are also satisfactory. White's general test to detect nonconstant variance of residuals (heteroskedasticity) fails to reject the null hypothesis of no heteroskedasticity or, if heteroskedasticity is present, it is unrelated to the regressors (White, 1980). Likewise, the LM test for a specific form of nonstable variance, autoregressive conditional heteroskedasticity (ARCH), fails to reject the null hypothesis of no $\mathrm{ARCH}$ for the regression residuals (Engle, 1982). The regression specification (RESET) test (Ramsey, 1969) for neglected nonlinearity in the specification of the regression equation fails to reject the null hypothesis that the linear functional form of the regression model is correctly specified.

The null hypothesis that the regression errors are drawn from a normal distribution is not rejected by the Jarque-Bera LM test for normality based on the skewness and kurtosis of the observed distribution of residuals (Jarque \& Bera, 1980). Finally, the regression model for $A V A$ tracks the observed data reasonably well, as indicated by the squared correlation between the in-sample predictions (fitted values) of $A V A$ from the model and the actual $A V A$ data values $\left(R^{2}\right.$ $=0.524)$.

\subsubsection{Model Comparisons Using the $A I C c$}

A model-comparison procedure based on an objective criterion of model adequacy, the Akaike Information Criterion (AIC) (Akaike, 1973), likewise offers additional strong empirical support for the estimated, or fitted, model reported in Table 1. We utilise a version of the AIC recommended for samples of all sizes, the AICC (Anderson, 2008; Brockwell \& Davis, 2016). The $A I C c$ is given by:

$$
A I C c=-2 \log (L)+2 k+2 k(k+1) /(N-k-1)
$$


where $\log (L)$ is the natural logarithm of the maximised log likelihood for the model, $k$ is the number of estimated model parameters (including intercept and variance of residuals), and $N$ is the sample size (which is required to be the same for all compared models). The $A I C c$ quantifies a tradeoff between model fit and model complexity, or parsimony (e.g., see Shibata, 1983). The log likelihood term in equation 2 measures model fit, while the remaining two expressions are theoretically based (not ad hoc, as often believed) bias-correction terms that also serve as a penalty for model complexity (Anderson, 2008, pp. 58-59).

The $A I C$ has a strong theoretical foundation based on information theory and entropy. The AICC is used to select an optimally parsimonious model that "minimizes information loss... and properly separates noise (non-information, or entropy) from structural information [about relationships of variables in the model]" (Burnham \& Anderson, 2002, p. 454). In comparing fitted models, the model with the smallest $A I C C$ (or $A I C$ ) minimises the mathematically expected (or averaged) Kullback-Leibler (K-L) information loss when approximating an unknown true model (Anderson, 2008; Burnham \& Anderson, 2002). Larimore (1983) also demonstrated that for both large and small samples, use of the AIC as a measure of model approximation error can be justified on the basis of an asymptotic likelihood principle as well as the fundamental statistical principle of sufficiency.

In comparing a set of alternative fitted models, the model with smallest $A I C c$ minimises the averaged 'K-L distance' between the approximating model and the unknown true model generating the observed data. For example, as shown by comparing models 1 and 2 in Table 2, the $A I C c$ for the fitted $A V A$ regression model under the alternative hypothesis $\mathrm{H} 1$ of a reduced trend for $A V A$ (model 1 in Table 2) is substantially less than the $A I C c$ for the same model under the null hypothesis $\mathrm{H} 0$ of no trend shift. Thus, the $A I C c$ indicates a preference for model 1, the fitted $\mathrm{H} 1$ model with trend shift which is reported Table 1 .

In addition to ranking nested or non-nested fitted models for the purpose of model selection, the AICc can also be used to quantify the relative strength of empirical evidence for competing models. When comparing two models, for example under a null hypothesis $\mathrm{H} 0$ and alternative hypotheses $\mathrm{H} 1$, an advantage of the $A I C c$ approach is that it permits a direct comparison of the strength of empirical support for both the $\mathrm{H} 0$ and $\mathrm{H} 1$ models. The NHT approach is said to provide information about the strength of evidence against $\mathrm{H} 0$, as indicated by the $p$ value, but failure to reject $\mathrm{H} 0$ does not imply that it is true or provide a quantitative measure of the degree of empirical support for H0. Nor does the NHT approach directly test or quantify the evidence supporting H1, only the evidence against H0.

Table 2. Comparison of Alternative Fitted OLS Regression Models for AVA Using the AICc Criterion.

\begin{tabular}{|c|c|c|c|c|c|c|}
\hline $\begin{array}{c}\text { Model } \\
\text { Number }\end{array}$ & $\begin{array}{c}\text { Model } \\
\text { Description }\end{array}$ & $\begin{array}{c}\text { No. of } \\
\text { Parameters } \\
(k)^{1}\end{array}$ & $A I C c$ & $\triangle A I C c$ & $\begin{array}{l}\text { Posterior Model } \\
\text { Probability }^{2}\end{array}$ & $\begin{array}{c}\text { Evidence Ratio } \\
\text { (Odds Ratio) for } \\
\text { Model 1 } 1^{3}\end{array}$ \\
\hline 1 & $\begin{array}{l}\text { Model reported } \\
\text { in Table } 1 \text { with } \\
\text { trend shift }\end{array}$ & 10 & 665.259 & 0 & 0.9935 & NA \\
\hline 2 & $\begin{array}{l}\text { Model } 1 \text { minus } \\
\text { trend shift }\end{array}$ & 9 & 709.241 & 43.983 & $2.795 \times 10^{-10}$ & $3.577 \times 10^{9}$ \\
\hline 3 & $\begin{array}{l}\text { Model } 1 \text { minus } \\
5 \text { outliers and } \\
\text { level shift }\end{array}$ & 4 & 745.811 & 80.553 & $3.202 \times 10^{-18}$ & $3.123 \times 10^{17}$ \\
\hline 4 & $\begin{array}{l}\text { Model } 1 \text { minus } \\
5 \text { outliers }\end{array}$ & 5 & 732.287 & 67.028 & $2.768 \times 10^{-15}$ & $3.612 \times 10^{14}$ \\
\hline 5 & $\begin{array}{l}\text { Model } 1 \text { minus } \\
\text { level shift }\end{array}$ & 9 & 682.084 & 16.825 & 0.000221 & 4532.808 \\
\hline 6 & $\begin{array}{l}\text { Model } 1 \text { plus } 11 \\
\text { seasonal } \\
\text { variables and } \\
\text { intercept shift }\end{array}$ & 22 & 675.389 & 10.130 & 0.00627 & 159.399 \\
\hline
\end{tabular}

Note: Sample is January 1990-December 2008, $N=228$. OLS $=$ ordinary least squares. $A I C c=$ Akaike Information Criterion corrected for use with small as well as larger samples. $\triangle A I C c=A I C c$ for the model in a given row of the table minus the $A I C c$ for the minimum $A I C c$ model (Model 1). 
${ }^{1}$ The number of estimated model parameters in the fitted regression model, which includes the variance of residuals. ${ }^{2}$ The posterior model probability is the probability that a fitted model minimises the expected Kullback-Leibler (K-L) information loss when using the fitted model to approximate the unknown true model (Anderson, 2008). ${ }^{3}$ The posterior odds ratio (evidence ratio) in favour of the minimum AICC model (Model 1) when compared with another fitted model is the ratio of the posterior model probability for Model 1 divided by that for the alternative fitted model.

Table 2 summarises the results of applying this information-theoretic approach to the comparison of six alternative fitted OLS regression models for $A V A$, including the fitted model reported in Table 1 (model 1 in Table 2). The AICc can be used to quantitatively compare a set of two or more alternative fitted models with the same dependent variable by calculating the 'model probability' for each model. The AICc-based approach can be easily extended to calculate model probabilities for multiple models and to rank these models in terms of relative degrees of empirical support (see Anderson, 2008, p. 88), as shown in Table 2. The model probability is defined as the probability that a fitted model minimises the expected K-L information loss when using the fitted model to approximate the unknown true model (Anderson, 2008).

Model probabilities are data-based posterior probabilities based on a K-L information-theoretic framework. Model probabilities are also known as 'Akaike weights'. Burnham and Anderson (2002, pp. 284-305; 2004) show that the AIC (and $A I C c$ ) can be justified in a Bayesian framework, and that under a K-L based formulation of prior probabilities on alternative models (i.e., 'savvy priors'), model probabilities are Bayesian posterior probabilities. They also provide a detailed discussion of the relative merits of the $A I C$ versus the Bayesian Information Criterion $(B I C)$, which, despite its name, has no connection to information theory.

Table 2 reports model probabilities for each of the six alternative models. The model probability in each case is calculated from the difference between the $A I C c$ for the specific model and the $A I C c$ for the fitted model in the set that minimises the $A I C c$ (model 1). For example, in Table 2 consider the comparison of model 1, which is the fitted model reported in Table 1 above, with model 2, which omits the trend-shift component from model 1. Subtracting the AICc for the fitted model 1 in Table 2 from that for model 2 yields an $A I C c$ difference given by $\triangle A I C c=43.983$. The model probability for model $i$ in a set of $R$ fitted models is given by the following expression:

$$
\text { model probability } i=\frac{\exp \left(-1 / 2 \Delta A I C c_{i}\right)}{\sum_{r=i}^{R} \exp \left(\triangle A I C c_{r}\right)}
$$

where the summation is over the set of $R$ models and $\exp (-a)=1 / \mathrm{e}^{a}$. As shown in Table 2 , the model probability for model 2, which omits the trend shift included in model 1 , is essentially zero $\left(2.795 \times 10^{-10}\right)$, while the probability for model 1 exceeds 0.99 . The model probabilities for the other alternatives to model 1 are also near zero.

An additional quantitative measure of the relative weight of empirical evidence supporting two competing fitted models is provided by the posterior odds ratio, or 'evidence ratio', given by the ratio of two model probabilities. For example, dividing the model probability for model 1 by that for model 2, the resulting evidence ratio favouring model 1 is approximately $3.58 \times 10^{9}$. The interpretation of this posterior odds ratio (following Anderson, 2008, pp. 89-90) is that model 1 has approximately 3.58 billion times the weight of empirical evidence than that for model 2, where the latter model assumes no trend shift in AVA. Similarly, strong support for model 1 (the model reported in Table 1) as compared with the other four alternative models in Table 2 is indicated by the large evidence ratios in favour of model 1 for each pairwise comparison.

In sum, the results in Table 2 support the following two major conclusions: (1) the weight of empirical evidence strongly favours the fitted model for $A V A$ reported in Table 1, as shown by the large evidence ratios (or posterior odds ratios) in favour of model 1, and (2) the fitted regression model in Table 1 has lowest $A I C c$ of the six models considered, indicating that it minimises the averaged (mathematically expected) Kullback-Leibler information loss when used to approximate the unknown true model for $A V A$.

Similar results in favour of the fitted model reported in Table 1 were obtained in a pairwise comparison of models 1 and 2 in Table 2 using an approximate Bayesian hypothesis testing procedure. The Bayesian test employs a diffuse prior (the unit-information prior) for the distribution of the model parameter of interest (Wagenmakers, 2007). Assuming equal prior probability for model 2 (the $\mathrm{H} 0$ model) and model 1 (the $\mathrm{H} 1$ model), the posterior probability of model 2, given the observed data, is close to zero $\left(1.42 \times 10^{-9}\right)$ and the posterior probability for model 1 is thus essentially 1.0. The approximate Bayes factor, or Bayesian posterior odds ratio, for $\mathrm{H} 1$ versus $\mathrm{H} 0$ implies that the weight of empirical evidence favouring model 1 is 702.9 million times greater than that for model 2 (which omits the trend-shift component). This degree of support for model 1 is termed "conclusive" in the classification scheme provided by Fox (2016, p. 680). 


\subsubsection{Summary of Quantitative Results}

In sum, the estimated reduction in trend for $A V A$ during the 1993-2008 impact-assessment period is highly statistically significant and has the predicted negative sign. The null hypothesis of no change in the trend of monthly $A V A$ during 1993-2008 can be strongly rejected using a segmented-trend interrupted TS regression model. The form of the fitted model was selected from a set of possible alternative models using an objective procedure based on information theory. The information-theoretic approach selects the model that minimises the $A I C c$ criterion. The resulting model minimises the averaged (mathematically expected) Kullback-Leibler information loss when the selected model is used to approximate the unknown true model for $A V A$. Because the $A I C c$ is not a statistical test (Anderson, 2008, p. 64), this approach to model selection avoids the issue of repeated testing in interpreting the final reported model coefficients. Posterior model probabilities and posterior odds ratios (evidence ratios) for the set of six alternative possible $A V A$ model provided by this approach (see Table 2) also offer additional strong empirical support for the trend-shift model reported in Table 1. All diagnostic tests for the estimated ITS regression model are satisfactory, supporting statistical conclusion validity for the statistical inferences reported in Table 1. Finally, the TS analysis indicates that the reduction in trend for $A V A$ cannot be explained by prior baseline period trends or drifts, autocorrelation of the regression residuals, spurious regression, seasonal variation, outliers, or violation of key statistical assumptions. The medium effect size for the estimated trend-shift in $A V A$ and the $96.17 \%$ (6.01\% annual) estimated annual reduction in the count of all violent actions from December 1992 to December 2008 indicate that the reduction in AVA trend is both practically and statistically significant.

\subsection{Qualitative Results}

\subsubsection{Baseline Period Violence}

Since the 1960s, Cambodia has had a well-documented violent history. "The principal spill-over [of violence created by] the Khmer Rouge period" of 1975-1979, the editorial staff of the Phnom Penh Post pointed out in 1993,

was the swathe cut through the intellectual life of the country. While true, this ignores a deeper, sadder reality. All Khmers over the age of 20 years have experienced a bewildering series of psychically-damaging events. Periods of years in which the very fabric of traditional society has been severely strained. For example, they have lived through an attempt - which very nearly succeeded - to overturn marital bonds and family structures with their close-knit ties; to expunge the central role of regular Buddhist practices; and to eradicate all traditional art forms and music of an individual character. (Post Staff, 1993)

At a purely psychological level, as a consequence

one may well surmise that all those who lived through the Khmer Rouge period and its aftermath, and especially the large number of orphans that were a product thereof, have been traumatized to some degree or another. This goes a long way to explain examples of paranoid and anti-social behaviour, primitive reactions to problem-solving, the violence with which personal grievances are settled, the callous indifference towards the disabled and handicapped, sudden bouts of depression, and the onset of an unusual degree of alcoholism among young males. (Post Staff, 1993)

Therefore, "violent unrest was spreading through the Cambodian capital" in December 1991 (Agence France-Presse, 1991). The Khmer Rouge had been violently active in Cambodia until 1993. For example, as Shenon (1992) reported at the time,

five days before the nearly 370,000 refugees are scheduled to return home from camps in Thailand [during late 1992], refugee workers warned...that Khmer Rouge guerrillas are attempting to undermine the refugee program sponsored by the United Nations. The Communist Khmer Rouge, they said, seem to be trying to force refugees into areas of Cambodia under their control.

According to a United Nations' spokesperson, the KR blew up a bridge "every two days" in territory it controlled prior to 1993 (Jenner, 1997). Moreover, contemporaneous accounts of life in Cambodia include Moorthy and Sotheacheath's (1998) report that

political violence is a vivid memory for most veterans of the run-up to the 1993 polls...The human rights component of UNTAC said there were 200 'politically motivated' deaths with identifiable culprits over a ten-week period before the 1993 elections...one UN volunteer in the troubled Bavel district of Battambang...said the violence was so bad it drove him away, adding he was particularly shaken by the...murders of a $[\mathrm{UN}]$ volunteer and his interpreter in Kampong Thom. 
These personal views are reflected in pre-1993 headlines, which included: "[Khmer Rouge] slay Bulgarian hosts of peace dinner"; "Bangladeshi killed in mortar attack"; and [UN] "volunteers fear for their lives" (Moorthy \& Sotheacheath, 1998). The KR leadership itself were not immune to violent actions prior to 1993. For example, in November 1991, Khieu Samphan, the nominal leader of the KR, was

nearly lynched by an angry mob seeking vengeance for the bloody years of Khmer Rouge rule. If he was attacked again, the Khmer Rouge said, they would plunge Cambodia back into civil war. Khieu Samphan tried to come again on December 21, but Phnom Penh authorities asked him to postpone the trip due to the unstable security situation in the capital. Later that day, at least seven people died in violence resulting from anti-government corruption demonstrations. The army was called in to restore order. (Prasso, 1992)

Thayer (1992) also reported that

the government sent troops to regain control of the streets, imposed a curfew, shut down universities and banned demonstrations. Three guerrilla groups - the Khmer Rouge, the Khmer People's National Liberation Front and an army loyal to Prince Norodom Ranariddh-were in loose coalition fighting the Vietnamese-installed government led by Premier Hun Sen [during this time].

On 13-15 December 1991, according to radio broadcasts monitored in Bangkok, Cambodian villages were shelled in "artillery, mortar and rocket attacks" by unknown forces "massacring women and children" (Reuters News, 1992). In early 1992, the international community was informed that

Cambodia could return to war if the United Nations does not send peacekeeping troops and administrators to oversee the fragile peace accord, a U.S. congressman warned. So far the peace agreement [of October 1991] has succeeded in bringing an end to the fighting, but it could very easily fail if U.N. forces do not arrive soon, said Rep[resentative] Stephen Solarz. (The Record, 1992)

However,

the October 23, 1991, Paris agreement establishing terms for peace for Cambodia promises to end the almost continuous warfare that has ravaged that country since the 1970s. [But] the transition to peace and a new administration in Cambodia is likely to take a long time, at least a year, and could involve a very large and expensive U.N. presence in the country during that time. (Sutter, 1992)

This presence was begun in early 1992 with the arrival of the United Nations Transitional Authority in Cambodia (UNTAC) and continued through until the end of 1993 with elections in May 1993. The result was "the deployment throughout Cambodia of 14,860 peacekeeping troops from 30 countries. It means the establishment of offices of the Civil Administration component in 18 provinces; it includes over 100 investigations of complaints alleging violations of human rights" (Akashi, 1992). During this time, worry surrounding the demobilisation and disarmament of more than 200,000 troops (70\% of four warring armies) who might turn to banditry and violence was also raised in the media (Pringle, 1992). But "after 21 years of war and political terror, Cambodians entered the new year [1992] with more hope than for two decades" (Pringle, 1992). "Despite [UNTAC head] Akashi's renewed commitment to go forward with elections in the atmosphere of violence, diplomats and others here are becoming increasingly pessimistic that, even if elections are held, they can result in forming the basis for a stable government" (Thayer, 1993). Quoting KR leader Kieu Samphan, Thayer (1993) noted that

as the events in the recent past have clearly shown, the Cambodian people will never accept [the results of a UN-backed election] and during the next months it will be shown clearly that such elections cannot be held...If they are it seems the prospect of peace to follow is dim.

But as 1993 came around, hope began to fade even further. In February of that year,

UN officials accused...state officials of confiscating the voter registration cards of thousands of Cambodians. Others reported death threats and attacks aimed at scaring villagers into voting for the ruling party. And in the past two weeks, the Maoist Khmer Rouge, which ruled the country from 1975-78, has killed four UN peacekeepers and more than 20 ethnic Vietnamese in attacks aimed at destabilizing the campaign. (Casella, 1993)

The weeks prior to the election were

marred by assassination and intimidation, giving at least one party — led by a Cambodian-Canadian from Quebec - second thoughts. 'I don't want my people killed', says Khy Tainglim, chairman of the Khmer National Congress Party, whose executives are Cambodian professionals from Canada, the United States and 
Europe who say they want to help rebuild the country. The campaign kicked off this past Wednesday, but Mr. Khy said he and other party officials may pull their 150 candidates off the hustings.

They believe violence will escalate. 'We are really worried about security. There is no certainty. We have too many risks and we don't want to send our people out into risk,' he said in an interview this week... None of his party's members has been killed. But despite the presence of 16,000 UN peacekeepers and a further 3,000 UN civil police, members of higher-profile parties have been kidnapped and killed during the past year. (Casella, 1993)

Casella (1993) also pointed out that politicians were not the only ones at risk:

UN electoral staff have come under attack while travelling the countryside to register and educate voters. On Thursday, a Japanese volunteer and his Cambodian interpreter were killed in an ambush. Since Christmas [1992], the UN human rights office has logged more than 50 armed attacks.

According to the Buddhist Liberal Democratic Party leader, Ieng Mouly, "this election will be a bloody one" (Thayer, 1993).

\subsubsection{Impact-Assessment Period Violence}

The election held in early May 1993, four months after the establishment of the group of meditators at MVU, was described as "surprisingly peaceful" (Smith, 1998) and "unimaginably successful" (Roberts, 2000, p. ix). According to Ogden (1994), "the overall picture [in 1993] is of genuine stability". Thus, two key phenomena occurred during and after 1993: "peace has now come for thousands of Cambodians and the Polpotists [i.e., the KR] have lost their financial resources and nearly three fifths of their armed forces" (Jenner, 1997), despite claims to the contrary (Goodspeed, 1994). Even pro-Royalist secessionist forces in and around MVU endeavouring to set up what they called the "King Father Autonomous Zone" (McNulty, 1993) in the weeks after the election did not halt the onset of peace in Cambodia.

Thereafter, "a string of defections" (Thayer, 1998a) beginning as early as August 1996 meant the last remnants of the violent KR were negotiating with the Cambodian government. One of the chief Khmer Rouge negotiators, Cor Bun Heng, said of the unprecedented Bangkok meeting:

'It was a good beginning and cordial. But these things take time'. Added the other senior [KR] negotiator, Gen[eral] Nuon: 'We believe that the only way out is national reconciliation between all the parties. We know that the entire Cambodian population wants peace'. (Thayer, 1998b)

The most compelling and rigorous accounts of declining socio-political violence in Cambodia after 1993 have been presented by The Asia Foundation and Broadhurst, Bouhours, and Bouhours (2015). For example, as shown in Figure 11, The Asia Foundation (2017) compiled data on politically motivated killings in Cambodia from 1993 to 2013, finding a sharp decrease from 380 killings in 1993 to 40 killings by 1998, with a steady decline to 23 in 2008 and to zero in 2013. Moreover, as of 2017, "there are no reports of transnational terrorists operating in Cambodia (The Asia Foundation, 2017, p. 43).

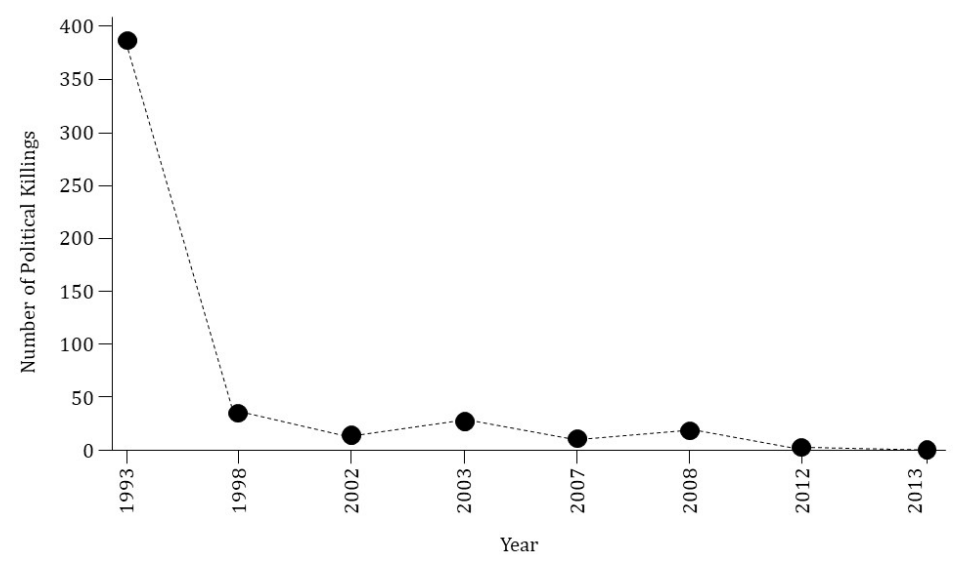

Figure 11. Killings of Political Activists and Party Members in Cambodia Between 1993 and 2013 (Source: The Asia Foundation, 2017, p. 42) 
Similarly, as shown in Figure 12 using data from The Committee for Free and Fair Elections in Cambodia (COMFREL), The Asia Foundation (2017) reported the number of political activists killed in Cambodia during commune elections decreased from 18 in 2002 to nine in 2007 (dotted line) and three in 2012, an 84\% reduction, and 39 cases of threats or intimidation in 2012 [down from 138 in 2002, a 72\% reduction, solid line]. The activists who were killed belonged to opposition political parties. The number of violent cases decreased significantly compared to previous commune elections. [Moreover] commune elections held in June 2017, saw escalating political tensions between the ruling and opposition parties but little reported violence. (The Asia Foundation, 2017, p. 44)

More comprehensive data can be seen in the research of Broadhurst and Bouhours (2009), with Broadhurst (2002) also providing detailed personal accounts of crime and violence. The authors

draw on the significant decline in the level of crime as measured by national police statistics, press reports and the United Nations International Crime Victim Surveys (UNICVS) conducted in 2001/2002 and repeated in 2006/2007. We suggest that the dramatic fall in the rates of 'street crime' is the result of a nexus of factors that include modernisation (i.e., marked socio-economic improvement supported by international aid), relative political stability and cultural resilience. (Broadhurst \& Bouhours, 2009, p. 174)

For example, "in 1998, 32\% of homicides reported by the press involved police, military/militia or vigilante action, but this had fallen to $8.8 \%$ in 2006" (Broadhurst \& Bouhours, 2009, p. 179), and

since 1998, crime rates have steadily decreased to only 32.4 per 100,000 in 2005 [from a high of 58.5 per 100,000]. Estimates of homicide victims including suspect death, grenade events and common murder/manslaughter drawn from RGC [Royal Government of Cambodia] judicial police and other sources from $1992-2005 \ldots$... show that suspect death and grenade events have become less frequent while overall rates of homicide victims have fluctuated between a high 12.9 per 100,000 in 1993 and a low 3.8 per 100,000 in 2005. (Broadhurst \& Bouhours, 2009, p. 179)

Broadhurst and Bouhours go on to

track key indicators of crime and security in Cambodia over 15 years (1992-2007). Data from several sources were used to estimate changes in violence as measured by homicide incidents, other violent and property crime victimisation, election violence and vigilantism, as well as attitudes towards crime and corruption. The prevalence of homicide and the severity of violence in Cambodia have been detailed and a decline in homicide has been observed. More recent data confirm this trend, which extends to crime in general. (Broadhurst \& Bouhours, 2009, p. 176)

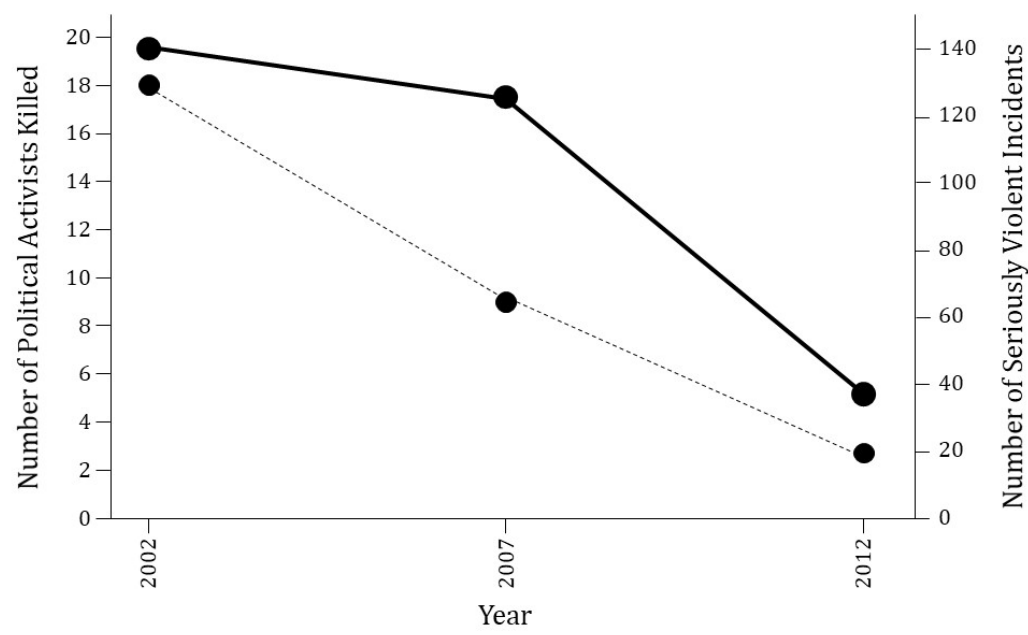

Figure 12. Number of Politically Motivated Murders and Other Violent Incidents During Commune Elections between 2002 and 2012 (Source: The Asia Foundation, 2017, p. 44)

The authors, however, are uncertain as to why such a decline has occurred, but suggest improvements in socio-economic standing, reductions in the availability of small arms, and political stability as causal factors (Broadhurst \& Bouhours, 2009, p. 176). "With the slow but final demise of organised armed struggle between 1993 and 1998, political stability and the reduction of electoral violence have also occurred" (Broadhurst \& Bouhours, 
2009, p. 177). Large-scale surveys indicated that $7.8 \%$ of the population of Phnom Penh experienced being assaulted or being threatened with assault in Phnom Penh in 2000, but this percentage had decreased to $2.0 \%$ of the population by 2005 . Similarly, in Kandal province $4.4 \%$ of the population reported being assaulted or being threatened with assault in 2000 , but these too had decreased to $2.8 \%$ of the population by 2005 .

In Kampong Cham, the province neighbouring Prey Veng province where MVU was located, $6.2 \%$ of the population reported being assaulted or being threatened with assault in 2000, but this figure too decreased to $2.3 \%$ in 2005 (Broadhurst \& Bouhours, 2009, p. 182), a 63\% reduction in five years. Broadhurst, Bouhours, and Bouhours (2015) also point out there was a significant reduction in the prevalence of lethal violence in Cambodia between 1993 and 2008 as well as a reduction in the number of victims of violence. Results from their extensive research indicate that both co-offending and multiple victimisation declined significantly beginning in the 1993 .

Despite the turbulent upheavals of 1997, which caused large-scale evacuations from the capital (Mydens, 1997), Mydens (1998) reported that

...something else emerged from the week of turmoil. In a brief outpouring of something that looked like 'people power', many thousands of Cambodians filled the streets to cheer for peace and democracy. For the first time, residents rose in defiance to demand an end to the violence and power struggles that have ravaged their country for decades.

Estimates of political and election related violence compiled by the UN and other human rights groups also showed significant reductions. Of the 1998 elections, Bit Seanglim, president of the Free Republican Party, agreed.

'A week before the election last time [in 1993], we knew we were going to lose,' the two-time candidate said. 'I was running in the provinces, in Kampong Cham. There were threats, party members were beaten up, candidates were killed...Now [in 1998] I am running in Phnom Penh and the level of intimidation is much lower than in 1993'. (Moorthy \& Sotheacheath, 1998)

Moreover, no new landmines were imported or laid in Cambodia after 1992 (Sokhet, 1995) and "the rate of homicide victims has fallen from 23.5 per 100,000 population in 1993 to 2.4 in 2012" (Broadhurst, Bouhours, \& Bouhours, 2014), a 90\% reduction in 19 years and "researchers have found Cambodia's current regime has reduced violence to historic lows" (Jackson, 2015). In the first six months of 1999 alone, Cambodia's crime rate fell by 32\% and kidnappings declined by $25 \%$ (EFE News Service, 1999).

Of the 2003 elections, Mydens (2003) reported that "the threats and killings have been fewer, the airwaves a bit freer, the speeches a little more substantive. Third time around, Cambodia is getting the hang of parliamentary elections". According to Sciaroni (2006),

the business community is not indifferent to the democratic progress being achieved in Cambodia. For example, we have applauded the improvement in the three national elections held since 1993, with steadily declining violence and greater accountability associated with each successive election.

By 2008, Phnom Penh was said to be a safer city than London, New York, Copenhagen, Amsterdam, and Buenos Aries (Strangio, 2008).

Incidents of domestic violence also decreased significantly during the impact-assessment period (although data does not exist for the baseline period). For example, the Cambodian government's Ministry of Women Affairs (2014, p. 4) reported that incidents of domestic violence in most category types decreased between 2005 and 2009, including $12 \%$ of women reporting being knocked on the head by their husbands in 2005 down to $4 \%$ by 2009 , a $66 \%$ reduction; $4 \%$ of women reporting being tied up and hit in 2005 down to $1 \%$ by 2009 , a $75 \%$ reduction; and $5 \%$ of women reporting being threatened with a knife in 2004 down to $1 \%$ by 2009 , an $80 \%$ reduction.

However, while the United Nations' Development Program (2009) indicated that violent domestic abuse data was significantly higher in both 2005 and 2009 compared with data provided by the Ministry of Women Affairs, it too observed similar trend reductions across all abuse categories.

In the specific context of rising social coherence and a reduction of socio-political violence throughout Cambodia during 1993-1996, members of the Royal Government of Cambodia recognised the relation between MVU students' practicing the Transcendental Meditation and TM-Sidhi program and a decline in violence. For example, His Excellency Son Soubert, Second Vice President of the National Assembly of the Kingdom of Cambodia told Maharishi in 1995:

there is hope for us in Cambodia with...Maharishi Vedic University in one of the poorest provinces of my country. I hope that all the students of this University, who are practicing the Transcendental Meditation 
and TM-Sidhi programme, will persuade our leadership to see the necessity of this programme. (Maharishi Vedic University, 1995, p. 10)

At the same time, His Excellency Dr Ung Huot quoted Cambodian Ambassador to Australia, Chheang Vun, who said "the Royal Government of Cambodia is extremely pleased with the success of Maharishi Vedic University" (Fergusson \& Bonshek, 2013, p. vi), and Hatchard and Cavanaugh (2009) cited the late King Norodom Sihanouk as saying: "Maharishi Vedic University is playing an important role in human resource development and in [the] restoration of peace and expansion of prosperity throughout the country".

However, since abandonment of the coherence-creating group at MVU in 2008 by the government of Cambodia, the country has slid back toward greater unrest. Adams (2016) maintains that

when the Agreements on a Comprehensive Political Settlement of the Cambodia Conflict were signed by Cambodian leaders and representatives of 17 other countries in Paris on October 23, 1991, Cambodians had reason to hope for an end to one-party rule, political trials and political killings. Yet, 25 years later, the leader of the opposition is in exile, politicians and human rights activists are in prison, and dissidents continue to be killed. The prospects for free and fair elections in 2018 are almost nil and Cambodia is hurtling back toward a one-party state... Why did Paris fail to deliver democracy and human rights?

\section{Discussion}

The data provided from both the TS quantitative and multiple qualitative sources indicate that the trend in socio-political violence in Cambodia during the 1990-1993 baseline period was decidedly upward. However, this trend turned dramatically downward at the beginning of the impact-assessment period, what Broadhurst (2002, p. 3) aptly refers to as Cambodia's "re-organization episode". This shift in trend is reflected independently in Figure 13, which schematically represents the homicide rate for Cambodia from 1900 to 2012.

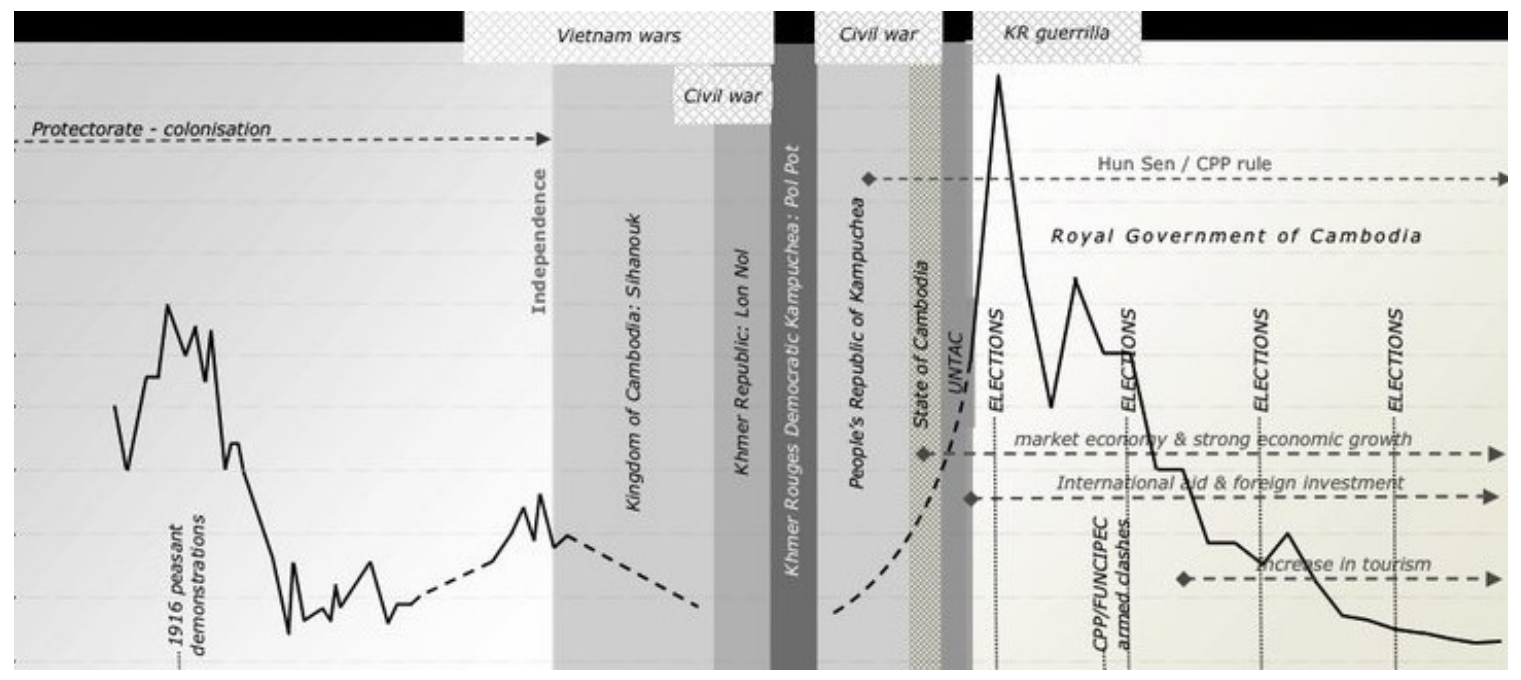

Figure 13. Schematic Representation of the Homicide Rate in Cambodia from 1910-2012 (Source: Broadhurst, Bouhours, \& Bouhours, 2015)

Of interest for this study is the period labelled 'UNTAC' and up to when the first use of the word 'ELECTIONS' in this diagram (i.e., the baseline period) and the overall trend in homicides from that point to the end of the right-hand side of the diagram in 2012 (i.e., including the impact-assessment period). The noticeable peak in homicides to the right of centre of Figure 13 represents the point of shift in trend observed by the TS data in Figure 9, which we associate with the influence of group practice in the Transcendental Meditation and TM-Sidhi program at MVU beginning in January 1993. However, given the sizable and widespread presence of UNTAC during 1992 and 1993, its possible role in creating the observed downward shift in socio-political violence cannot be completely discounted and we therefore turn to a discussion of UNTAC's role in Cambodia during this time. 


\subsection{UNTAC and Decline of Socio-Political Violence}

With agreement of the ruling State of Cambodia, UNTAC was established in February 1992 under UN Security Council Resolution 745 to implement the Paris Peace Accords of October 1991. UNTAC's mission was to end the fighting between the Phnom Penh government, the Khmer Rouge, and other armed groups, to demobilise and disarm all warring factions, to oversee the return and resettlement of 350,000 refugees along the Thai border, and to oversee the country's first 'free and fair' elections in 1993 (Kamm, 1998, p. xxii). UNTAC was headed by Yasushi Akashi of Japan, Lieutenant-General John Sanderson of Australia, and Brigadier-General Klaas Roos of the Netherlands, and the Authority included approximately 16,000 military personnel from countries such as Australia, India, Germany, Hungary, Poland, and New Zealand, 3,500 civilian police, and 2,000 civilians as well as locally recruited staff, most of whom acted as interpreters. During the period leading up to the May 1993 election (what Marquis [1992] called the "Great Cambodian Operation", or plan to "build a government atop the ruins of the Khmer Rouge holocaust"), some 50,000 Cambodians served as electoral staff and returning officers.

Socio-political violence in Cambodia has often been associated with elections and warring political factions. Indeed spikes, albeit receding ones, can be seen in Figure 13 associated with the elections of 1993, 1998, and 2003. Thus, it can be argued that the presence of UNTAC in 1992 and the elections of 1993 were the cause of the observed sudden and rapid decline in violence during the transition between these two years. However, the UN's own report and independent observers have suggested otherwise (e.g., Doyle, 1998; Findlay, 1995; St John, 2005), and Akashi himself suggested "We have not been able to achieve peace and reconciliation" in Cambodia (Kamm, 1998, p. 219). Moreover, beginning in the summer of 1992, the Khmer Rouge refused to disarm or allow UNTAC officials to enter zones under their control.

Following suit, the Phnom Penh government then likewise balked at disarming (Kamm, p. xxii). As a result, UNTAC implicitly accepted "that the proposed cantonment of troops and disarmament are a dead letter" (Kamm, 1998, p. xxii). Thus, while it is indisputable that the presence of UNTAC affected Cambodia, it would be foolhardy to lay a great deal of the praise for reduced violence at the feet of UNTAC. For example, while the Authority "satisfactorily" achieved many of its goals (including verifying withdrawal of Vietnamese troops and beginning "the process of reconstructing Cambodia's infrastructure, administration and economy" and was thus hailed as "a major achievement of the United Nations" [Findlay, 1995, pp. 103-104]), it cannot reasonably be claimed that UNTAC helped create favourable non-violent conditions in Cambodia during the early 1990s, particularly as it was directly responsible for the introduction of AIDS into the country, caused highly inflated property prices in Phnom Penh, had to remove 2,000 of its own Bulgarian military contingent (the so-called 'BulgaBatt') because some of them threatened to kill Sanderson over a pay dispute, and the UN itself reported that the Paris Peace Accords "failed to bring peace to Cambodia" (Findlay, 1995, p. 106). According to well-regarded sources, UNTAC failed to achieve its primary mission, which was to disarm and demobilise the contending military forces and promote national reconciliation but had to fall back on making the election their primary focus (Brinkley, 2011, pp. 72-73; Kamm, 1998, pp. 207-208, 218-219). As Findlay (1995) noted, in the year after UNTAC was disbanded, Cambodia

led a roller-coaster existence, experiencing the highs of newly won international recognition and support along with the lows of continuing political instability and violence. The country's wildly fluctuating fortunes have jeopardised some of the gains of the Paris Accords and called into question some of the fundamental assumptions behind the deployment of UNTAC. (p. 161)

However, Findlay does go on the say that few of the negative developments that occurred in Cambodia after UNTAC left can be directly attributable to UNTAC, and therefore the least parsimonious interpretation of UNTAC's role in reducing socio-political violence after 1993 would be to say it partially contributed to the creation of an environment of social and political stability upon which future social harmony and reduced violence might have been realised.

Similarly, Broadhurst, Bouhours and Bouhours' (2015) argument that reductions in violence during this period are the result of a so-called 'civilizing effect' as postulated by Norbert Elias and supported by the modernization theory advanced by Durkheim are unpersuasive because their own research indicates that only "weak and inconsistent findings have emerged" to support such an effect.

It might also be argued that the transition from a controlled economy to a market-driven economy created a more stable economic environment, the type of economy in which the populace is happier and less prone to violent behaviour. From 1980 through to 1994, the Cambodian economy was administered through a centralised, planned system inherited from the Soviet Union. The government moved from a planned economic model to a market-driven model in 1995, and it is to the adoption of this style of government that some Western observers attribute Cambodia's economic prosperity and reduced violence in the late 1990s and 2000s (Institute for International Cooperation, 2002, p. 165). 
However, as the data suggests (Fergusson, 2016b), many of the growth indicators in the economy were occurring prior to 1995 , and thus a switch to a market-driven approach cannot fully account for economic stability between 1993 and 1995. This conclusion can be seen in the aforementioned inflation data of Figure 7: Cambodia's government moved from a planned to a market-driven economic model in 1995, but after averaging $119 \%$ between 1989 and 1993, inflation dropped to $10.4 \%$ in 1994 the year after MVU was established, remaining low thereafter. It would therefore be injudicious to suggest that a market-driven model introduced in 1995 could have caused this significant drop in inflation in 1994 and thus the beginning of a more stable economy.

Other theories related to social solidarity, social equality, catharsis, and war-fatigue as explananda for reductions in violence after the so-called 'state induced collective disaster' of the 1970s through 1990s in Cambodia appear equally unlikely. For example, research on levels of violence after a long period of civil war or conflict regardless of outcome suggests that violence should have increased in the impact-assessment period, not decreased as observed; this statement is particularly true for Cambodia given that the scale of loss of life in a conflict is a predictor of greater crime and violence thereafter (Archer \& Gartner, 1976), but such a prediction did not occur in Cambodia after January 1993.

Similarly, explananda such as a "distressed post-war economy, return of violent veterans, or demographic changes" while not fully tested in this study, apparently fail (at least according to conflict theory [Broadhurst, 2002]) to account for the types of decreased socio-political violence observed in this research. We therefore argue that had there not been an influence of coherence in the collective consciousness of Cambodia beginning in 1993, the demobilization of 200,000 troops alone (Pringle, 1992), a significantly violent fighting force, prior to and including during 1993 should have had under normal circumstances accounted for an increase in violence in Cambodia, but no such increase was identified in either the quantitative or qualitative findings of this study.

\section{Conclusion}

The present research further investigates Maharishi's testable predictions related to the individual and group practice of his Transcendental Meditation and TM-Sidhi program and coherence in collective consciousness of society. This study is the first of its kind we believe to examine a possible relationship between group practice of the Transcendental Meditation and TM-Sidhi program and social change using a mixed methods approach. All prior research on this topic has employed either a single-strand quantitative or single-strand qualitative design and none have considered the relationship of social coherence, as defined in this study, to reductions in socio-political violence. The present explanatory design has therefore allowed us the opportunity to explore the phenomenon from multiple viewpoints and thereby provide a better understanding of life in Cambodia during the baseline and impact-assessment periods.

We conclude that the quantitative and qualitative data for socio-political violence presented in this study provide reasonable evidence to suggest a significant downward shift in baseline trend violence began in January 1993 when the group of meditating students was established at MVU, thereby answering RQ1. Such a conclusion is supported by the time series data across 228 monthly data points, which found the shift in trend was significant to a value of $p<1 \times 10^{-7}$, and by statements such as "the overall picture [in 1993] is of genuine stability" (Ogden, 1994) and "peace has now come for thousands of Cambodians" (Jenner, 1997). Also, the information-theoretic analysis provides direct estimates of posterior probabilities that suggest the null hypothesis of no effect is highly implausible and that the data favours the alternative hypothesis of a reduction in the trend in socio-political violence.

The question posited in RQ2 of whether the group practice of the Transcendental Meditation and TM-Sidhi program by the students at MVU significantly contributed to the observed shift in trend examined in RQ1 is harder to answer. Clearly the observed shift in socio-political violence beginning in January 1993 is consistent with: A) the predictions made by Maharishi and social scientists over a 40-year period and the published research designed to test them; B) theories and research associated with action-at-a-distance, inter-subject brainwave coherence, including cooperative brainwave behaviour and interactional synchrony; C) theories of social change associated with individual and group practice of the Transcendental Meditation and TM-Sidhi program as proposed by Maharishi and social scientists since the 1970s; and D) theories of disequilibrium to equilibrium and the role of catalysts in systems posited by Prigiogine and others.

Moreover, the observed downward shift in the present data is consistent with previous findings which have quantitatively documented the impact of this program on crime, accidents, war deaths, and so on, and the apparent upward spike in late 2008 when the group was abandoned supports the predicted contribution of the MVU group to social coherence.

Consistent with the theory of social coherence posited by this study, which suggests that when the influence of 
coherence in the social field is discontinued violence may eventually begin to return, we also note that independent media reports suggest that some forms of violence have increased after 2008, although the evidence is inconsistent on this matter. For example, while progress in reducing domestic violence and violence against women in Cambodia has improved significantly (e.g., Ministry of Women Affairs, 2017) and reports such as "the occurrence of violence at workplaces has declined...employers pay more attention now than before to the safety of their female employees" are not uncommon (Sokha, 2016), political violence has apparently not similarly declined (e.g., Cuddy, 2015; Virek \& French, 2015). In this sense, statements such as "warnings of 'instability'...have given way to pointed threats of violence, threats that analysts say reflect not only deepening insecurity on the part of the ruling party, but also the psychological hold violence still has on Cambodia after decades of killing" (Nachemson, 2017) and more broadly speak to a lack of coherence in the collective consciousness of the country.

Thus, we reasonably conclude that an association existed between the group practice of the Transcendental Meditation and TM-Sidhi program and the observed downward trend in socio-political violence, and that the reduction in violence is consistent with the hypothesis that the group practice contributed to this decline. Interrupted time series research designs are widely acknowledged to be the strongest for addressing the type of research questions examined in the current study, but such quasi-experimental designs do not allow definitive inferences of causal relationships in complex social systems. The confounding influence of omitted variables always must be considered, and potential alternative explanations persuasively addressed.

However, the lack of compelling alternative explanations for the reduced trend in social violence strengthen the case for the conclusion that the MVU group helped reduce social violence in Cambodia. Certainly, anecdotal testimony by government representatives and by the King of Cambodia suggest that well-positioned officials recognised that the group practice of the Transcendental Meditation and TM-Sidhi program contributed to the observed downward trend in socio-political violence.

\section{Acknowledgements}

Transcendental Meditation, Transcendental Meditation-Sidhi, TM-Sidhi, Maharishi, Maharishi Vedic University, and other terms used in this paper are subject to trademark protection in many countries worldwide, including the United States, and are used with permission. The second author wishes to express his appreciation to the Wege Foundation for its financial support of this research.

\section{References}

Adams, B. (2016, November 4). Opinion-The Paris Agreements at 25: Requiem instead of celebration. The Cambodia Daily. Retrieved from http://www.wayback.com/.

Agence France-Presse. (1991, December 31). Cambodia violence. Agence France-Press. Retreived from https://www.dowjones.com/products/factiva.

Akaike, H. (1973). Information theory and an extension of the maximum likelihood principle. In B. N. Petrov \& F. Csake (Eds.), Second International Symposium on Information Theory (pp. 267-281). Budapest: Akademiai Kiada.

Akashi, Y. (1992, July 24). UNTAC news. The Phnom Penh Post. Retreived from https://www.phnompenh post.com/

Anderson, D. R. (2008). Model based inference in the life sciences: A primer on evidence. New York, NY: Springer. https://doi.org/10.1007/978-0-387-74075-1

Archer, D., \& Gartner, R. (1976). Violent acts and violent times: A comparative approach to postwar homicide rates. American Sociological Review, 41, 937-963. https://doi.org/10.2307/2094796

Arenander, A., \& Travis, F. T. (2004). Brain patterns of self-awareness. In B. Beitman \& J. Nair (Eds.), Self-awareness deficits (pp. 112-126). New York, NY: WW Norton.

Asia Foundation, The. (2017). Cambodia. In The state of conflict and violence in Asia (pp. 38-49). San Francisco, CA: Author.

Assimakis, P. D., \& Dillbeck, M. C. (1995). Time series analysis of improved quality of life in Canada: Social change, collective consciousness, and the TM-Sidhi program. Psychological Reports, 76(3), 1171-1193. https://doi.org/10.2466/pr0.1995.76.3c.1171 
Associated Press, The. (2005, May 1). Cambodian workers gather to honor slain union leader on May Day. The Associated Press. Retrieved from http://www.wayback.com/

Banerjee, A., Dolado, J. J., Galbraith, J. W., \& Hendry, D. F. (1993). Co-integration, error correction and the econometric analysis of non-stationary data. Oxford, UK: Oxford University Press. https://doi.org/10.1093/0198288107.001.0001

Banquet, J. P. (1973). Spectral analysis of the EEG in meditation. Electroencephalography and Clinical Neurophysiology, 35(2), 143-151. https://doi.org/10.1016/0013-4694(73)90170-3

Banquet, J. P., \& Lesèvre, N. (1980). Event-related potentials in altered states of consciousness. Progress in Brain Research, 54, 447-453. https://doi.org/10.1016/S0079-6123(08)61659-3

Baum, C. F. (2006). An introduction to modern econometrics using Stata. College Station, TX: Stata Press.

Bennet, A., \& Bennet, D. (2008). The human knowledge system: Music and brain coherence. Vine, 38(3), 277-295. https://doi.org/10.1108/03055720810904817

Beresford, M., \& Clements, G. (1989). Real time EEG coherence analysis of the Transcendental Meditation and TM-Sidhi programme. In R. Chalmers, G. Clements, H. Schenkluhn, \& M. Weinless (Eds.), Scientific research on Maharishi's Transcendental Meditation and TM-Sidhi programme: Collected papers (Vol. 3) (pp. 1738-1748). Vlodrop, the Netherlands: Maharishi Vedic University Press.

Bernroider, G. (2007). Quantum-neurodynamics and the relation to conscious experience. NeuroQuantology, 1(2), 163-168. https://doi.org/10.14704/nq.2003.1.2.10

Bischof, M. (2008). Synchronization and coherence as an organizing principle in the organism, social interaction, and consciousness. NeuroQuantology, 6(4), 440-451. https://doi.org/10.14704/nq.2008.6.4.200

Bond, D., Bond, J., Oh, C., Jenkins, J. C., \& Taylor, C. H. (2003). Integrated data for events analysis (IDEA): An event typology for automated events data development. Journal of Peace Research, 40(6), 733-745. https://doi.org/10.1177/00223433030406009

Borland, C., \& Landrith, G. S. (1977). Improved quality of life through the Transcendental Meditation program: Decreased crime rate. In D. W. Orme-Johnson \& J. T. Farrow (Eds.), Scientific research on the Transcendental Meditation program: Collected papers (Vol. 1) (pp. 639-648). Rheinweiler, West Germany: Maharishi European Research University Press.

Box, G. E. P., \& Jenkins, G. M. (1976). Time series analysis: Forecasting and control. San Francisco, CA: Holden-Day.

Box, G. E. P., \& Tiao, G. C. (1975). Intervention analysis with applications to economic and environmental problems. Journal of the American Statistical Association, 70(349), 70-79. https://doi.org/10.1080/01621459.1975.10480264

Box-Steffensmeier, J. M., Freeman, J. R., Hitt, M. P., \& Pevehouse, J. C. W. (2014). Time series analysis for the social sciences. New York, NY: Cambridge University Press. https://doi.org/10.1017/CBO9781139025287

Brickell, K., \& Springer, S. (Eds.) (2016). The handbook of contemporary Cambodia. London, England and New York, NY: Routledge.

Brinkley, J. (2011). Cambodia's curse: The modern history of a troubled land. New York, NY: Public Affairs (Perseus Books Group).

Broadhurst, R. (2002). Lethal violence, crime and state formation in Cambodia. Australian and New Zealand Journal of Criminology, 35(1), 1-26. https://doi.org/10.1375/acri.35.1.1

Broadhurst, R., \& Bouhours, T. (2009). Policing in Cambodia: Legitimacy in the making? Policing \& Society, 19(2), 174-190. https://doi.org/10.1080/10439460802187589

Broadhurst, R., Bouhours, T., \& Bouhours, B. (2014, January 22). The pot that calls the kettle black. The Phnom Penh Post. Retrieved from https://www.phnompenhpost.com.

Broadhurst, R., Bouhours, T., \& Bouhours, B. (2015). Violence and the civilizing process in Cambodia. Cambridge, UK: Cambridge University Press. https://doi.org/10.1017/CBO9781316271339

Brockwell, P. J., \& Davis, R. A. (2016). Introduction to time series and forecasting (3rd ed.). New York, NY: Springer. https://doi.org/10.1007/978-3-319-29854-2

Bujatti, M., \& Riederer, P. (1976). Serotonin, noradrenaline, dopamine metabolites in Transcendental Meditation 
technique. Journal of Neural Transmission, 39, 257-267. https://doi.org/10.1007/BF01256514

Burnham, K. P., \& Anderson, D. R. (2002). Model selection and multimodel inference: A practical information-theoretic approach (2nd ed.). New York, NY: Springer.

Burnham, K. P., \& Anderson, D. R. (2004). Multimodel inference: Understanding AIC and BIC in model selection. Sociological Methods and Research, 33, 261-304. https://doi.org/10.1177/0049124104268644

Cameron, A. C., \& Trivedi, P. K. (2013). Regression analysis of count data (2nd ed.). New York, NY: Cambridge University Press. https://doi.org/10.1017/CBO9781139013567

Campbell, D. T., \& Stanley, J. C. (1966). Experimental and quasi-experimental designs for research. Boston, MA: Houghton Mifflin.

Casella, E. (1993, April 10). Countdown in Cambodia violence fears rise as election campaign opens. The Hamilton Spectator. Retreived from http://www.wayback.com.

Cavanaugh K. L., Gelderloos, P., \& Dillbeck M. C. (2018). Group practice of the Transcendental Meditation-Sidhi program and improved U.S.-Soviet relations. Journal of Maharishi Vedic Research Institute, 8, 125-164.

Cavanaugh, K. L., \& Dillbeck, M. C. (2017a). Field effects of consciousness and reduction in U.S. urban murder rates: Evaluation of a prospective quasi-experiment. Journal of Health and Environmental Research, 3(3-1), 32-43. https://doi.org/10.11648/j.jher.s.2017030301.13

Cavanaugh, K. L., \& Dillbeck, M. C. (2017b). The contribution of proposed field effects of consciousness to the prevention of U.S. accidental fatalities: Theory and empirical tests. Journal of Consciousness Studies, 24(1-2), 53-86.

Cavanaugh, K. L., \& Gelderloos, P. (2011). U.S.-Soviet relations and the Maharishi Effect: A time series analysis. In R. Goodman \& W. Sands (Eds.), Consciousness-Based education and government (pp. 455-495). Fairfield, IA: Maharishi University of Management Press.

Chalmers, R., Clements, G., Schenkluhn, H., \& Weinless, M. (Eds.). (1989). Scientific research on Maharishi's Transcendental Meditation and TM-Sidhi programme: Collected papers (Vol. 3). Vlodrop, the Netherlands: Maharishi Vedic University Press.

Choi, I. (2015). Almost all about unit roots: Foundations, developments, and applications. New York, NY: Cambridge University Press. https://doi.org/10.1017/CBO9781316157824

Cochran, J. K., Chamlin, M. S., \& Seth, M. (1994). Deterrence or brutalization? An impact assessment of Oklahoma's return to capital punishment. Criminology, 32(1), 107-134. https://doi.org/10.1111/j.1745-9125.1994.tb01148.x

Cohen, J. (1988). Statistical power analysis for the behavioral sciences (2nd ed.). Hillsdale, NJ: Erlbaum.

Cook, T. D., \& Campbell, D. T. (1979). Quasi-experimentation: Design \& analysis issues for field settings. Boston, MA: Houghlin Mifflin.

Creswell, J. W., \& Plano Clark, V. L. (2011). Designing and conducting mixed methods research (2 ${ }^{\text {nd }}$ ed.). Thousand Oaks, CA: Sage Publications.

Cuddy, A. (2015, October 28). Attacks may be 'tip of the iceberg'. The Phnom Penh Post. Retreived from https://www.phnompenhpost.com

Darlington, R. B., \& Hayes, A. F. (2017). Regression analysis and linear models: Concepts, applications, and implementation. New York, NY: Guilford Press.

Davidson, J. (2016). Time Series Modelling version 4.49: Models and methods. Retrieved from http://www.timeseriesmodelling.com

Davies, J. L., \& Alexander, C. N. (2005). Alleviating political violence through reducing collective tension: Impact assessment analyses of the Lebanese war. Journal of Social Behavior and Personality, 17, 285-338.

Dillbeck, M. C. (1990). Test of a field hypothesis of consciousness and social change: Time series analysis of participation in the TM-Sidhi program and reduction of violent death in the US. Social Indicators Research, 22(4), 399-418. https://doi.org/10.1007/BF00303834

Dillbeck, M. C., \& Cavanaugh, K. L. (2016). Societal violence and collective consciousness: Reduction of U.S. homicide and urban violent crime rates. SAGE Open, 6(2), 1-16. https://doi.org/10.1177/2158244016637891

Dillbeck, M. C., \& Cavanaugh, K. L. (2017). Group practice of the Transcendental Meditation and TM-Sidhi program 
and reductions in infant mortality and drug-related death: A quasi-experimental analysis. SAGE Open, 7(1), 1-15. https://doi.org/10.1177/2158244017697164

Dillbeck, M. C., \& Orme-Johnson, D. W. (1987). Physiological differences between Transcendental Meditation and rest. American Psychologist, 42(9), 879-881. https://doi.org/10.1037/0003-066X.42.9.879

Dillbeck, M. C., Banus, C. B., Polanzi, C., \& Landrith, G. S. (1988). Test of a field model of consciousness and social change: Transcendental Meditation and TM-Sidhi program and decreased urban crime. The Journal of Mind and Behavior, 9(4), 457-486.

Dillbeck, M. C., Cavanaugh, K. L., Glenn, T., Orme-Johnson, D. W., \& Mittlefehldt, V. (1987). Effects of Transcendental Meditation and the TM-Sidhi program on quality of life indicators: Consciousness as a field. The Journal of Mind and Behavior, 8, 67-104.

Dillbeck, M. C., Landrith, G. S., \& Orme-Johnson, D. W. (1981). The Transcendental Meditation program and crime rate change in a sample of forty-eight cities. Journal of Crime and Justice, 4, 25-45.

Doornik, J. A., \& Hendry, D. F. (2013a). Empirical econometric modelling: PcGive 14 (Vol. 1). London, UK: Timberlake Consultants Press.

Doornik, J. A., \& Hendry, D. F. (2013b). Modelling dynamic systems: PcGive 14 (Vol. 2). London, UK: Timberlake Consultants Press.

Doyle, M. W. (1998). Peacebuilding in Cambodia: The continuing quest for power and legitimacy. In F. Z. Brown \& D. G. Timberman (Eds.), Cambodia and international community: The quest for peace development and democracy (pp. 79-100). Singapore: Institute of Southeast Asian Studies.

Dugan, L. (2010). Estimating effects over time for single and multiple units. In A. R. Piquero \& D. Weisburd (Eds.), Handbook of quantitative criminology (pp. 741-763). New York, NY: Springer. https://doi.org/10.1007/978-0-387-77650-7_35

Earl, J., Martin, A., McCarthy, J. D., \& Soule, S. A. (2004). The use of newspaper data in the study of collective action. Annual Review of Sociology, 30, 65-80. https://doi.org/10.1146/annurev.soc.30.012703.110603

EFE News Service. (1999, July 21). Crime in Cambodia falls 32 pct in first half of 1999. EFE News Service. Retreived from http://www.wayback.com/

Enders, W., \& Sandler, T. (2012). The political economy of terrorism (2nd ed.). New York, NY: Cambridge University Press.

Enders, W. (2015). Applied econometric time series (4th ed.). Hoboken, NJ: Wiley.

Enders, W., \& Sandler, T. (2005). After 9/11 is it all different now? Journal of Conflict Resolution, 49(2), 259-277. https://doi.org/10.1177/0022002704272864

Enders, W., \& Sandler, T. (2006). Distribution of transnational terrorism among countries by income classes and geography after 9/11. International Studies Quarterly, 50(2), 367-393. https://doi.org/10.1111/j.1468-2478.2006.00406.x

Engle, R. F. (1982). Autoregressive conditional heteroskedasticity with estimates of the variance of United Kingdom inflation. Econometrica, 50, 987-1007. https://doi.org/10.2307/1912773

Fales, E., \& Markovsky, B. (1997). Evaluating heterodox theories. Social Forces, 76, 511-525. https://doi.org/10.2307/2580722

Fergusson, L. (2016a). Vedic Science-based education, poverty removal and social well-being: A case history of Cambodia from 1980 to 2015. Journal of Indian Education (Journal of the National Council of Educational Research and Training), 41(4), 16-45.

Fergusson, L. (2016b). The impact of Maharishi Vedic University on Cambodian economic and social indicators from 1980 to 2015. Journal of Maharishi Vedic Research Institute, 2, 77-135.

Fergusson, L., \& Bonshek, A. (Eds.). (2013). Maharishi Vedic University in Cambodia: Educational reconstruction and social renewal. Gold Coast, Australia: Prana World Publishing.

Fergusson, L., \& Bonshek, A. (Eds.). (2017). Maharishi Vedic University in Cambodia: Education reconstruction and social renewal (2nd ed.). Gold Coast, Australia: Maharishi Vedic Research Institute Press.

Fergusson, L. \& Le Masson, G. (1997). A culture under siege: Post-colonial higher education and teacher education 
in Cambodia from 1953 to 1979. History of Education, 26(1), 91-112. https://doi.org/10.1080/0046760970260106

Fergusson, L., Bonshek, A., \& Boudigues, J-M. (1995). Personality and health characteristics of Cambodian undergraduates: A case for student development. Journal of Instructional Psychology, 22(4), 308-319.

Fergusson, L., Bonshek, A., \& Boudigues, M. (1994). Transcendental Meditation and five factors relevant to higher education in Cambodia. College Student Journal, 28(1), 103-107.

Fergusson, L., Bonshek, A., \& Le Masson, G. (1996). Vedic Science-based education and nonverbal intelligence: A preliminary longitudinal study in Cambodia. Higher Education Research and Development, 14(1), 73-82. https://doi.org/10.1080/0729436960150106

Fergusson, L., Le Masson, G., \& Bonshek, A. (1996). A descriptive analysis of Cambodian higher education and teacher education from 1979 to the present. Education Research and Perspectives, 22(2), 132-148.

Findlay, T. (1995). Cambodia: The legacy and lessons of UNTAC. Stockholm International Peace Research Institute, SIPRI Research Report No. 9. Oxford, UK: Oxford University Press.

Fox, J. (2016). Applied regression analysis and generalized linear models (3rd ed.). Thousand Oaks, CA: SAGE Publications.

Gelderloos, P., \& Van den Berg, W. (1989). Maharishi's TM-Sidhi program: Participating in the infinite creativity of nature to enliven the totality of the cosmic psyche in all aspects of life. Modern Science and Vedic Science, 2(4), 373-412.

Gelderloos, P., Cavanaugh, K. L, \& Davies, J. L. (1990). A simultaneous transfer function model of U.S.-Soviet relations: A test of the Maharishi Effect. In Proceedings of the American Statistical Association, Social Statistics Section (pp. 297-302). Alexandria, VA: American Statistical Association.

Gelderloos, P., Cavanaugh, K. L, \& Davies, J. L. (2011). The dynamics of U.S.-Soviet relations, 1979-1986: Effects of reducing social stress through the Transcendental Meditation and TM-Sidhi programs. In R. S. Goodman (Ed.), Consciousness-based education and world peace (pp. 351-393). Fairfield, IA: Maharishi University of Management Press.

Gelderloos, P., Cavanaugh, K. L., Frid, M. J., \& Xue, X. (2018). Warming U.S.-Soviet relations during the Cold War as measured by U.S. presidential statements: Impact of the group practice of the Transcendental Meditation-Sidhi program. Journal of Maharishi Vedic Research Institute, 9, 93-134.

Gelderloos, P., Frid, M. J., Goddard, P. H., Xue, X., \& Löliger, S. (1988). Creating world peace through the collective practice of the Maharishi Technology of the Unified Field: Improved U.S.-Soviet relations. Social Science Perspectives Journal, 4(2), 80-94.

Gelderloos, P., Goddard, P. H., Ahlström, H. H., \& Jacoby, R. (1987). Cognitive orientation towards positive values in advanced participants of the TM and TM-Sidhi program. Perceptual and Motor Skills, 64(3), 1003-1012. https://doi.org/10.2466/pms.1987.64.3.1003

Gelderloos, P., Hermans, H. J., Ahlström, H. H., \& Jacoby, R. (1990). Transcendence and psychological health: Studies with long-term participants of the Transcendental Meditation and TM-Sidhi program. Journal of Psychology, 124(2), 177-197. https://doi.org/10.1080/00223980.1990.10543215

Ghysels, E., \& Osborn, D. R. (2001). The econometric analysis of seasonal time series. Cambridge, UK: Cambridge University Press. https://doi.org/10.1017/CBO9781139164009

Giraitis, L., Kokoszka, P., Leipus, R., \& Teyssiere, G. (2003). Rescaled variance and related tests for long memory in volatility and levels. Journal of Econometrics, 112, 265-294. https://doi.org/10.1016/S0304-4076(02)00197-5

Glaser, J. L., Brind, J. L., Vogelman, J. H., Eisner, M. J., Dillbeck, M. C., \& Wallace, R. K. (1992). Elevated serum dehydroepiandrosterone sulfate levels in practitioners of the Transcendental Meditation (TM) and TM-Sidhi programs. Journal of Behavioral Medicine, 15(4), 327-341. https://doi.org/10.1007/BF00844726

Glass, G. V. (1997). Interrupted time series quasi-experiments. In R. M. Jaeger (Ed.), Complementary methods for research in education (2nd ed.) (pp. 589-608). Washington, DC: American Educational Research Association.

Glass, G. V., Willson, V. L., \& Gottman, J. M. (1975). Design and analysis of time-series experiments. Boulder, CO: Colorado Associated University Press.

Godfrey, L. G. (1978). Testing for higher order serial correlation in regression equations when the regressors include 
lagged dependent variables. Econometrica, 46, 1303-1313. https://doi.org/10.2307/1913830

Goodman, R. S., Orme-Johnson, D. W., Rainforth, M. V., \& Goodman, D. H. (1997). Transforming political institutions through individual and collective consciousness: The Maharishi Effect and government. Dissertation Abstracts International, 58(6), 2385a.

Goodspeed, P. (1994, June 26). Cambodians are still dreaming of peace-The chaos is worse. And soon, the killing may get worse. Toronto Star. Retrieved from http://www.wayback.com/

Granger, C. W. J., \& Newbold, P. (1986). Forecasting economic time series (2nd ed.). Orlando, FL: Academic Press.

Hagelin, J. S. (1987). Is consciousness the unified field? A field theorist's perspective. Modern Science and Vedic Science, 1(1), 29-87.

Hagelin, J. S. (1989). Restructuring physics from its foundation in light of Maharishi's Vedic Science. Modern Science and Vedic Science, 3(1), 3-72.

Hagelin, J. S., Rainforth, M. V., Orme-Johnson, D. W., Cavanaugh, K. L., Alexander, C. A., Shatkin, S. F., ... Ross, E. (1999). Effects of group practice of the Transcendental Meditation program on preventing violent crime in Washington, DC: Results of the National Demonstration Project, June-July 1993. Social Indicators Research, 47, 153-201. https://doi.org/10.1023/A:1006978911496

Hahn, H. R., \& Whalen, T. E. (1989). The effects of the Transcendental Meditation program on levels of hostility, anxiety and depression. In R. Chalmers, G. Clements, H. Schenkluhn, \& M. Weinless (Eds.), Scientific research on Maharishi's Transcendental Meditation and TM-Sidhi programme: Collected papers (Vol. 2) (pp. 1030-1035). Vlodrop, the Netherlands: Maharishi Vedic University Press.

Harris, D., McCabe, B., \& Leybourne, S. (2008). Testing for long memory. Econometric Theory, 24, 143-175. https://doi.org/10.2139/ssrn.936267

Hatchard, G., \& Cavanaugh, K. (2009). The peace and well being of nations: An analysis of improved quality of life and enhanced economic performance through the Maharishi Effect in New Zealand, Norway, USA, Cambodia, and Mozambique-A longitudinal, cross-country, panel-regression analysis of the IMD Index of National Competitive Advantage. Hamilton, ON: Canadian Centers for Teaching Peace.

Hatchard, G., \& Cavanuagh, K. L. (2017). The effect of coherent collective consciousness on national quality of life and economic performance indicators: An analysis of the IMD Index of National Competitive Advantage. Journal of Maharishi Vedic Research Institute, 5, 41-77.

Human Rights Watch. (2009). World report 2009. New York, NY: Author.

Institute for International Cooperation. (2002). The Kingdom of Cambodia: From reconstruction to sustainable development. Tokyo, Japan: Country Study for Japan's Official Development Assistance to Kingdom of Cambodia, Japan International Cooperation Agency.

International Monetary Fund. (2015, April). World economic outlook: Uneven growth, short- and long-term factors. Washington, DC: Author.

Jackson, W. (2015, August 29). A history of violence. The Phnom Penh Post. Retreived from https://www.phnompenhpost.com.

Jarque, C. M., \& Bera, A. K. (1980). Efficient tests for normality, homoskedasticity and serial independence of regression residuals. Economics Letters, 6, 255-259. https://doi.org/10.1016/0165-1765(80)90024-5

Jedrczak, A., Beresford, M., \& Clements, G. (1985). The TM-Sidhi program, pure consciousness, creativity and intelligence. Journal of Creative Behavior, 19(4), 270-275. https://doi.org/10.1002/j.2162-6057.1985.tb00409.x

Jenner, R. M. (1997, February 21). The greatest governmental successes. The Phnom Penh Post. Retrieved from https://www.phnompenhpost.com.

Kamm, H. (1998). Cambodia: Report from a stricken land. New York, NY: Arcade Publishing.

Katz, V. (2011). Conversations with Maharishi: Maharishi Mahesh Yogi speaks about the full development of human consciousness (Vol. 1). Fairfield, IA: Maharishi University of Management Press.

King, G., \& Lowe, W. (2003). An automated information extraction tool for international conflict data with performance as good as human coders: A rare events evaluation design. International Organization, 57, 617-642. https://doi.org/10.1017/S0020818303573064 
Kwiatkowski, D., Phillips, P. C. B., Schmidt, P., \& Shin, Y. (1992). Testing the null hypothesis of stationarity against the alternative of a unit root. Journal of Econometrics, 54, 159-178. https://doi.org/10.1016/0304-4076(92)90104-Y

Larimore, W. E. (1983). Predictive inference, sufficiency, entropy and an asymptotic likelihood principle. Biometrika, 70, 175-181. https://doi.org/10.1093/biomet/70.1.175

Levine, P. H., Hebert, R., Haynes, C. T., \& Strobel, U. (1977). EEG coherence during the Transcendental Meditation technique. In D. W. Orme-Johnson \& J. T. Farrow (Eds.), Scientific research on the Transcendental Meditation program: Collected papers (Vol. 1) (pp. 186-207). Rheinweiler, West Germany: Maharishi European Research University Press.

Levitt, P., \& Schiller, N. G. (2004). Conceptualizing simultaneity: A transnational social field perspective on society. International Migration Review, 38(3), 1002-1039. https://doi.org/10.1111/j.1747-7379.2004.tb00227.x

Lewis-Beck, M. S. (1979). Some economic effects of revolution: Models, measurement and the Cuban evidence. American Journal of Sociology, 84(5), 1127-1149. https://doi.org/10.1086/226903

Lewis-Beck, M. S. (1986). Interrupted time series analysis. In W. D. Berry \& M. S. Lewis-Beck (Eds.), New tools for social scientists: Advances and applications in research methods (pp. 209-240). Beverly Hills, CA: Sage.

Linden, A. (2015). Conducting interrupted time-series analysis for singled- and multiple-group comparisons. The Stata Journal, 15(2), 480-500. https://doi.org/10.1177/1536867X1501500208

Linden, A. (2017). A comprehensive set of postestimation measures to enrich interrupted time-series analysis. The Stata Journal, 17(1), 73-88. https://doi.org/10.1177/1536867X1701700105

Liu, L-M. (2009). Time series analysis and forecasting (2nd ed.). River Forest, IL: Scientific Computing Associates.

Liu, L-M., \& Chen, C. (1991). Recent developments of time series analysis in environmental impact studies. Journal of Environmental Science and Health A., 26(7), 1217-1252. https://doi.org/10.1080/10934529109375694

Lustenberger, C., Boyle, M. R., Foulser, A. A., Mellin, J. M., \& Fröhlich, F. (2015). Functional role of frontal alpha oscillations in creativity. Cortex, 67, 74-82. https://doi.org/10.1016/j.cortex.2015.03.012

MacLean, C. R. K., Walton, K. G., Wenneberg, S. R., Levitsky, D. K., Mandarino, J. V., Waziri, R.,...Schneider, R. H. (1997). Effects of the Transcendental Meditation program on adaptive mechanisms: Changes in hormone levels and responses to stress after 4 months of practice. Psychoneuroendocrinology, 22, 277-295. https://doi.org/10.1016/S0306-4530(97)00003-6

Maharishi European Research University. (1977a). Enlightenment in world psychiatry: The Transcendental Meditation technique new light on consciousness. Rheinweiler, West Germany: Maharishi European Research University Press.

Maharishi European Research University. (1977b). Enlightenment and the siddhis: A new breakthrough in human potential. Rheinweiler, West Germany: Maharishi European Research University Press.

Maharishi International University. (1974). A glimpse of the practical philosophy of life that has demonstrated the possibility of eliminating the age-old problems of mankind in this generation. Rheinweiler, West Germany: Maharishi International University Press.

Maharishi International University. (1977). Maharishi International University: An invitation to enlightenment. Fairfield, IA: Maharishi International University Press.

Maharishi Mahesh Yogi. (1960). Deep meditation. London, England: Spiritual Regeneration Movement Foundation of Great Britain.

Maharishi Mahesh Yogi. (1966). The science of Being and art of living. Washington, DC: Age of Enlightenment Press.

Maharishi Mahesh Yogi. (1976a). Creating an ideal society: A global undertaking. Rheinweiler, West Germany: Maharishi European Research University.

Maharishi Mahesh Yogi. (1976b). An invitation to create and ideal society: A scientifically validated program. Rheinweiler, West Germany: Maharishi European Research University.

Maharishi Mahesh Yogi. (1977). The scientific age rising to be the Age of Enlightenment. Rheinweiler, West Germany: Maharishi International University Press.

Maharishi Mahesh Yogi. (1978). Enlightenment to every individual, invincibility to every nation. Rheinweiler, West 
Germany: Maharishi European Research University Press.

Maharishi Mahesh Yogi. (1986). Thirty years around the world: Dawn of the Age of Enlightenment, volume one, 1957-1964. Vlodrop, the Netherlands: Maharishi Vedic University Press.

Maharishi Vedic University. (1991). Maharishi's master plan to create heaven on earth: Reconstruction of the whole world. Vlodrop, the Netherlands: Maharishi Vedic University Press.

Maharishi Vedic University. (1994). International conference-Invincible defence: Creation of a prevention wing in the military of every nation, bringing national law into alliance with natural law. Vlodrop, the Netherlands: Maharishi Vedic University Press.

Maharishi Vedic University. (1995). Second international conference-Invincible defence: Creation of a prevention wing in the military of every nation to raise military power to invincibility and prevent the birth of an enemy. Vlodrop, the Netherlands: Maharishi Vedic University Press.

Maharishi Vedic University. (2008). Maharishi Mahesh Yogi's Transcendental Meditation Sidhi programme of Yogic flying: Experiences of Yogic flying in the light of the forty values of the Vedic literature - the total constitution of the universe. Vlodrop, the Netherlands: Maharishi Vedic University Press.

Marquis, C. (1992, January 1). Former U.N. leader renewed world's hope. Austin American-Statesman. Retreived from http://www.wayback.com

McCleary, R., McDowall, D., \& Bartos, B. J. (2017). Design and analysis of time series experiments. New York, NY: Oxford University Press. https://doi.org/10.1093/oso/9780190661557.001.0001

McEvoy, T. M., Frumkin, L. R., \& Harkins, S. W. (1980). Effects of meditation on brainstem auditory evoked $\begin{array}{lllll}\text { potentials. International Journal of Neuroscience, } & 10(2 / 3), & \text { 165-170. }\end{array}$ https://doi.org/10.3109/00207458009160494

McNulty, S. (1993, June 13). Sihanouk's son prepares for war to retake secessionist provinces. The Associated Press. Retreived from http://www.wayback.com.

Ministry of Tourism. (2008). Tourism statistical report 2008. Phnom Penh, Cambodia: Author.

Ministry of Women Affairs. (2014). Violence against women and girls: Cambodia gender assessment. Phnom Penh, Cambodia: Author.

Ministry of Women Affairs. (2017, October 23). Stopping violence against women is our top priority. The Phnom Penh Post. Retreived from https://www.phnompenhpost.com.

Miskiman, D. E. (1977). The effect of the Transcendental Meditation program on the organization of thinking and recall (secondary organization). In D. W. Orme-Johnson \& J. T. Farrow (Eds.), Scientific research on the Transcendental Meditation program: Collected papers (Vol. 1) (pp. 385-392). Rheinweiler, West Germany: Maharishi European Research University Press.

Moorthy, E., \& Sotheacheath, C. (1998, July 24). A look back at the 1993 polls. The Phnom Penh Post. Retrieved from https://www.phnompenhpost.com.

Mydens, S. (1997, July 10). Hundreds flee Cambodia; violence chills the capital. The New York Times. Retrieved from https://www.nytimes.com.

Mydens, S. (1998, September 20). Cambodia: A new try. The New York Times. Retreived from https://www.nytimes.com.

Mydens, S. (2003, July 27). Inching toward democracy, Cambodia again visits the polls. The New York Times. Retrieved from https://www.nytimes.com

Nachemson, A. (2017, May 30). Will CPP threats turn to violence? The Phnom Penh Post. Retrieved from https://www.phnompenhpost.com.

Newey, W. K., \& West, K. (1987). A simple positive semi-definite, heteroskedasticity and autocorrelation consistent covariance matrix. Econometrica, 55, 703-708. https://doi.org/10.3386/t0055

Newey, W. K., \& West, K. D. (1994). Automatic lag selection in covariance matrix estimation. Review of Economic Studies, 61, 631-653. https://doi.org/10.3386/t0144

Nidich, S. I., Ryncarz, R. A., Abrams, A. I., Orme-Johnson, D. W., \& Wallace, R. K. (1983). Kohlbergian moral perspective responses, EEG coherence, and the Transcendental Meditation and TM-Sidhi program. Journal of 
Moral Education, 12(3), 166-173. https://doi.org/10.1080/0305724830120304

Ogden, J. (1994, June 17). Balance of payments gap rises to $\$ 124 \mathrm{~m}$. The Phnom Penh Post. Retrieved from https://www.phnompenhpost.com.

Orme-Johnson, D. (1989). EEG coherence and the TM-Sidhi program. In R. Chalmers, G. Clements, H. Schenkluhn, \& M. Weinless (Eds.), Scientific research on Maharishi's Transcendental Meditation and TM-Sidhi programme: Collected papers (Vol. 3) (pp. 1654-1655), Vlodrop, the Netherlands: Maharishi Vedic University Press.

Orme-Johnson, D. W., \& Dillbeck, M. C. (1987). Maharishi's program to create world peace: Theory and research. Modern Science and Vedic Science, 1(2), 207-259.

Orme-Johnson, D. W., \& Fergusson, L. (2018). Global impact of the Maharishi Effect from 1974 to 2017: Theory and research. Journal of Maharishi Vedic Research Institute, 8, 13-79.

Orme-Johnson, D. W., \& Oates, R. M. (2009). A field-theoretic view of consciousness: Reply to critics. Journal of Scientific Exploration, 23, 139-166.

Orme-Johnson, D. W., Alexander C. N., Davies J. L., Chandler, H., \& Larimore, L. (1988). International peace project: The effects of the Maharishi Technology of the Unified Field. Journal of Conflict Resolution, 32(4), 776-812. https://doi.org/10.1177/0022002788032004009

Orme-Johnson, D. W., Alexander, C. N., \& Davies, J. L. (1990). The effects of the Maharishi Technology of the Unified Field: Reply to a methodological critique. Journal of Conflict Resolution, 34, 756-768. https://doi.org/10.1177/0022002790034004009

Orme-Johnson, D. W., Clements, G., Haynes, C. T., \& Badaoui, K. (1977). Higher states of consciousness: EEG coherence, creativity, and experiences of the sidhis. In D. W. Orme-Johnson \& J. T. Farrow (Eds.), Scientific research on the Transcendental Meditation program: Collected papers (Vol. 1) (pp. 701-712). Rheinweiler, West Germany: Maharishi European Research University Press.

Orme-Johnson, D. W., Dillbeck, M. C., \& Alexander, C. N. (2003). Preventing terrorism and international conflict: Effects of large assemblies of participants in the Transcendental Meditation and TM-Sidhi programs. Journal of Offender Rehabilitation, 36, 283-302. https://doi.org/10.1300/J076v36n01_13

Orme-Johnson, D. W., Dillbeck, M. C., Wallace, R. K., \& Landrith, G. S. (1982). Intersubject EEG coherence: Is consciousness a field? International Journal of Neuroscience, 16(3/4), 203-209. https://doi.org/10.3109/00207458209147147

Orme-Johnson, D. W., Gelderloos, P., \& Dillbeck, M. C. (1988). The long-term effects of the Maharishi Technology of the Unified Field on the quality of life in the United States (1960 to 1984). Social Science Perspectives Journal, 2(4), 127-146.

Orme-Johnson, D. W., Schneider, R. H., Son, Y. D., Nidich, S., \& Cho, Z-H. (2006). Neuroimaging of meditation's effect on brain reactivity to pain. Neuroreport, 17(12), 1359-1363. https://doi.org/10.1097/01.wnr.0000233094.67289.a8

Palva, S., \& Palva, J. M. (2007). New vistas for $\alpha$-frequency band oscillations. Trends in Neuroscience, 30(4), 150-158. https://doi.org/10.1016/j.tins.2007.02.001

Patterson, K. (2012). Unit root tests in time series (Vol. 2): Extensions and developments. New York, NY: Palgrave Macmillan. https://doi.org/10.1057/9781137003317

Pickup, M. (2015). Introduction to time series analysis. Thousand Oaks, CA: Sage Publications. https://doi.org/10.4135/9781483390857

Post Staff. (1993, November 5). The roots of violence. The Phnom Penh Post. Retreived from https://www.phnompenhpost.com.

Post Staff. (2000, March 31). Letter: Statement of concern. The Phnom Penh Post. Retreived from https://www.phnompenhpost.com.

Post Staff. (2007, June 29). In (sacred) memory: Must politics obstruct honoring the dead? The Phnom Penh Post. Retreived from https://www.phnompenhpost.com.

Prasso, S. (1992, January 1). Despite setbacks, Cambodian peace on path into new year. Agence France-Presse. Retreived from http://www.wayback.com. 
Pridemore, W. A., Chamlin, M. B., \& Trahan, A. (2008). A test of competing hypotheses about homicide following terrorist attacks: An interrupted time series analysis of September 11 and Oklahoma City. Journal of Quantitative Criminology, 24(4), 381-396. https://doi.org/10.1007/s10940-008-9052-8

Pridemore, W. A., Chamlin, M. S., \& Cochran, J. K. (2007). An interrupted time-series analysis of Durkheim's social-deregulation thesis: The case of the Russian Federation. Justice Quarterly, 24(2), 271-290. https://doi.org/10.1080/07418820701294813

Pringle, J. (1992, January 2). Demobbed soldiers may turn to banditry. The Times. Retreived from https://www.dowjones.com/products/factiva.

Ramsey, J. B. (1969). Tests for specification errors in classical linear least squares regression analysis. Journal of the Royal Statistical Society Series B-Methodological, $\quad 31, \quad 350-371$. https://doi.org/10.1111/j.2517-6161.1969.tb00796.x

Rasler, K. (1986). War, accommodation, and violence in the United States, 1890-1970. American Political Science Review, 80, 921-945. https://doi.org/10.2307/1960545

Record, The. (1992, January 2). Cambodia a powder keg, U.N. is told. The Record. Retreived from http://www.wayback.com.

Reuters News. (1992, January 1). Khmer Rouge accuses Vietnam of village massacre. Reuters News. Retreived from http://www.wayback.com.

Roberts, D. (2000). Political transition in Cambodia 1991-99: Power, elitism and democracy. New York, NY: Routledge.

Said, S. E., \& Dickey, D. (1984). Testing for unit roots in autoregressive moving-average models with unknown order. Biometrika, 71, 599-607. https://doi.org/10.1016/0304-4076(91)90067-N

Schiller, N. G. (2017). Transborder citizenship: An outcome of legal pluralism within transnational social fields. In F. von Benda-Beckmann \& K. von Benda-Beckmann (Eds.), Mobile people, mobile law: Expanding legal relations in a contracting world (pp. 39-62). New York, NY: Routledge.

Schrodt, P. (1990). Methodological critique of 'International peace project in the Middle East'. Journal of Conflict Resolution, 34, 756-768. https://doi.org/10.1177/0022002790034004008

Schrodt, P., \& Gerner, D. (2001). Automated coding of international event data using sparse parsing techniques. Paper presented at the $42^{\text {nd }}$ Annual Convention of the International Studies Association, Chicago, IL, 20-24 February.

Sciaroni, B. D. (2006, January 13). Free speech not for the irresponsible. The Phnom Penh Post. Retrieved from https://www.phnompenhpost.com.

Shadish, W. R., Cook, T. D., \& Campbell, D. T. (2002). Experimental and quasi-experimental designs for generalized causal inference. Boston, MA: Houghton Mifflin.

Shenon, P. (1992, March 26). Khmer Rouge said to harass refugees. The New York Times. Retrieved from https://www.nytimes.com.

Shibata, R. (1983). A theoretical view of the use of AIC. In O. D. Anderson (Ed.), Time series analysis: Theory and practice 4 (pp. 237-244). New York, NY: North-Holland.

Simpson, S. S., Bouffard, L. A., Garner, J., \& Hickman, L. (2006). The influence of legal reform on the probability of arrest in domestic violence cases. Justice Quarterly, 23(3), 297-316. https://doi.org/10.1080/07418820600869087

Smith, J. (1998, July 24). Ballot-box fears bring back memories of 1993. The Cambodia Daily. Retreived from http://www.wayback.com.

Sokha, T. (2016, November 29). Progress touted on safe workplaces for women. The Phnom Penh Post. Retreived from https://www.phnompenhpost.com.

Sokhet, R. (1995, March 10). Army assures that no new mines laid. The Phnom Penh Post. Retreived from https://www.phnompenhpost.com.

StataCorp. (2017). Stata base reference manual, release 15. College Station, TX: Stata Press.

Strangio, S. (2008, April 17). Phnom Penh safer than London: Report. The Phnom Penh Post. Retreived from https://www.phnompenhpost.com.

Sutter, R. G. (1992, January 1). The Cambodian peace agreement: Issues for U.S. policy. Congressional Research 
Report, Penny Hill Press. Retreived from http://www.wayback.com.

Teddlie, C. \& Tashakkori, A. (2009). Foundations of mixed methods research: Integrating quantitative and qualitative approaches in the social and behavioral science. Thousand Oaks, CA: Sage Publications.

Thayer, N. (1992, January 1). Cambodian peace depends on quick U.N. arrival, congressman says. The Associated Press. Retreived from http://www.wayback.com.

Thayer, N. (1993, April 9). KR vows to foil UNTAC election split emerges in FUNCINPEC. The Phnom Penh Post. Retreived from https://www.phnompenhpost.com.

Thayer, N. (1998a, April 30). Dying breath: The inside story of Pol Pot's last days and the disintegration of the movement he created. Far Eastern Economic Review. Retreived from http://www.wayback.com/.

Thayer, N. (1998b, April 16). The resurrected: The Khmer Rouge haven't disappeared — they're in power. Far Eastern Economic Review. Retreived from http://www.wayback.com.

Tomljenović, H., Begić, D., \& Maštrović, Z. (2016). Changes in trait brainwave power and coherence, state and trait anxiety after three-month Transcendental Meditation practice. Psychiatria Danubina, 28(1), 0-72.

Travis, F. (1979). The Transcendental Meditation technique and creativity: A longitudinal study of Cornell University undergraduates. The Journal of Creative Behavior, 13(3), 169-180. https://doi.org/10.1002/j.2162-6057.1979.tb00203.x

Travis, F. (2002). Development along an integration scale: Longitudinal transformation in brain dynamics with regular

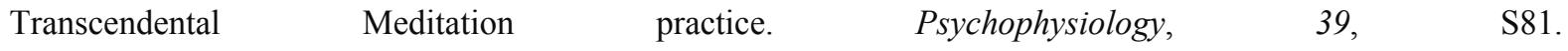
https://doi.org/10.1002/j.2162-6057.1979.tb00203.x

Travis, F. (2014). Transcendental experiences during meditation practice. Annals of the New York Academy of Sciences, 1307(1), 1-8. https://doi.org/10.1111/nyas.12316

Travis, F. T., Haaga, D. H., Hagelin, J. S., Tanner, M., Arenander, A., \& Nidich, S. (2009). A self-referential default brain state: Patterns of coherence, power, and eLORETA sources during eyes-closed rest and the Transcendental Meditation practice. Cognitive Processes, 11(1), 21-30. https://doi.org/10.1007/s10339-009-0343-2

Travis, F., \& Arenander, A. (2009). Cross-sectional and longitudinal study of effects of Transcendental Meditation practice on interhemispheric frontal asymmetry and frontal coherence. International Journal of Neuroscience, 116(12), 1519-1538. https://doi.org/10.1080/00207450600575482

Travis, F., \& Orme-Johnson, D. W. (1989). Field model of consciousness: EEG coherence changes as indicators of field effects. International Journal of Neuroscience, 49, 203-211. https://doi.org/10.3109/00207458909084826

Travis, F., \& Orme-Johnson, D. W. (1990). EEG coherence and power during yogic flying. International Journal of Neuroscience, 54, 1-12. https://doi.org/10.3109/00207459008986616

Travis, F., Haaga, D. A., Hagelin, J. S., Tanner, M., Nidich, S., \& Gaylord-King, C. (2009). Effects of Transcendental Meditation practice on brain functioning and stress reactivity in college students. International Journal of Psychophysiology, 71(2), 170-176. https://doi.org/10.1016/j.ijpsycho.2008.09.007

Travis, F., Sarina, G., \& Stixrud, W. (2011). ADHD, brain functioning, and Transcendental Meditation practice. Mind \& Brain: The Journal of Psychiatry, 2(1), 73-81.

United Nations Development Program. (2009). Violence against women: Follow-up survey 2009. Phnom Penh: United Nations Development Program, sponsored by GTZ Promoting Women's Rights Project (PWR), United Nations Population Fund (UNFPA), United Nations Development Program (UNDP) under the Partnership for Gender Equity (UNDP/MoWA/PGE), UNIFEM, and AusAID.

United Nations Educational, Scientific and Cultural Organization (UNESCO). (2011). The hidden crisis: Armed conflict and education. Paris, France: United Nations Educational, Scientific and Cultural Organization.

Verbeek. M. (2012). A guide to modern econometrics (4th ed.). West Sussex, UK: Wiley.

Virek, O., \& French, R. (2015, October 31). MP bashing may be only the beginning. The Phnom Penh Post. Retreived from https://www.phnompenhpost.com/

Wagenmakers, E-J. (2007). A practical solution to the pervasive problems of $p$ values. Psychonomic Bulletin and Review, 14(5), 779-804. https://doi.org/10.3758/BF03194105

Wagner, A. K., Soumerai, S. B., Zhang, F., \& Ross-Degnan, D. (2002). Segmented regression analysis of interrupted 
time series studies in medication use research. Journal of Clinical Pharmacy and Therapeutics, 27, 299-309. https://doi.org/10.1046/j.1365-2710.2002.00430.x

Walton, K. G., Cavanaugh, K. L., \& Pugh, N. D. C., (2005). Effect of group practice of the Transcendental Meditation program on biochemical indicators of stress in non-meditators: A prospective time series study. Journal of Social Behavior and Personality, 17(1), 339-373.

Walton, K. G., Pugh, N. D. C., Gelderloos, P., \& Macrae, P. (1995). Stress reduction and preventing hypertension: Preliminary support for a psychoneuroendocrine mechanism. Journal of Alternative and Complementary Medicine, 1, 263-283. https://doi.org/10.1089/acm.1995.1.263

Werner, O. R., Wallace, R. K., Charles, B., Janssen, G., Stryker, T., \& Chalmers, R. A. (1986). Long-term endocrinologic changes in subjects practicing the Transcendental Meditation and TM-Sidhi program. Psychosomatic Medicine, 48(1/2), 59-66. https://doi.org/10.1097/00006842-198601000-00004

White, H. (1980). A heteroskedastic-consistent covariance matrix estimator and a direct test for heteroskedasticity. Econometrica, 48, 817-838. https://doi.org/10.2307/1912934

Widyono, B. (2009). Dancing in shadows: Sihanouk, the Khmer Rouge, and the United Nations in Cambodia. Lanham, MD: Rouman \& Littlefield.

World Bank Group. (2015). Interwoven: How the better work program improves job and life quality in the apparel sector. Washington, DC: International Bank for Reconstruction and Development, The World Bank.

World Bank, The. (2014, April). Cambodia poverty assessment 2013: “Where have all the poor gone?” Washington, DC: Cambodia Socio-Economic Survey, World Bank Country Study ACS4545, (2 ${ }^{\text {nd }}$ ed.).

World Bank, The. (2015). World development indicators 2015. Washington, DC: Author. https://doi.org/10.1596/978-1-4648-0440-3

World Government of the Age of Enlightenment. (1978a). World Government News, Issue no. 1. Rheinweiler, West Germany: Maharishi European Research University Press.

World Government of the Age of Enlightenment. (1978b). World Government News, Issue no. 3. Rheinweiler, West Germany: Maharishi European Research University Press.

World Government of the Age of Enlightenment. (1979). World Government News, Issue no. 11. Rheinweiler, West Germany: Maharishi European Research University Press.

Zhang, F., Wagner, A. K., Soumerai, S. B., \& Ross-Degnan, D. (2009). Methods for estimating confidence intervals in interrupted time series analyses of health interventions. Journal of Clinical Epidemiology, 62, 143-148. https://doi.org/10.1016/j.jclinepi.2008.08.007 